\title{
Proposta de aprimoramento para o protocolo de assinatura digital Quartz
}

\author{
Ewerton Rodrigues Andrade \\ DISSERTAÇÃO APRESENTADA \\ $\mathrm{AO}$ \\ Instituto DE MATEMÁticA E EstatístiCA \\ DA \\ UNIVERSIDADE DE SÃO PAUlO \\ PARA \\ OBTENÇÃO DO TÍTULO \\ DE \\ Mestre EM CiênCIAS \\ Programa: Ciência da Computação \\ Orientador: Prof. Dr. Routo Terada \\ Durante o desenvolvimento deste trabalho \\ o autor recebeu auxílio financeiro da CAPES
}

São Paulo, outubro de 2013 


\title{
Proposta de aprimoramento para o protocolo de assinatura digital Quartz
}

\author{
Esta versão da dissertação contém as correções e alterações sugeridas \\ pela Comissão Julgadora durante a defesa da versão original do trabalho, \\ realizada em 27/08/2013. Uma cópia da versão original está disponível no \\ Instituto de Matemática e Estatística da Universidade de São Paulo.
}

Comissão Julgadora:

- Prof. Dr. Routo Terada (orientador) - IME-USP

- Prof. ${ }^{\text {a }}$ Dr. ${ }^{\text {a }}$ Denise Hideko Goya - CMCC-UFABC

- Prof. Dr. Marco Dimas Gubitoso - IME-USP 


\section{Agradecimentos}

Ao meu orientador e professor, Routo Terada, por confiar em mim e me guiar durante o desenvolvimento desta dissertação com seu conhecimento, paciência e experiência.

Aos meus pais, Carlos Lopes Andrade e Terezinha Aparecida Rodrigues Andrade, por tudo que me ensinaram e mostraram, me fazendo enfrentar os desafios e transpor meus limites, sempre balizado pela ética e moral.

À minha irmã, Karla Rodrigues Andrade, pelo apoio, afeto e compreensão que me ajudaram a enfrentar a última etapa deste mestrado.

Aos membros da banca de qualificação (professores Marco Dimas Gubitoso e Daniel Macedo Batista) e da comissão julgadora (professor Marco Dimas Gubitoso e professora Denise Hideko Goya), pelos questionamentos, correções, sugestões e comentários.

Aos amigos e membros do Laboratório de Segurança de Dados do IME-USP pelo companheirismo e conhecimento compartilhado.

À CAPES, pelo auxílio financeiro.

A todos professores, alunos e funcionários do Instituto de Matemática e Estatística da Universidade de São Paulo que colaboraram com minha formação, viabilizando a produção desta obra.

$\mathrm{E}$ a todos os demais que conviveram comigo durante o desenvolvimento deste trabalho, dedico meus sinceros agradecimentos. 


\section{Resumo}

ANDRADE, Ewerton R. Proposta de aprimoramento para o protocolo de assinatura digital Quartz. 2013. 89 f. Dissertação (Mestrado) - Instituto de Matemática e Estatística, Universidade de São Paulo, São Paulo, 2013.

Atualmente, podemos perceber que uma grande dependência dos sistemas desenvolvidos sob a seara da criptografia foi instaurada em todos nós. Principalmente no tocante dos sistemas criptográficos de chave pública, que são vastamente utilizados na Internet. No entanto, a criptografia de chave pública viu-se ameaçada e começou a investigar novas fontes de problemas para seus sistemas quando Shor em 1997 desenvolveu um algoritmo de tempo polinomial para fatorar inteiros e para calcular o logaritmo discreto em um computador quântico [Sho97]. Neste contexto, Patarin propõe a função alçapão HFE (Hidden Field Equations) [Pat96a], uma trapdoor baseada nos Problemas $\mathcal{M Q}$ (Multivariate $\mathcal{Q}$ uadratic) e IP (Isomorfismo de Polinômios). Tais problemas não são afetados pelo algoritmo de Shor, além disto o Problema $\mathcal{M Q}$ foi demonstrado por Patarin e Goubin como sendo NP-completo [PG97]. Apesar do HFE ter sua versão básica quebrada, ele apresenta variações - obtidas através de modificadores genéricos - resistentes aos principais ataques da atualidade. $\mathrm{O}$ Quartz - esquema de assinatura digital baseado no HFEv-, com escolha especial de parâmetros - é um bom exemplo desta resistência a ataques algébricos que visem a recuperação da chave privada, pois até hoje permanece seguro. Além de também se destacar por gerar assinaturas curtas. Todavia, Joux e Martinet - baseados em axiomas do Ataque pelo Paradoxo de Aniversário - provaram que o Quartz é maleável, demonstrando que caso o adversário possua um par (mensagem, assinatura) válido, ele conseguirá obter uma segunda assinatura com $2^{50}$ computações e $2^{50}$ chamadas ao oráculo de assinatura [JM03], logo muito abaixo dos padrões de segurança atuais que são de, no mínimo, $2^{112}$ [BR11]. Desta forma, baseado no Quartz, apresentamos um novo esquema de assinatura digital resistente a ataques adaptativos de mensagem escolhida que realizem chamadas ao oráculo aleatório, com um nível de segurança estimado em $2^{112}$. Nosso criptossistema proporciona, ainda, um ganho de eficiência no algoritmo de verificação de assinatura e na inicialização dos vetores que serão utilizados pelos algoritmos de assinatura e verificação. Além de, também, disponibilizarmos uma implementação do Quartz Original e do Quartz Aprimorado, na linguagem de programação Java.

Palavras-chave: Criptografia Pós-Quântica, Problema $\mathcal{M Q}$, Assinatura Digital, Quartz, MPKC. 


\section{Abstract}

ANDRADE, Ewerton R. Proposal of enhancement for digital signature protocol Quartz. 2013. 89 f. Dissertação (Mestrado) - Instituto de Matemática e Estatística, Universidade de São Paulo, São Paulo, 2013.

Today, we can see that a large dependence of the systems developed under the cryptography was introduced in all of us. Especially in terms of public key cryptosystems, which are widely used on the Internet. However, public key cryptography was threatened and began to investigate new sources of problems for their systems when Shor in 1997 developed a polynomial time algorithm for factoring integers and to compute the discrete logarithm in a quantum computer [Sho97]. In this context, Patarin proposed Hidden Field Equations (HFE) [Pat96a], a trapdoor based on $\mathcal{M Q}$ (Multivariate $\mathcal{Q}$ uadratic) and IP (Isomorphism of Polynomials) problems. Such problems are not affected by the Shor algorithm, moreover $\mathcal{M Q}$ Problem was demonstrate by Patarin and Goubin as NP-complete [PG97]. Despite the basic HFE has broken, it varies secure, obtained by generic modification. The Quartz - digital signature scheme based on HFEv-, with special choice of parameters - is a good example of this resistance to algebraic attacks aimed at the recovery of the private key, because even today remains secure. Furthermore, it also generates short signatures. However, Joux and Martinet - based on axioms of Birthday Paradox Attack - proved that Quartz is malleable, showing that if the adversary has a pair (message, signature) valid, he can get a second signature with $2^{50}$ computations and $2^{50}$ calls to the signing oracle [JM03], so far the current security standards that are at least $2^{112}$ [BR11]. Thus, based on Quartz, we present a new digital signature scheme, achieving the adaptive chosen message attacks that make calls to the random oracle, with a secure level estimated at $2^{112}$. Our cryptosystem also provides an efficiency gain in signature verification algorithm and initialization vectors that will be used for signing and verification algorithms. Further we provide an implementation of Original Quartz and Enhanced Quartz in the Java programming language.

Keywords: Post-Quantum Cryptography, $\mathcal{M Q}$ Problem, Digital Signature, Quartz, MPKC. 


\section{Sumário}

$\begin{array}{ll}\text { Lista de Abreviaturas } & \text { ix }\end{array}$

Lista de Símbolos $\quad$ xi

Lista de Figuras $\quad$ xiii

Lista de Tabelas $\quad$ xv

1 Introdução $\quad 1$

1.1 Caracterização do Problema . . . . . . . . . . . . . . . . . . . 1

1.2 Criptografia Pós-Quântica . . . . . . . . . . . . . . . . . . . 2

1.3 Proposta original do Quartz . . . . . . . . . . . . . . . . . 3

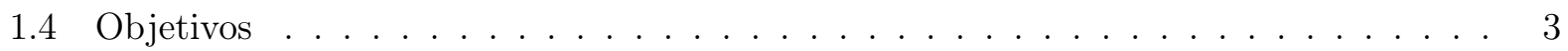

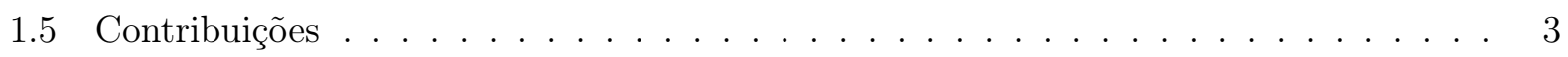

1.6 Organização do Trabalho . . . . . . . . . . . . . . . . . . . . . . 4

2 Conceitos Preliminares $\quad 5$

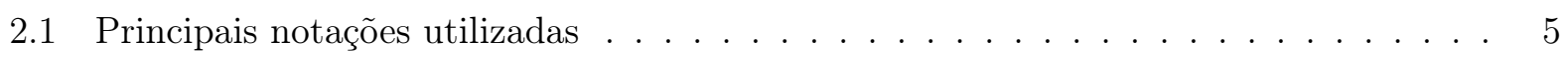

2.2 Funções Unidirecionais . . . . . . . . . . . . . . . . . . . . . . . . . . . 5

2.2 .1 Função alçapão $($ trapdoor $) \ldots \ldots \ldots \ldots \ldots \ldots$

2.2 .2 Função Hash . . . . . . . . . . . . . . . . . . . . . . . . . . . . 6

2.3 Definições . . . . . . . . . . . . . . . . . . . . . . . . 7

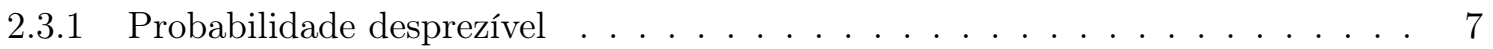

2.3 .2 Adversário . . . . . . . . . . . . . . . . . . . . 7

2.3 .3 Vítima . . . . . . . . . . . . . . . . . . . . . . 7

2.3 .4 Colisão em funções Hash . . . . . . . . . . . . . . . . . . . . . . 7

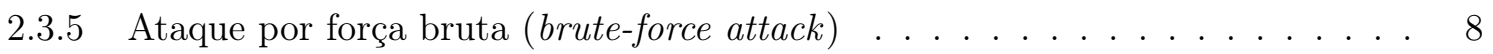

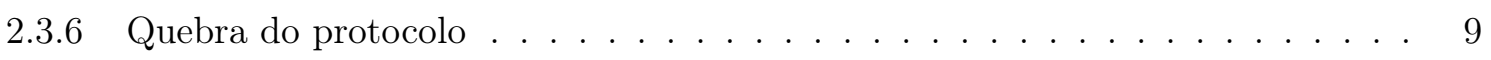

2.4 Noções de esquemas de Assinatura Digital . . . . . . . . . . . . . . . . . . . . . . 9

2.4.1 Criptoanálise de esquemas de Assinatura Digital . . . . . . . . . . . . . 10

3 Criptossistemas de Chave Pública Multivariável 13

3.1 O problema $\mathcal{M} \mathcal{Q} \ldots \ldots \ldots \ldots \ldots \ldots \ldots \ldots \ldots$

3.2 Visão geral dos MPKCs . . . . . . . . . . . . . . . . . . . . . 15

3.3 Esquema genérico de operações em MPKC . . . . . . . . . . . . . . . . . . . . . 16

3.3 .1 Assinatura . . . . . . . . . . . . . . . . . . . 16 
3.3.2 Verificação de Assinatura . . . . . . . . . . . . . . . . . . . . . 17

3.3 .3 Encriptação . . . . . . . . . . . . . . . . . . . . . . . . . . . . . . . . . . . . .

3.3 .4 Decriptação . . . . . . . . . . . . . . . . . . . . . . . 18

3.4 Isomorfismo de Polinômios . . . . . . . . . . . . . . . . . . . . . . 19

3.5 Principais $\mathcal{M} \mathcal{Q}$-trapdoors . . . . . . . . . . . . . . . . . . . . . . . . . . . . 19

3.6 Modificadores Genéricos . . . . . . . . . . . . . . . . . . . . 20

3.7 Principais Criptoanálises dos MPKC . . . . . . . . . . . . . . 21

4 Revisando o Quartz $\quad 23$

4.1 HFE (Hidden Field Equation) . . . . . . . . . . . . . . . . . . . 23

4.2 Quartz Original . . . . . . . . . . . . . . . . . . . . . . . . . 24

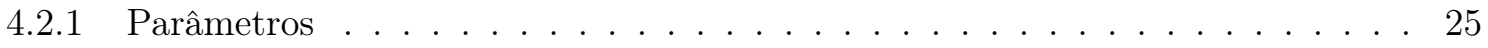

4.2 .2 Geração de Chaves . . . . . . . . . . . . . . . . . . . . . . . . . 27

4.2 .3 Assinando Mensagens . . . . . . . . . . . . . . . . . . . . . . . . 30

4.2.4 Verificando Assinatura . . . . . . . . . . . . . . . . . . . . . . . 32

4.3 Sobre a segurança do Quartz $(\mathrm{HFEv}-) \ldots \ldots \ldots \ldots$

4.4 A questão do SHA-1 . . . . . . . . . . . . . . . . . . . . . 36

5 Aprimorando o Quartz $\quad 37$

5.1 Quartz Aprimorado . . . . . . . . . . . . . . . . . . . . 37

$5.1 .1 \quad$ Parâmetros . . . . . . . . . . . . . . . . . . . . . . . 38

5.1 .2 Geração de Chaves . . . . . . . . . . . . . . . . . . . . . . . . 40

5.1 .3 Assinando Mensagens . . . . . . . . . . . . . . . . . . . . . . . 42

5.1 .4 Verificando Assinatura . . . . . . . . . . . . . . . . . . . . . 44

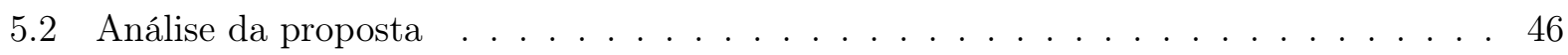

5.3 Estimativa de Segurança . . . . . . . . . . . . . . . . . . . 50 50

5.4 Comparando o Quartz Aprimorado com outros protocolos . . . . . . . . . . . . . . 52

6 Implementação de Referência $\quad 53$

6.1 Descrição da implementação . . . . . . . . . . . . . . . . . . . . . . . . 53

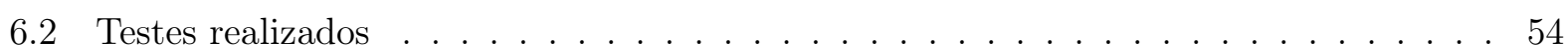

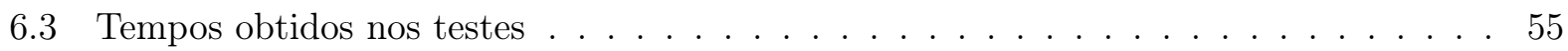

$\begin{array}{lll}7 & \text { Conclusão } & 57\end{array}$

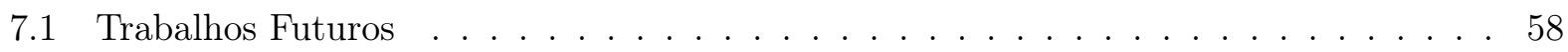

A Fundamentos Matemáticos $\quad 59$

A.1 Grupo . . . . . . . . . . . . . . . . . . . . . . . . 59

A.2 Anel . . . . . . . . . . . . . . . . . . . . . . . 60

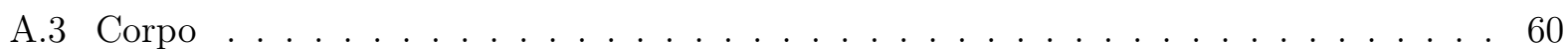

A.4 Espaço Vetorial . . . . . . . . . . . . . . . . . . . . . . . . . 61

$\begin{array}{ll}\text { Referências } & 63\end{array}$ 


\title{
Lista de Abreviaturas
}

\author{
CPQ Criptografia Pós-Quântica \\ MPKC Criptossistema de Chave Pública Multivariável (Multivariate Public-Key \\ Cryptosystem) \\ RSA Acrônimo de Rivest, Shamir e Adleman, autores deste criptossistema \\ ECC Elliptic Curve Cryptography \\ ECDSA Elliptic Curve Digital Signature Algorithm \\ MIA Matsumoto Imai Scheme A \\ HFE Hidden Field Equation \\ UOV Unbalanced Oil and Vinegar \\ STS Stepwise Triangular Systems

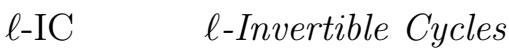 \\ SHA Secure Hash Algorithm \\ DES Data Encryption Standard \\ AES Advanced Encryption Standard \\ NIST National Institute of Standards and Technology \\ IST Information Societies Technology \\ NESSIE New European Schemes for Signatures, Integrity and Encryption \\ CSPRBG Gerador de Bit Pseudoaleatório Criptograficamente Seguro (Cryptographically \\ Secure Pseudorandom Bit Generator)
}




\title{
Lista de Símbolos
}

\author{
$\mathbb{F}$ ou $\mathbb{F}_{q} \quad$ Um Corpo de Galois, ou simplesmente Corpo Finito, de ordem $q$ \\ $q \quad$ Ordem do Corpo Finito $\mathbb{F}$, ou seja, $\mathrm{n}^{\mathrm{o}}$ de elementos de $\mathbb{F}(q:=|\mathbb{F}|)$ \\ $\mathbb{F}^{n} \quad$ Espaço vetorial de dimensão $n$ sobre $\mathbb{F}$ \\ $d \quad$ Grau do sistema de equações $-d \in \mathbb{N}$ \\ $n \quad$ Número de variáveis $-n \in \mathbb{N}$ \\ $m \quad$ Número de equações $-m \in \mathbb{N}$ \\ $v \quad$ Número de variáveis vinagre $-v \in \mathbb{N}$ \\ $r \quad$ Número de polinômios removidos $-r \in \mathbb{N}$ \\ $h \quad h \stackrel{\text { def }}{=} n-v$. Ou seja, $h \stackrel{\text { def }}{=}$ Número de variáveis - Número de variáveis vinagre. No \\ Quartz, $h$ representa o grau da extensão do Corpo Finito utilizado \\ $[\lambda]_{p \rightarrow q} \quad$ Dada uma cadeia de bits $\lambda=\left(\lambda_{0}, \ldots, \lambda_{t}\right)$ e dois inteiros $p$ e $q$ tais que $0 \leq p \leq q \leq t$, \\ temos que $[\lambda]_{p \rightarrow q}=\left(\lambda_{p}, \lambda_{p+1}, \ldots, \lambda_{q-1}, \lambda_{q}\right)$ \\ $\| \quad$ Concatenação \\ $\lambda \| \mu \quad$ Se $\lambda=\left(\lambda_{0}, \ldots, \lambda_{t}\right)$ e $\mu=\left(\mu_{0}, \ldots, \mu_{u}\right)$ são duas cadeias de bits, então $\lambda \| \mu=$ \\ $\left(\lambda_{0}, \ldots, \lambda_{t}, \mu_{0}, \ldots, \mu_{u}\right)$ \\ $p\left(x_{1}, \ldots, x_{n}\right) \quad$ Um polinômio de grau $d$ com $n$ variáveis sobre $\mathbb{F}$ \\ $\mathcal{P}=\left(p_{1}, \ldots, p_{m}\right) \quad$ Um sistema de $m$ polinômios de grau $d$ com $n$ variáveis sobre $\mathbb{F}$ \\ $a \in_{R} \mathcal{D} \quad$ Um valor $a$ pertencente ao domínio $\mathcal{D}$ é escolhido aleatoriamente, com igual pro- \\ babilidade, entre todos os elementos pertencentes \\ $\{0,1\}^{*} \quad$ Conjunto de todas as cadeias binárias com tamanho arbitrário finito \\ $\{0,1\}^{t} \quad$ Conjunto de todas as cadeias binárias com tamanho igual a $t$ \\ $A \times B \quad$ Conjunto de todos os pares $(a, b)$, onde $a \in A$ e $b \in B$ \\ $f: A \mapsto B \quad$ Uma função $f$ tendo como domínio o conjunto $A$ e como imagem o conjunto $B$ \\ $|\alpha| \quad$ Comprimento de $\alpha$ \\ $x>>y \quad$ Dados dois números $x$ e $y$ qualquer, temos que $x$ é significativamente maior do \\ que $y$ \\ $x<<y \quad$ Dados dois números $x$ e $y$ qualquer, temos que $x$ é significativamente menor do \\ que $y$
}




\section{Lista de Figuras}

3.1 Modelo MPKC . . . . . . . . . . . . . . . . . . . . . . . . . . . 15

3.2 Encriptação em sistemas MPKC . . . . . . . . . . . . . . . . . . 17

3.3 Decriptografia em sistemas MPKC . . . . . . . . . . . . . . . . . 18

4.1 Assinando com Quartz Original (começando com $i=1$ ) . . . . . . . . . . . . . 31

4.2 Verificando Assinatura com Quartz Original (começando com $i=4$ ). . . . . . . . . . 33

5.1 Assinando com Quartz Aprimorado (começando com $i=1$ ) . . . . . . . . . . . . . 43

5.2 Verificando Assinatura com Quartz Aprimorado (começando com $i=2$ ) . . . . . . . 45 


\section{Lista de Tabelas}

3.1 Principais $\mathcal{M} \mathcal{Q}$-trapdoors conhecidas atualmente. . . . . . . . . . . . . . . . . . . . 19

3.2 Principais modificadores genéricos e algumas de suas características. . . . . . . . . 20

4.1 Definições, Notação e Terminologia pertinentes ao Quartz. . . . . . . . . . . . . . . 25

5.1 Tamanho das assinaturas de alguns criptossistemas. . . . . . . . . . . . . . 52

6.1 Tempos obtidos durante a realização dos testes no Brucutu. . . . . . . . . . . . . 55

6.2 Tempos obtidos durante a realização dos testes no Ewerton-PC. . . . . . . . . . . . . 55

A.1 Símbolos utilizados em cada tipo de Grupo. . . . . . . . . . . . . . . . . . . . . 60 


\section{Capítulo 1}

\section{Introdução}

A escrita oculta, ou simplesmente criptografia (do grego kryptós, que significa oculto ou escondido; e gráphein, que significa escrita) é tão antiga quanto o esforço do homem em preservar ou destruir o sigilo de uma mensagem. Tamanha é sua antiguidade que alguns dos primeiros relatos sobre a criptografia datam de Heródoto, "o pai da história", que narrou os conflitos entre a Grécia e a Pérsia, ocorridos no quinto século antes de Cristo [Sin08].

No início, a criptografia tinha o intuito de apenas esconder segredos militares e de estado; seja através da ocultação de mensagens em tabuletas de madeira com uma cobertura feita a base de cera; seja por meio da escrita encoberta no couro cabeludo de soldados, que raspavam seus cabelos e tinham as mensagens escritas em suas cabeças, e após algum tempo (quando seus cabelos haviam crescido novamente) partiam até o destinatário das mensagens; ou até mesmo através da transposição e/ou substituição de letras; o fato é que, nos primórdios, a criptografia restringia-se ao sentido literal da palavra que dá nome a sua ciência, ou seja, ocultar mensagens.

Todavia, nos últimos anos não somente reis, rainhas, generais e governantes dependem de comunicações eficientes e seguras, mas sim toda a população. Isto porque uma diversidade de dados eletrônicos são manipulamos cotidianamente por todos nós. Desta forma, passamos a necessitar de um canal de comunicação seguro, com informações íntegras e legítimas. Tornando a criptografia, assim, uma ciência com interesse em estudos muito mais abrangentes, que faz uso de uma grande variedade de disciplinas e tecnologias, da matemática à linguística, da teoria da informação à teoria quântica.

Percebemos, então, que a criptografia moderna deixou de ser uma ferramenta de uso meramente militar, ou de governantes, e passou a fazer parte do cotidiano de cada um de nós. Ela está presente nos celulares, nos computadores pessoais, nas televisões, nos vídeo games, nas conexões seguras a sítios eletrônicos, em documentos digitais assinados, enfim, em uma infinidade de locais por vezes até impensáveis. A criptografia tornou-se um elemento tecnológico indispensável à segurança dos homens, ou seja, passou a ser o instrumento que fornecerá os fechos e as chaves da Era da Informação.

\subsection{Caracterização do Problema}

Podemos perceber que atualmente, seja conscientemente ou não, uma grande dependência dos sistemas desenvolvidos sob a seara da criptografia foi instaurada em todos nós. Principalmente no tocante dos sistemas criptográficos de chave pública, que são vastamente utilizados na Internet, incluindo-se aí os esquemas de assinatura digital que também são criptossistemas de chave pública. 
No entanto, desde quando Shor em 1997 desenvolveu um algoritmo de tempo polinomial para fatorar inteiros e para calcular o logaritmo discreto num computador quântico [Sho97] - computador este, proposto por Deutsch em 1985 [Deu85] - a criptografia de chave pública se viu ameaçada e começou a investigar novas fontes de problemas para seus sistemas. Este alarde ocorrera porque, basicamente, os criptossistemas de chave pública usados na atualidade têm sua segurança baseada na intratabilidade dos problemas da fatoração de inteiros, no caso de sistemas RSA, e do logaritmo discreto, em sistemas ElGamal ou de Curvas Elípticas, e tal descoberta tornaria estes sistemas inseguros quando possuíssemos computadores quânticos com a capacidade adequada para implementarmos o algoritmo de Shor.

Acreditamos que a possibilidade de evolução dos computadores quânticos não deveria ser encarada como único fator para a obsolescência dos criptossistemas de chave pública atuais. Pois além de existir incontáveis estudos acerca da segurança destes problemas ditos clássicos, a capacidade computacional aumenta significativamente a cada década, e isto, sem dúvida, torna padrões outrora considerados seguros em inseguros.

Uma interessante proposta para enfrentarmos estes desafios é utilização de sistemas MPKC (acrônimo da nomenclatura em inglês que significa Criptossistema de Chave Pública Multivariável), que se apoiam no Problema $\mathcal{M Q}(\mathcal{M}$ ultivariate $\mathcal{Q}$ uadratic $)$ para o desenvolvimento ou aprimoramento de sistemas criptográficos de chave pública seguros.

Quanto ao Problema $\mathcal{M Q}$, vale ressaltar que Patarin e Goubin demonstraram-no como sendo NP-completo [PG97], não se conhecendo até hoje nenhum algoritmo, nem mesmo quântico, que possa resolvê-lo em tempo polinomial [BBD09, NC10], garantindo assim uma relativa segurança para os criptossistemas baseados nesta primitiva.

\subsection{Criptografia Pós-Quântica}

Convencionou-se chamar de Criptografia Pós-Quântica a área de pesquisa onde são desenvolvidos sistemas criptográficos baseados em problemas intratáveis em computadores quânticos e onde, também, determina-se a complexidade quântica destas hipóteses de intratabilidade [dSM12].

Dentro deste universo, podemos destacar que as principais classes de criptossistemas aceitos como pós-quânticos são [BBD09]: Códigos Corretores de Erros, Hash, Reticulados e Chave Pública Multivariável. Valendo destacar que ainda não foi possível desenvolver uma comprovação tangível -em computadores quânticos- da intratabilidade de todos problemas em que estes criptossistemas se baseiam, como bem destaca Buchmann et al. na conclusão de seu trabalho [BCD $\left.{ }^{+} 04\right]$.

Sendo que, dentre essas quatro classes citadas, iremos explorar neste trabalho os Criptossistemas de Chave Pública Multivariável. Pois, além de serem considerados resistentes a computadores quânticos, os MPKCs ainda possibilitam a criação de esquemas de assinatura digital com tamanho assinaturas extremamente reduzidos [Cou04], apresentando implementações comprovadamente rápidas e eficientes, tanto em software, quanto em hardware [BERW08, $\mathrm{CCC}^{+} 09$ ], além de também serem indicados como uma opção para sistemas embarcados com restrição de processamento [DGS06a, BBD09, Hei09]. 


\subsection{Proposta original do Quartz}

O Quartz é um esquema de assinatura digital baseado no HFEv-, com escolha especial de parâmetros. Sua versão original proposta por Patarin, Courtois e Goubin em 2001 [PCG01b] foi atualizada pelos mesmos autores logo em seguida [CGP01], sendo que desde então adotamos esta última como versão original. Este esquema de assinatura foi submetido e aceito no NESSIE, um projeto de pesquisa desenvolvido para identificar sistemas criptográficos seguros que forneçam, em sentido amplo, confidencialidade e integridade dos dados, além de autenticidade das entidades [NES04]. Sendo que o principal trunfo deste esquema são suas assinaturas curtas (apenas 128 bits) e a fundamentação em um problema intratável até mesmo em computadores quânticos (o problema $\mathcal{M Q})$ [MS01].

O HFE, por sua vez, foi proposto por Patarin em 1996 [Pat96a] após ele ter quebrado o MIA (Matsumoto Imai Scheme A) [Pat95]. Esta nova trapdoor é uma generalização que modifica a função de mapeamento central $F$ do MIA. Tal generalização tem como principal característica a troca dos monômios, empregados na trapdoor quebrada, por polinômios. Além disto, no protocolo de assinatura Quartz, como os próprios modificadores já sugerem (HFEv-), algumas variáveis extra (chamadas de "variáveis vinagre") são adicionadas, e também, alguns "polinômios de perturbação" são inseridos no local dos polinômios removidos.

\subsection{Objetivos}

Os objetivos principais deste trabalho são:

- análise do esquema de assinatura digital Quartz, proposto por Patarin, Courtois e Goubin, idealizado para gerar assinaturas extremamente curtas;

- a apresentação de um novo protocolo de assinatura digital Quartz Aprimorado, com foco no aumento da segurança;

- o desenvolvimento de uma implementação do Quartz, tanto em seu modelo original quanto aprimorado;

- análise de nossa proposta de aprimoramento, através da estimativa de segurança e apreciação dos tempos obtidos durante os testes realizados a partir de nossa implementação.

\subsection{Contribuições}

As principais contribuições deste trabalho são:

- a apresentação de um novo protocolo de assinatura digital baseado no Quartz, logo, com assinaturas curtas e fundamentado em um problema intratável até mesmo em computadores quânticos;

- obtenção de um criptossistema resistente a ataques adaptativos que realizem chamadas ao oráculo aleatório, com um nível de segurança estimado em $2^{112}$, contra os $2^{50}$ do protocolo original; 
- demonstração de que nosso aprimoramento irá testar até 4.096 vezes menos hipóteses de utilização da chave pública durante a verificação de assinatura, quando comparado com o Quartz Original;

- implementação do Quartz Original e do Quartz Aprimorado em uma linguagem de programação portável.

\subsection{Organização do Trabalho}

No Capítulo 2, apresentamos os conceitos, notações e definições necessários para o desenvolvimento deste trabalho. No Capítulo 3, detalhamos o Problema $\mathcal{M Q}$ e seu uso na criptografia de chave pública, apresentando seu esquema genérico de funcionamento e as principais $\mathcal{M Q}$-trapdoors conhecidas na atualidade. Neste ponto, também tratamos sobre o Problema de Isomorfismo de Polinômios e elencamos os principais modificadores genéricos aplicáveis as funções $\mathcal{M Q}$ básicas. Em seguida, encerramos este Capítulo com uma visão geral acerca das criptoanálises de MPKCs.

Os Capítulos 4, 5 e 6 compõem a parte principal de nosso trabalho. Neles, revisamos o HFE e o Quartz Original, apresentamos nossa proposta de aprimoramento, analisamos as modificações propostas, estimamos o impacto destas modificações na segurança, e ainda, apresentamos os tempos obtidos durante os testes realizados a partir de nossa implementação de referência.

Por fim, no Capítulo 7, apresentamos as considerações finais de nossa pesquisa e propomos novas direções para trabalhos futuros. Frisando que, no Apêndice A, abordamos alguns conceitos matemáticos empregados em Criptossistemas de Chave Pública Multivariável. 


\section{Capítulo 2}

\section{Conceitos Preliminares}

Para o desenvolvimento deste trabalho utilizamos diversos conhecimentos oriundos de conceitos básicos da criptologia e ciências correlatas. Por isto, neste capítulo, buscaremos relacioná-los e explicá-los de forma sucinta e direta.

Consideramos importante destacar e explanar os conceitos aqui contidos para facilitar o entendimento deste trabalho, principalmente para aqueles não familiarizados com a área da criptografia. Todavia, leitores habituados com tais conceitos, sintam-se a vontade para pular este capítulo.

Além disto, ressaltamos que no Apêndice A abordamos alguns conceitos matemáticos empregados em Criptossistemas de Chave Pública Multivariável.

\subsection{Principais notações utilizadas}

Em nossa Lista de Símbolos, constante na página xi, vislumbramos a relação completa de notações e símbolos utilizados nesta dissertação. Porém, com intuito de facilitar a leitura, destacamos aqui as notações comumente empregadas neste trabalho.

Utilizaremos $\mathbb{F}$ ou $\mathbb{F}_{q}$ para indicar um Corpo Finito de ordem $q$, onde $q$ possua característica $p$, para algum $p$ primo, e $k \in \mathbb{N}$, tal que $q=p^{k}$. Quando utilizarmos $n$ estaremos tratando sobre o número de variáveis do sistemas de equações. Por sua vez, quando empregarmos $m$ estaremos indicando a quantidade de equações utilizadas em nosso sistema, sendo que $r$ denotará quantas destas equações foram removidas, quando for o caso. E ainda, por definição, temos que $h$ representará o grau da extensão do Copo Finito $\mathbb{F}$, ou seja $h \stackrel{\text { def }}{=} n-v$ e $\mathbb{E}=\mathbb{F}_{q^{h}}$.

\subsection{Funções Unidirecionais}

Funções unidirecionais (one-way functions) desempenham um importante papel na criptografia moderna. Com elas, conseguimos facilmente obter uma saída, mas dificilmente conseguiremos inverter tal função.

Conhecer este tipo de função é importante pois assumindo a existência dela, podemos construir criptossistemas de chave privada seguros, todavia, somente sua existência não garante a obtenção de um criptossistema de chave pública seguro [Sip12]. Contudo, tais funções são essenciais a obtenção de funções alçapão (trapdoor), que por sua vez dão origem aos criptossistemas de chave pública. Formalmente, podemos definir funções unidirecionais conforme segue. 
Definição 2.2.1. (Função Unidirecional). Seja $f: \mathcal{D} \mapsto \mathcal{I}$ uma função. $f$ é dita uma função unidirecional se as seguintes propriedades forem atendidas [PG97]:

Fácil de Calcular: Dado $x \in \mathcal{D}$, é possível calcular $y=f(x)$ em tempo polinomial.

Difícil de Inverter: Dado $y \in_{R} \mathcal{I}$, não se conhece algoritmo de tempo polinomial ou subexponencial em $|y|$ que calcule $x \in \mathcal{D}$ tal que $f(x)=y$.

\subsubsection{Função alçapão (trapdoor)}

O conceito de função alçapão (trapdoor), também chamada de função unidirecional com segredo, foi definido pela primeira vez juntamente com a apresentação da própria criptografia de chave pública (criptografia assimétrica) [DH76]. Neste trabalho, diversos axiomas e teoremas são estabelecidos, entretanto, seguiremos apresentando uma definição de função alçapão mais discreta e coerente com o contexto de nosso trabalho.

Definição 2.2.1.1. (Função Alçapão). Seja $f: \mathcal{D} \mapsto \mathcal{I}$ uma função. $f$ é dita uma função alçapão se as seguintes propriedades forem atendidas [PG97]:

Unidirecional: $f$ é uma função unidirecional.

Informação secreta: Existe uma informação secreta $\kappa$ tal que, dado $y \in_{R} \mathcal{I}$ e $\kappa$, é possivel calcular em tempo polinomial $x \in \mathcal{D}$ tal que $f(x)=y$.

\subsubsection{Função Hash}

Chamamos $H$ de função hash, ou função de espalhamento [Ter08], se $H:\{0,1\}^{*} \mapsto\{0,1\}^{t}$. Ou seja, dado um texto legível $x$, a função $H$ calcula $y=H(x)$ de comprimento relativamente menor que $x$. Por exemplo, seja $|x|$ da ordem de milhares de bytes, como o nome e informações curriculares de uma pessoa, e seja $|y|$ da ordem de alguns bits (160 bits, para ilustrar), assim $|y|<<|x|$. Desta forma, podemos estabelecer função hash conforme a definição abaixo.

Definição 2.2.2.1. (Função Hash). Seja $H: \mathcal{D} \mapsto \mathcal{I}$ uma função. $H$ é dita uma função hash se as seguintes propriedades forem atendidas [Ter08]:

Unidirecional: $H$ é uma função unidirecional.

Entrada de tamanho variável: Dado $x \in \mathcal{D}, x$ é de comprimento variável, relativamente longo.

Saída de tamanho fixo: É possivel calcular $y \in \mathcal{I}$, onde y é de comprimento fixo, relativamente curto.

A definição descrita acima é a de função hash unidirecional, havendo também, definições mais genéricas para função hash, sem o requisito das propriedades de função unidirecional [MOVR96]. Para nós, no entanto, interessa apenas a definição que expomos acima pois ela garante que a função não é facilmente inversível e também que a cadeia de dados da entrada tenha sua integridade verificável, como ocorre em esquemas de assinatura digital, por exemplo. 


\subsection{Definições}

Visando uniformizar o entendimento dos capítulos posteriores, nesta seção, introduziremos breves explicações acerca de algumas outras definições essenciais a este trabalho.

\subsubsection{Probabilidade desprezível}

É intuitivo imaginar que algo com uma probabilidade desprezível tem uma possibilidade muito remota de acontecer, tão remota que podemos ignorar. Todavia, apenas essa ideia, sem uma definição específica, poderá nos levar a entendimentos diversos, causando controvérsias no momento de formalizarmos provas e estimativas de segurança.

Empiricamente podemos estabelecer uma probabilidade desprezível como sendo qualquer acontecimento que ocorra como uma probabilidade menor que um determinado valor, $2^{-30}$ por exemplo. Porém, acreditamos que é preferível utilizarmos uma definição assintótica, conforme definição que segue.

Definição 2.3.1.1. (Probabilidade Desprezível). $\epsilon-\epsilon(l)$ é desprezível em l se para qualquer polinômio $p, \epsilon \leqslant 1 / p(l)$ para todo $l$ grande o suficiente [CDD0r]].

\subsubsection{Adversário}

Em diferentes contextos podemos pensar em adversário como sendo uma pessoa, criatura ou entidade contra a qual se luta ou se disputa algo. Por exemplo, em uma partida de futebol adversário é o time contra o qual se joga, já em uma mesa de pôquer seus adversários são todos os demais jogadores. Por isto, neste trabalho, adotaremos a seguinte definição para adversário:

Definição 2.3.2.1. (Adversário). É um indivíduo ou serviço mal intencionado que usa suas habilidades para atacar protocolos de assinatura e com isso obter assinaturas falsificadas.

\subsubsection{Vítima}

Semelhante ao conceito anterior, podemos definir vítima de diversas formas, dependendo do contexto empregado. No ramo jurídico, vítima é a designação do indivíduo que sofre diretamente as consequências da violação de seus direitos. Em sentido mais amplo, vítima pode ser a pessoa que sofre os resultados infelizes dos próprios atos, dos de outrem ou do acaso. Desta forma, para não haver dubiedade no entendimento, adotaremos a seguinte definição para vítima:

Definição 2.3.3.1. (Vítima). É o dono das informações privadas, ou o destinatário das mensagens assinadas. Ou seja, vítima é um usuário (ou serviço) que assina as mensagens (remetente) ou é aquele que verifica a autenticidade e a integridade das mensagens assinadas (destinatário), que estão sendo atacados por um adversário.

\subsubsection{Colisão em funções Hash}

Dada uma função hash $H()$ diz-se que há colisão se existe um par de legíveis $x_{1}$ e $x_{2}$, onde $x_{1} \neq x_{2}$, que acarreta $H\left(x_{1}\right)=H\left(x_{2}\right)$ [Ter08]. Se este tipo de colisão for computacionalmente inviável (ou seja, possua uma probabilidade desprezível de ocorrer), diz-se que $H($ ) é resistente a colisões. 
Esta propriedade é imprescindível a funções hash seguras, pois ela garante que entradas distintas não gerem o mesmo resultado.

Buscando minimizar a probabilidade de colisões, os desenvolvedores de funções hash devem projetar $H()$ de modo a obter uma alta entropia ${ }^{1}$. Assim, $H(x)$ irá gerar um valor único para representar $x$, de modo que se poucos bits de $x$ forem alterados (mesmo que um único bit) o valor resultante tenha alta probabilidade de ser completamente distinto. Por exemplo, se $H($ ) for segura, então $H$ ("Joaquim") $\neq H$ ("Joaquin").

\section{Tipos de colisão}

Além da definição genérica citada anteriormente, podemos encontrar na literatura outras duas definições de colisões e resistência à colisão, que são [Ter08]:

Resistência à pré-imagem (preimage resistance ou one-wayness): para qualquer $y$, imagem de $H()$, é computacionalmente inviável calcular qualquer $x^{\prime}$ tal que $H\left(x^{\prime}\right)=y$ sem conhecer $x$ tal que $H(x)=y$.

Resistência à segunda pré-imagem (second preimage resistance): conhecendo-se $x$ tal que $H(x)=y$, é computacionalmente inviável calcular qualquer $x^{\prime} \neq x$ de tal forma que $H\left(x^{\prime}\right)=y=H(x)$.

\section{Ataque pelo Paradoxo de Aniversário}

O Paradoxo de Aniversário é uma metáfora aplicável a qualquer função hash. Nesta metáfora, pessoas em uma sala são retiradas e devolvidas a este ambiente; de modo que a retirada de uma pessoa com a mesma data de nascimento de outra, represente uma colisão. Baseado neste paradoxo, Yuval projetou um dos ataques a função hash mais conhecidos da atualidade [Yuv79]. Nele, seja $H(x)$ uma função hash onde $t$ representa o comprimento da sua imagem, então o adversário consegue encontrar uma colisão usando $\mathcal{O}\left(2^{t / 2}\right)$ execuções da função hash [Ter08].

Deste modo, temos que para alcançar uma segurança de $\lambda$ bits precisamos de uma função hash com saída de pelo menos $2 \lambda$ bits.

\subsubsection{Ataque por força bruta (brute-force attack)}

Este tipo de ataque não consiste em uma criptoanálise em si, mas em um processo automatizado de tentativa e erro com o objetivo de recuperar informações protegidas por um determinado criptossistema. Nele, o tamanho da chave é que determina sua viabilidade ou não. Assim, se tomarmos $K$ como sendo o tamanho da chave, podemos dizer que no pior caso o ataque por força bruta levará um tempo proporcional a $2^{K}$.

Em esquemas de assinaturas digitais este tipo de ataque também é chamado de Busca Exaustiva (Brute-force Search ou Exhaustive Search). Neste cenário, a resolução do problema consiste em enumerar sistematicamente todos os candidatos possíveis a solução (todas mensagens possíveis) e verificar qual destes candidatos satisfaz a declaração do problema (encontrar uma assinatura válida).

\footnotetext{
${ }^{1}$ Em linhas gerais, podemos dizer que entropia da indícios do grau de irreversibilidade de um criptossistema, encontrando-se geralmente associada a "desordem".
} 


\subsubsection{Quebra do protocolo}

Frequentemente lemos ou escutamos sobre alguma "quebra" de determinado protocolo. Todavia, o termo "quebra" possui significado distinto dependendo do contexto em que é empregado. Por este motivo, segue a relação das definições que utilizaremos no contexto desta dissertação.

Definição 2.3.6.1. Dizemos que um adversário quebra um protocolo (ou uma função hash) quando ele consegue recalcular a chave secreta (ou encontrar uma colisão na função hash) em tempo polinomial utilizando espaço (memória) polinomial, com ou sem pré-processamento.

Definição 2.3.6.2. Dizemos que um adversário quebra um protocolo (ou uma função hash) quando ele consegue recalcular a chave secreta (ou encontrar uma colisão na função hash) em tempo polinomial utilizando espaço (memória) exponencial, com ou sem pré-processamento.

Definição 2.3.6.3. Dizemos que um adversário quebra um protocolo (ou uma função hash) quando ele consegue recalcular a chave secreta (ou encontrar uma colisão na função hash) em tempo exponencial, estritamente menor que por força bruta, utilizando espaço (memória) polinomial, com ou sem pré-processamento.

Definição 2.3.6.4. Dizemos que um adversário quebra um protocolo (ou uma função hash) quando ele consegue recalcular a chave secreta (ou encontrar uma colisão na função hash) em tempo exponencial, estritamente menor que por força bruta, utilizando espaço (memória) exponencial, com ou sem pré-processamento.

Vale ressaltar que as definições acima são apenas adaptações de algumas das diversas formalizadas ao longo da história da criptografia. Lembrando que Shannon foi o primeiro autor a definir formalmente os requisitos que um criptossistema deveria apresentar para ser seguro, definindo claramente o que significa "quebrar" um sistema criptográfico [CDD07].

\subsection{Noções de esquemas de Assinatura Digital}

Em linhas gerais, podemos dizer que os esquemas de assinatura digital são métodos de autenticação de informação comumente comparados com o processo de assinatura física em papel. Isto porque, essencialmente, os objetivos de ambos são os mesmos, ou seja, tanto no meio físico quanto no digital são visados à autenticidade do remetente, a irretratabilidade de uma assinatura legítima e a integridade da mensagem assinada.

A autenticidade do remetente implica em possibilitar que o destinatário (quem recebeu a mensagem) possa, utilizando apenas informações públicas, verificar se a mensagem foi de fato assinada pelo remetente.

A irretratabilidade, por sua vez, implica na incapacidade do remetente (quem assinou a mensagem) negar (por exemplo, em um tribunal) que assinou determinada mensagem, isto porque somente ele conhece as informações secretas necessárias para o processo de assinatura.

Enquanto a integridade da mensagem diz respeito à habilidade que o destinatário tem para verificar (utilizando apenas informações públicas) se a mensagem não foi alterada antes de ser entregue a ele.

Assim, podemos formalizar esquema de assinatura digital conforme segue. 
Definição 2.4.1. (Esquema de Assinatura Digital). É um esquema (GerA, Assina, Verifica) definido da seguinte forma [SSH11a]:

Algoritmo gerador de chaves (GERA): é um algoritmo probabilístico que recebe como entrada um parâmetro do sistema $1^{\lambda}$ e retorna um par de chaves $(p k$, sk) que correspondem a chave pública e a chave privada, respectivamente.

Algoritmo de assinatura (Assina): é um algoritmo probabilistico que recebe como entrada uma mensagem $M$ a ser assinada, a chave privada sk, e retorna a assinatura resultante $\sigma=\operatorname{AssinA}_{s k}(M)$.

Algoritmo de verificação de assinatura (VERIFICA): é um algoritmo que recebe como entrada uma mensagem $M$, uma suposta assinatura $\sigma$, a chave pública pk, e retorna o bit obtido através de $\operatorname{VERIFICA}_{s k}(M, \sigma)$. Caso o algoritmo retorne 1 (um bit sinalizando verdadeiro) a assinatura é aceita. Caso contrário, o algoritmo retorne 0 (um bit sinalizando falso), a assinatura é rejeitada. É exigido que se $\sigma \leftarrow \operatorname{AssinA}_{s k}(M)$, então $\operatorname{VeRIFICA}_{s k}(M, \sigma)=1$.

\subsubsection{Criptoanálise de esquemas de Assinatura Digital}

Criptoanálise (anteriormente chamada de Criptanálise $^{2}$ ) é o termo utilizado para descrever alguma tentativa de comprometimento da segurança de um protocolo de criptografia, em nosso caso, de assinaturas. Em outras palavras, podemos dizer que criptoanálise são os ataques realizados a sistemas criptográficos.

\section{Tipos de ataques}

Basicamente existem quatro tipos de ataques a esquemas de assinatura digital, sendo eles [GMR88]:

Ataque apenas com a chave pública (Key-Only attack): É o ataque mais fraco, no sentido de que o adversário possui menos informação. Neste tipo ataque, o adversário conhece somente a chave pública da vítima e os parâmetros do sistema.

Ataque de mensagem conhecida (Known message attack): Nesse tipo de ataque, o adversário conhece alguns pares (mensagem, assinatura) que foram gerados previamente pela vítima, ou seja, o adversário possui uma lista de mensagens com assinaturas legítimas. Neste caso, os pares provavelmente foram interceptados pelo adversário.

Ataque de mensagem escolhida (Chosen message attack): Neste tipo de ataque, o adversário consegue obter assinaturas de um determinado número de mensagens selecionadas previamente.

Ataque adaptativo de mensagem escolhida (Adaptive chosen message attack): Neste tipo de ataque, o adversário consegue gerar assinaturas de mensagens escolhidas adaptativamente, isto é, o adversário tem acesso a assinaturas por intermédio de um oráculo, podendo requerer assinaturas de mensagens escolhidas conforme os resultados obtidos anteriormente.

\footnotetext{
${ }^{2}$ Mudança ocorrida devido as regras do novo acordo ortográfico da língua portuguesa [BRA08].
} 


\section{Objetivos do adversário}

Outro ponto importante no tocante das criptoanálises são os objetivos do adversário. Sabendo seus objetivos poderemos aferir o nível de sucesso que o adversário poderá atingir. Genericamente, em ataques que visem o comprometimento de esquemas de assinatura digital, o adversário possui quatro objetivos distintos:

Quebra total (Total break): É o nível mais alto de sucesso. Neste caso, o adversário consegue calcular a chave secreta da vítima.

Falsificação universal (Universal forgery): O adversário não tem conhecimento da chave secreta da vítima, mas consegue gerar uma assinatura válida (porém falsificada) para qualquer mensagem.

Falsificação selecionada (Selective forgery): O adversário consegue gerar uma assinatura válida (porém falsificada) para algumas mensagens escolhidas.

Falsificação existencial (Existential forgery): O adversário consegue gerar uma assinatura válida (porém falsificada), mas ele não consegue determinar ou modificar a mensagem cuja assinatura foi falsificada. É o nível mais baixo de sucesso.

Definição 2.4.1.1. (Esquema de Assinatura Seguro). Neste trabalho, um esquema de assinatura será dito seguro somente se ele for existencialmente seguro contra ataques adaptativos de mensagem escolhida. 


\section{Capítulo 3}

\section{Criptossistemas de Chave Pública Multivariável}

Conforme citado anteriormente, uma das motivações (não a única) para a nossa pesquisa é o risco do comprometimento dos atuais sistemas criptográficos de chave pública, que basicamente são fundamentados no problema da fatoração de inteiros e do logaritmo discreto, no caso de computadores quânticos com capacidade de processamento adequada serem desenvolvidos. Dentre as classes de criptossistemas pós-quânticos citados na Seção 1.2, os Criptossistemas de Chave Pública Multivariável (ou simplesmente MPKCs) se destacam por, principalmente, possibilitar a criação de esquemas de assinatura digital com tamanho de assinaturas reduzidos [Cou04], que é um objetivo implícito de nosso trabalho.

Pelo que podemos encontrar na bibliografia, o primeiro artigo que descreve um criptossistema de chave pública com mais de uma variável independente foi o de Ong e Schnorr [OS84]. Algum tempo depois, Fell e Diffie apresentaram um estudo onde um criptossistema com mais de uma equação era implementado [FD85]. No mesmo ano, Matsumoto et al. desenvolveram o primeiro sistema criptográfico com quatro variáveis [MIHM85], e até então o mais próximo dos MPKCs atuais. Todavia, todos estes criptossistemas não são MPKCs de fato, porém, foram eles que inspiraram Matsumoto e Imai a conceberem o $C^{*}$ (ou MIA, como normalmente é chamado) [MI88], considerado a primeira $\mathcal{M Q}$-trapdoor criada.

O MIA foi quebrado por Patarin em 1995 [Pat95], e talvez os MPKCs não tivessem sobrevivido sem as contribuições que o mesmo autor dera posteriormente, conforme destacado por Stern [Ste11]. O fato é que os Criptossistemas de Chave Pública Multivariável sobreviveram e eles tem sido amplamente desenvolvidos nas últimas duas décadas [BBD09]. Isto talvez, porque ser uma alternativa pós-quântica seja a menor das vantagens destes criptossistemas, uma vez que as implementações dos esquemas derivados desta primitiva têm se mostrado rápidas e eficientes, tanto em software, quanto em hardware [BERW08, $\mathrm{CCC}^{+}$09], além de serem indicados como uma opção para sistemas embarcados com restrição de processamento [DGS06a, BBD09, Hei09], já que não necessitam de co-processador.

Além destas características, Ding et al. realçam que: a segurança de criptossistemas derivados do RSA depende da intratabilidade da fatoração de inteiros, que por sua vez baseia-se em resultados oriundas da teoria dos números, desenvolvida durante os séculos XVII e XVIII; criptossistema sobre Curvas Elípticas empregam o uso da matemática desenvolvida no século XIX; enquanto MPKCs 
utilizam resultados da geometria algébrica desenvolvida durante o século XX [DGS06a].

Ainda teríamos diversos outros pontos positivos a apontar, mas consideramos desnecessário neste momento visto que já podemos conjecturar que os MPKCs constituem, dependendo do cenário, uma boa alternativa para esquemas de chave pública convencionais como, por exemplo, RSA e ECC. Desta forma, prosseguiremos explanando sobre conceitos e características inerentes aos Criptossistemas de Chave Pública Multivariável.

\section{$3.1 \quad$ O problema $\mathcal{M Q}$}

Seja $\mathbb{F}$ um Corpo Finito de ordem $q, n \in \mathbb{N}$ o número de variáveis, $m \in \mathbb{N}$ o número de equações, $d \in \mathbb{N}$ o grau do sistema de equações, $\mathcal{P}\left(x_{1}, \ldots, x_{n}\right)$ um sistema de $m$ polinômios com grau $d$ e $n$ variáveis sobre $\mathbb{F}$. Temos que o Sistema de Equações Polinomiais Multivariáveis Simultâneas consiste em encontrar $x=\left(x_{1}, \ldots, x_{n}\right) \in \mathbb{F}^{n}$ tal que $\mathcal{P}(x)=y$, sendo $y=\left(y_{1}, \ldots, y_{m}\right) \in \mathbb{F}^{m}$, onde $y$ é um vetor de dimensão $m$ :

$$
\mathcal{P}=\left\{\begin{array}{l}
p_{1}\left(x_{1}, \ldots, x_{n}\right)=y_{1} \\
p_{2}\left(x_{1}, \ldots, x_{n}\right)=y_{2} \\
\vdots \\
p_{m}\left(x_{1}, \ldots, x_{n}\right)=y_{m}
\end{array}\right.
$$

Assim, quando o grau de $\mathcal{P}$ é maior ou igual a 2 , ou seja $d \geq 2$, chamamos, então, este sistema de equações polinomiais de Problema $\mathcal{M Q}$.

O problema $\mathcal{M Q}$ baseia-se no trabalho apresentado por Garey e Johnson em 1979, onde os autores provaram que solucionar um sistemas de equações polinomiais multivariáveis sobre um corpo finito é, em geral, NP-difícil [GJ79]. Entretanto, a demonstração de segurança desta primitiva sendo utilizada na concepção de criptossistemas só foi apresentada em 1997. Neste novo trabalho, Patarin e Goubin demonstraram que uma trapdoor criada a partir do problema $\mathcal{M Q}$ é NP-completo [PG97], não se conhecendo até hoje nenhum algoritmo, nem mesmo quântico, de tempo polinomial que possa resolver este problema [BBD09, NC10].

Além disto, para caracterizar-se como um MPKC, Wolf e Preneel explicam que os $p_{\ell}$ polinômios de $\mathcal{P}$ devem explicitamente seguir a seguinte formato genérico [WP05]:

$$
\begin{gathered}
p_{1}\left(x_{1}, \ldots, x_{n}\right):=\sum_{1 \leq i \leq j \leq n} \alpha_{1, i, j} x_{i} x_{j}+\sum_{i=1}^{n} \beta_{1, i} x_{i}+\delta_{1} \\
\vdots \\
p_{\ell}\left(x_{1}, \ldots, x_{n}\right):=\sum_{1 \leq i \leq j \leq n} \alpha_{\ell, i, j} x_{i} x_{j}+\sum_{i=1}^{n} \beta_{\ell, i} x_{i}+\delta_{\ell} \\
\vdots \\
p_{m}\left(x_{1}, \ldots, x_{n}\right):=\sum_{1 \leq i \leq j \leq n} \alpha_{m, i, j} x_{i} x_{j}+\sum_{i=1}^{n} \beta_{m, i} x_{i}+\delta_{m}
\end{gathered}
$$

onde $1 \leq \ell \leq m, 1 \leq i \leq j \leq n$, e os coeficientes $\alpha_{\ell, i, j}, \beta_{\ell, i}, \delta_{\ell} \in \mathbb{F}$. E, no caso em que $d=2$ (ou seja, no caso geral), nós podemos dizer que o coeficiente $\alpha_{\ell, i, j}$ é quadrático, o coeficiente $\beta_{\ell, i}$ é linear, e $\delta_{\ell}$ é uma constante. 
Precisamos destacar ainda, que ao estabelecer os parâmetros para instanciar uma função $\mathcal{M Q}$, devemos ter $n>m$ e $n \approx m$ para que o problema permaneça intratável. Isto porque, caso $n<m$, teríamos um sistema de equações superdefinido, onde existiriam mais equações do que variáveis, o que tornaria a sua resolução "fácil" [CKPS00a]. Por outro lado, caso $n>>m$, teríamos um sistema de equações com muito mais variáveis do que equações, o que possibilitaria ao adversário utilizar o algoritmo proposto por Courtois et al. em 2002; sendo este algoritmo muito mais veloz do que a busca exaustiva [CGMT02].

Contudo, os MPKCs atuais não tem sua segurança baseada exclusivamente no problema $\mathcal{M} \mathcal{Q}^{1}$, uma vez que ainda não foi descoberta uma maneira de criar uma trapdoor a partir de uma instância aleatória da função $\mathcal{M Q}$. Desta forma, os MPKCs utilizam uma construção específica (como veremos nas seções subsequentes), que resulta na dependência de outros problemas. Em nosso caso, a segurança também depende da intratabilidade do problema de Isomorfismo de Polinômios (IP) -para detalhes sobre o problema IP, veja a Seção $3.4^{-}$.

\subsection{Visão geral dos MPKCs}

Sabemos que uma função construída a partir do problema $\mathcal{M Q}$ é uma função unidirecional [PG97], porém, conforme visto na Seção 2.2, para a construção de um criptossistema de chave pública é necessário que esta função seja também uma função alçapão (trapdoor). No entanto, Ding e Yang enfatizam, de forma simples e direta, que não é possível obter uma trapdoor a partir de uma instância aleatória de função $\mathcal{M Q}$ [BBD09]. Por isso, os atuais MPKCs utilizam um mapeamento $F: \mathbb{F}^{n} \mapsto \mathbb{F}^{m}$ inversível, juntamente com duas transformações afins $S$ e $T$ para criar uma função $\mathcal{M Q}$. Isto é, os MPKCs são construídos a partir de um conjunto de equações polinomiais "fáceis", utilizando-se de duas transformações afins para "criar" uma aparente instância aleatória de uma função $\mathcal{M Q}$ que servirá de chave pública.

Assim, a chave pública $\mathcal{P}$ é criada a partir da composição de duas transformações $S: \mathbb{F}^{n} \mapsto \mathbb{F}^{n}$, $T: \mathbb{F}^{m} \mapsto \mathbb{F}^{m}$ e um mapeamento central $F: \mathbb{F}^{n} \mapsto \mathbb{F}^{m}$, ou seja, $\mathcal{P}=T \circ F \circ S$, onde $T, F$ e $S$ são as chaves privadas [WP05]. Sendo este o modelo conceitual genérico adotado pelos criptossistemas MPKC, o qual pode ser vislumbrado na Figura 3.1.

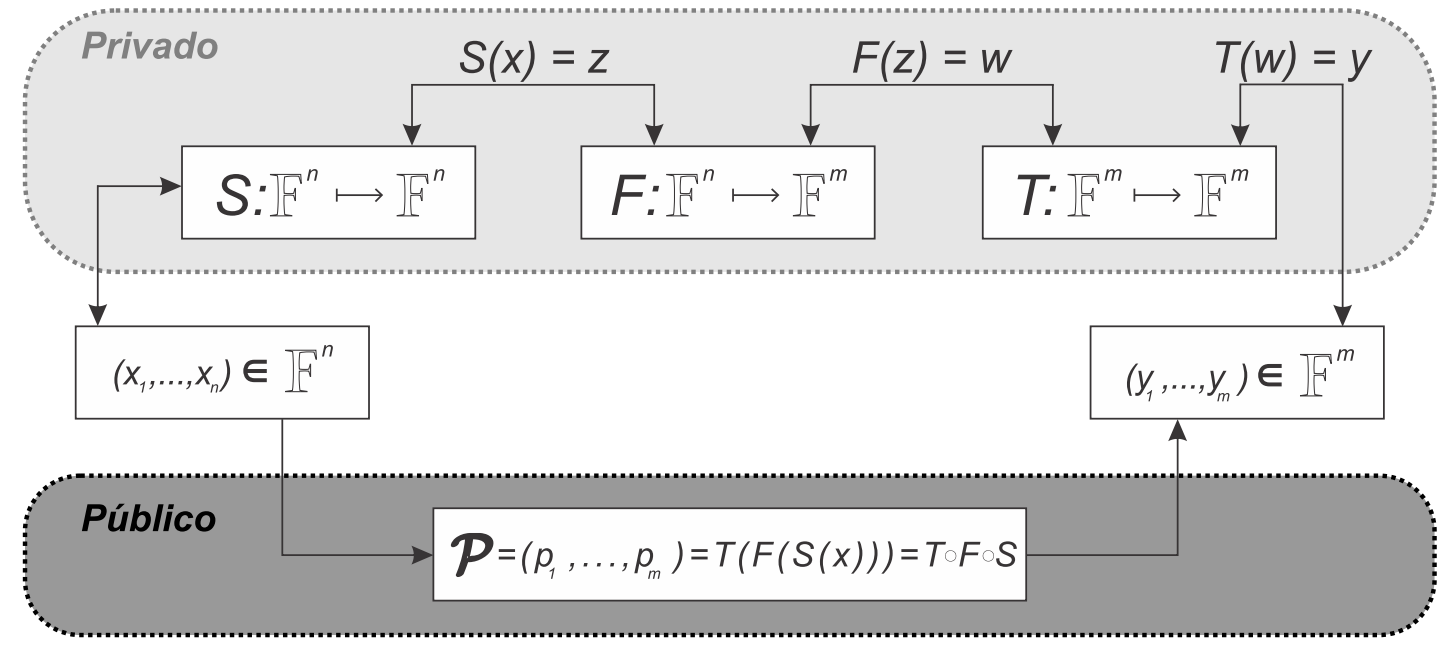

Figura 3.1: Modelo $M P K C$.

\footnotetext{
${ }^{1}$ Exceto o esquema de identificação proposto por Sakumoto et al. na CRYPTO 2011 [SSH11b].
} 
Lembramos que o fato de $\mathcal{P}=T \circ F \circ S$, ou seja, $\mathcal{P}$ ser uma composição de outras funções, faz com que os atuais Criptossistemas de Chave Pública Multivariável não dependam exclusivamente do problema $\mathcal{M Q}$. Esta interdependência entre o problema $\mathcal{M Q}$ e IP gera certa controvérsia, uma vez que mesmo acreditando-se que o problema IP seja difícil, nenhuma prova da intratabilidade deste problema foi formulada até o momento ${ }^{2}$. Além disso, também existe o fato de algumas criptoanálises terem utilizado estruturas específicas da trapdoor sob ataque, para recuperar as chaves privadas $T, F$ e $S$ somente conhecendo a chave pública $\mathcal{P}$ [NTCP03, DFSS07, BFMR11, BFFP11]; é o que aconteceu com o SFlash, que chegou a ser recomendado pelo NESSIE [NES04]. No entanto, esta "vulnerabilidade" não mostrou-se explorável no HFEv-, fato que reforça nossa confiança nesta trapdoor (para maiores detalhes, consulte as Seções 3.4 e 4.3).

Contudo, ressaltamos que o modelo aqui exposto é apenas uma generalização das diversas $\mathcal{M} \mathcal{Q}$ trapdoors existentes na atualidade, onde a principal diferença entre elas está, principalmente, no formato do mapeamento central $F$. Sendo que também existem algumas trapdoors, como é o caso da UOV, que utilizam apenas uma transformação afim para criar a chave pública $\mathcal{P}$, de modo que $\mathcal{P}=F \circ S$ [KPG99]. Característica que utilizamos para propor o modelo Aprimorado do Quartz (veja Seção 5.1), pois apesar de fugir ligeiramente do modelo genérico, este tipo de composição é amplamente aceito, já que uma segunda transformação afim não adiciona segurança alguma ao sistema criptográfico [BBD09, LFPW11], uma vez que suas operações são apenas lineares; e a não realização desta transformação melhora a performance do processo de assinatura e geração de chaves.

\subsection{Esquema genérico de operações em MPKC}

Nesta seção vamos ilustrar o funcionamento genérico das operações de Assinatura, Verificação de Assinatura, Encriptação e Decriptação em Criptossistemas de Chave Pública Multivariável. Nossa intenção, entretanto, não é esgotar todos os detalhes e minúcias atinentes a cada uma destas operações em algum criptossistema específico, pelo contrário, buscaremos explicitar o funcionamento comum a todos MPKCs, para posteriormente esclarecermos sobre o funcionamento do Quartz e do modelo aprimorado proposto.

\subsubsection{Assinatura}

Para assinarmos uma mensagem y utilizando um sistema criptográfico MPKC é necessário que empreguemos, individualmente e a cada passo, as funções inversas das chaves privadas $T, F$ e $S$. De forma que calculemos um vetor $w:=T^{-1}(y)$ para a mensagem $y$ dada, seguido por $z:=F^{-1}(w)$, e por último $x:=S^{-1}(z)[\mathrm{WP} 05]$; ou seja:

$$
y \in \mathbb{F}^{m} \stackrel{T^{-1}(y)=w}{\longrightarrow} w \in \mathbb{F}^{m} \stackrel{F^{-1}(w)=z}{\longrightarrow} z \in \mathbb{F}^{n} \stackrel{S^{-1}(z)=x}{\longrightarrow} x \in \mathbb{F}^{n} .
$$

Sendo possível visualizar na parte superior da Figura 3.1, que para assinarmos uma mensagem basta ela "percorrer", da direita para a esquerda, todas as chaves privadas que formam a função $\mathcal{M Q}$.

\footnotetext{
${ }^{2} \mathrm{O}$ problema da fatoração de inteiros e do logaritmo discreto também não possuem prova quanto a sua intratabilidade, mesmo assim, atualmente são largamente empregados em criptossistemas.
} 


\subsubsection{Verificação de Assinatura}

A verificação de assinatura funciona da mesma maneira em todos esquemas baseados na intratabilidade do problema $\mathcal{M Q}$ : avaliando se o vetor de polinômios $\mathcal{P}$ (chave pública dos criptossistemas MPKC) gera a assinatura $x \in \mathbb{F}^{n}$, recebida do remetente [WP05]. Assim, se o resultado destes cálculos for igual aos valores contidos no vetor da mensagem $y \in \mathbb{F}^{m}$, a assinatura é aceita, caso contrário é rejeitada.

Em outras palavras, a verificação de assinatura consiste em $y \stackrel{?}{=} \mathcal{P}(x)$, onde $\stackrel{?}{=}$ denota uma comparação, iterada $m$ vezes no espaço vetorial $\mathbb{F}$ :

$$
\begin{aligned}
y_{1} & \stackrel{?}{=} p_{1}\left(x_{1}, \ldots, x_{n}\right) \\
& \vdots \\
y_{m} & \stackrel{?}{=} p_{m}\left(x_{1}, \ldots, x_{n}\right)
\end{aligned}
$$

corroborando assim, com o que está sintetizado na parte inferior da Figura 3.1. Ou seja, dada uma assinatura $x \in \mathbb{F}^{n}$ e uma mensagem $y \in \mathbb{F}^{m}$, podemos verificar se $x$ é de fato uma assinatura de $y$ através da aplicação da chave pública $\mathcal{P}=\left(p_{1}, \ldots, p_{m}\right)=T(F(S(x)))=T \circ F \circ S$.

Como cada polinômio tem $\mathcal{O}\left(n^{d}\right)$ coeficientes, então uma verificação de assinatura realiza o total de $\mathcal{O}\left(m n^{d}\right)$ multiplicações e adições sobre $\mathbb{F}$ [WP05]. Porém, estratégias para uma verificação mais rápida são discutidas em [CGP01].

\subsubsection{Encriptação}

Dependendo das características do mapeamento central pode ocorrer de $F: \mathbb{F}^{n} \mapsto \mathbb{F}^{m}$ não ser injetora e consequentemente $\mathcal{P}: \mathbb{F}^{n} \mapsto \mathbb{F}^{m}$ também não será. Assim, para existir uma decriptação única, é necessário que uma redundância seja calculada, como mostrado na Figura 3.2. Desta forma, criptografar uma mensagem consistirá em dois passos:

1. $y:=\mathcal{P}(x)$, ou seja, encontrar um $y$ aplicando a chave pública $\mathcal{P}$ sobre o texto legível $x$;

2. $\tilde{x}:=H(x)$, onde $H$ é uma função hash.

Assim, a mensagem encriptada consistirá em um par $(y, \tilde{x}) \in \mathbb{F}^{m} \times\{0,1\}^{t}$, onde $t \in \mathbb{N}$, e $t$ correspondente ao comprimento da cadeia gerada pela função hash utilizada [WP05].

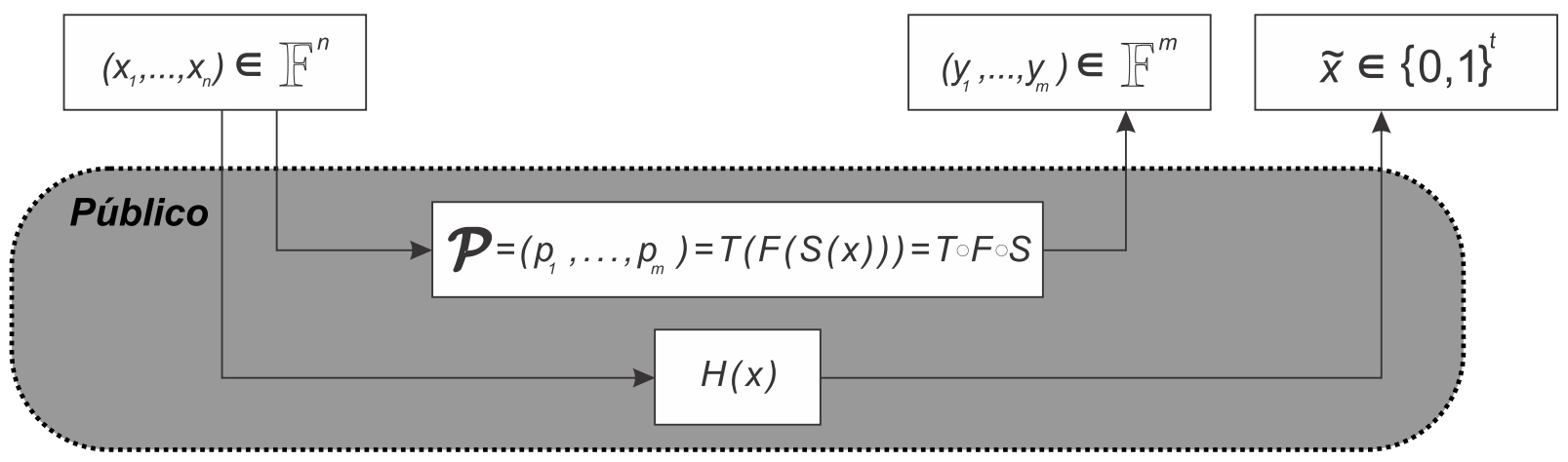

Figura 3.2: Encriptação em sistemas $M P K C$. 


\subsubsection{Decriptação}

De modo análogo ao que ocorre na Assinatura (ver Seção 3.3.1), na decriptografia também teremos que utilizar as funções inversas das chaves privadas $(T, F, S)$ para decriptar o texto cifrado $y$, recebido através da dupla $(y, \tilde{x})$. Destaca-se que comumente precisaremos calcular diversas ${ }^{3}$ possíveis pré-imagens $W_{1}, \ldots, W_{k} \in \mathbb{F}^{n}$ para satisfazer a equação $F(w)=z$ para um dado $z \in \mathbb{F}^{m}$, onde $k \in \mathbb{N}$ e as $W_{i}$ possíveis soluções formem o conjunto $Q$ de todas elas, tal que $Q:=\left\{W_{i} \in \mathbb{F}^{n}\right.$ : $W_{i}:=S^{-1}\left(W_{i}\right)$ para $\left.1 \leq i \leq k\right\}$ [WP05]. Desta forma, conforme um novo $W_{i}$ válido é adicionado ao conjunto $Q$ e um possível texto legível $x^{\prime}$ é obtido, a função hash $H()$ - a mesma que fora utilizada para encriptar - é utilizada para verificar se o valor de $\tilde{x}^{\prime}$ e $\tilde{x}$ coincidem, ou seja, $H\left(x^{\prime}\right) \stackrel{?}{=} \tilde{x}$ (conforme Figura 3.3).

$$
\begin{gathered}
y \in \mathbb{F}^{m} \stackrel{T^{-1}(y)=w}{\longrightarrow} w \in \mathbb{F}^{m} \stackrel{F^{-1}(w)=z}{\longrightarrow} z \in \mathbb{F}^{n} \stackrel{S^{-1}(z)=x^{\prime}}{\longrightarrow} x^{\prime} \in \mathbb{F}^{n} \\
\tilde{x}^{\prime}:=H\left(x^{\prime}\right) \\
\tilde{x}^{\prime} \stackrel{?}{=} \tilde{x}
\end{gathered}
$$

Note que todo o criptossistema é colocado em risco caso a função hash escolhida para se calcular a redundância $\tilde{x}$ possua pontos de insegurança, ou no pior caso tenha sido "quebrada"4 (por exemplo, MD5 e SHA-1 são funções consideradas inseguras devido as criptoanálises contidas em [WY05] e [WYY05], respectivamente). Neste cenário, o criptoanalista pode valer-se desta fragilidade para recuperar a mensagem original sem mesmo ter que atacar o problema $\mathcal{M Q}$.

Sendo que neste contexto ainda reside a pergunta: qual o comprimento ideal da saída da função hash? Este questionamento é importante pois caso $|\tilde{x}|$ seja muito curto, não encontrarmos um $x_{i}$ único para o conjunto $Q$, e por outro lado, caso o comprimento da saída da função hash seja excessivamente longa, teremos um desperdício de banda da rede [WP05].

Além disto, existe o fato de que um grande custo computacional está envolvido no cálculo de $W_{i}$, chegando ao ponto de tornar o esquema inviável para aplicações "práticas". Sendo recomendada, quando for desejado o emprego de somente criptossistemas pós-quânticos, a utilização de códigos corretores de erros para cifrar e decifrar textos, em vez de MPKC [BBD09].
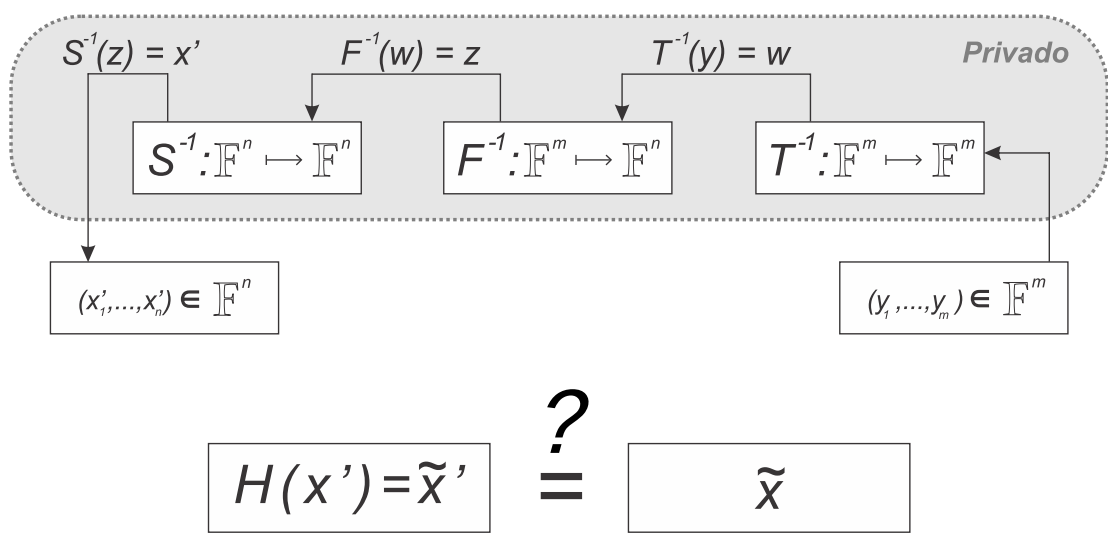

Figura 3.3: Decriptografia em sistemas $M P K C$.

\footnotetext{
${ }^{3}$ No pior caso chega a ser todas.

${ }^{4}$ No sentido de possuir um ataque mais rápido do que o Ataque pelo Paradoxo de Aniversário [Yuv79], detalhes na Seção 2.3.4.
} 


\subsection{Isomorfismo de Polinômios}

Conforme discutido anteriormente, não se conhece até hoje uma forma direta para construção de uma trapdoor a partir de, somente, uma instância aleatória de função $\mathcal{M Q}$ [BBD09], sendo tal construção feita, então, por intermédio de problemas relacionados. No caso do Quartz (HFEv-), o Isomorfismo de Polinômios (IP) é o problema utilizado para derivar a $\mathcal{M Q}$-trapdoor do criptossistema. Neste sistema criptográfico, a chave pública $\mathcal{P}$ é criada a partir da composição de duas transformações $S: \mathbb{F}^{n} \mapsto \mathbb{F}^{n}, T: \mathbb{F}^{m} \mapsto \mathbb{F}^{m}$ e um mapeamento central $F: \mathbb{F}^{n} \mapsto \mathbb{F}^{m}$, ou seja, $\mathcal{P}=T \circ F \circ S$, onde $T, F$ e $S$ são as chaves privadas (para detalhes, veja as Seções 3.2 e 4.2).

O problema IP foi proposto por Patarin em 1996 juntamente com a trapdoor HFE [Pat96a], nele, a segurança do criptossistema está garantida pela dificuldade de se encontrar as duas transformações afins $S$ e $T$ somente através do conhecimento da chave pública $\mathcal{P}$ e do formato do mapeamento central inversível $F$ [WP05]. Ou seja, dados $\mathcal{P}$ e $F$, encontrar $S$ e $T$ tais que $T \circ F \circ S=T(F(S(x)))=$ $\mathcal{P}$, é computacionalmente inviável.

Acredita-se que uma instância aleatória do problema IP seja difícil, mesmo existindo algumas criptoanálises que ataquem este problema explorando estruturas específicas de determinadas $\mathcal{M} \mathcal{Q}$ trapdoors ([NTCP03] [DFSS07], [BFMR11] e [BFFP11] por exemplo). Isto porque determinadas trapdoors, como HFEv- e UOV, até hoje permanecem seguras [Cou04, BBD09, LFPW11], resistindo, inclusive, a ataques que explorem o problema do Isomorfismo de Polinômios.

Lembrando que uma maior discussão acerca da segurança do HFEv- pode ser encontrada na Seção 4.3.

\subsection{Principais $\mathcal{M Q}$-trapdoors}

Atualmente são conhecidas cinco $\mathcal{M} \mathcal{Q}$-trapdoors básicas a partir das quais se originam inúmeros esquemas MPKC. Lembramos que, conforme apontado nas Seções 3.2 e 3.3, todas estas trapdoors possuem o mesmo esquema genérico de funcionamento, porém o formato do mapeamento central de cada uma delas se difere significativamente das demais, postulando, assim, tal formato de $F$ como a principal diferença entre estas $\mathcal{M Q}$-trapdoors.

Outra grande diferença que devemos destacar é que algumas dessas trapdoors utilizam uma extensão do corpo $\mathbb{F}_{q}$, normalmente chamadas de $\mathbb{E}$ tal que $\mathbb{E}=\mathbb{F}_{q^{k}}$, além de empregarem o corpo $\mathbb{F}_{q}$. Estes criptossistemas são intitulados como "Big Field", enquanto os que empregam somente o corpo $\mathbb{F}_{q}$ são ditos como "Single Field" [DWY07].

Desta forma, na Tabela 3.1 listamos as principais $\mathcal{M Q}$-trapdoors encontradas na bibliografia, enquadrando-as em suas classes, relacionando seus autores, ano de criação e respectivas referências aos seus artigos completos para que possam ser consultados caso haja necessidade de um detalhamento maior acerca da mesma.

\begin{tabular}{|c|c|c|c|c|}
\hline \multicolumn{2}{|r|}{ Nome (Acrônimo) } & Autores & Ano & Referência \\
\hline \multirow{2}{*}{ 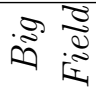 } & Matsumoto Imai Scheme A (MIA) & Matsumoto e Imai & 1988 & [MI88] \\
\hline & Hidden Field Equations (HFE) & Patarin & 1996 & [Pat96a] \\
\hline \multirow{3}{*}{ 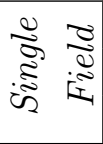 } & Unbalanced Oil and Vinegar (UOV) & Kipnis, Patarin e Goubin & 1999 & [KPG99] \\
\hline & Stepwise Triangular Systems (STS) & Wolf, Braeken e Preneel & 2004 & [WBP04] \\
\hline & $\ell$-Invertible Cycles ( $\ell$-IC) & Ding, Wolf e Yang & 2007 & [DWY07] \\
\hline
\end{tabular}

Tabela 3.1: Principais $\mathcal{M Q}$-trapdoors conhecidas atualmente. 
Como, excluindo-se a trapdoor HFE, não utilizaremos nenhuma destas funções $\mathcal{M Q}$ para o desenvolvimento de nossos objetivos, nos permitimos manter fora do escopo desta dissertação o detalhamento dos mapeamentos centrais e demais detalhes técnicos específicos de cada uma delas, visando assim privilegiar a fluidez da leitura, sem comprometer o entendimento dos assuntos necessários. Ressaltando que os detalhes sobre o HFE podem ser consultados na Seção 4.1 deste trabalho.

\subsection{Modificadores Genéricos}

Com o passar dos anos, e também devido o aumento dos estudos acerca de MPKC, foi constatado que todas as versões básicas das $\mathcal{M} \mathcal{Q}$-trapdoors existentes na atualidade são inseguras [WP05, BBD09]. Contudo, para que todos estes criptossistemas não fossem descartados, modificadores genéricos (que, a grosso modo, são blocos construtores que alteram algumas estruturas das funções alçapão básicas) foram desenvolvidos para serem aplicados (pelo menos na teoria) em todas estas funções $\mathcal{M Q}$ básicas.

A Tabela $3.2^{5}$ expressa de maneira sucinta - sem querer abordar todos os aspectos pertinentes a este tema -, os principais modificadores existentes, seguidos de suas características mais marcantes.

\begin{tabular}{|c|c|c|c|c|}
\hline Símb. & Segurança & Segurança & Ideia básica & Perda \\
\hline- & Menos & seguro & descarta alguns polinômios & encriptação mais lenta \\
\hline+ & Mais & maioria sem efeito & adiciona polinômios & assinatura mais lenta \\
\hline $\mathrm{v}$ & Vinagre & pouco mais seguro & variáveis extras são definidas & encriptação mais lenta \\
\hline $\mathrm{p}$ & Pré-fixo ou Pós-fixo & em aberto & força algum $p_{l}=0$ & assinatura mais lenta \\
\hline $\mathrm{i}$ & Pertubação Interna & em aberto & equivalente a $\mathrm{p}+\mathrm{v}$ & tudo mais lento \\
\hline $\mathrm{f}$ & Fixador & em aberto & usa algumas variáveis aleatórias & - \\
\hline $\mathrm{m}$ & Mascaramento & em aberto & descarta algumas variáveis & - \\
\hline s & Esparso & em aberto & usa polinômios esparsos & speedup mais lento \\
\hline
\end{tabular}

Tabela 3.2: Principais modificadores genéricos e algumas de suas características.

Vale ressaltar, também, que alguns destes modificadores mostraram-se mais eficientes para alguns esquemas do que para outros [WP05], por exemplo, os modificadores "v" (vinagre) e "-" (menos) demonstraram uma melhoria de segurança mais significativa no HFE do que no MIA ou STS.

Além disto, assim como ocorrera nas versões básicas das $\mathcal{M Q}$-trapdoors, alguns modificadores genéricos também foram considerados inseguros ou sem efeito, sendo os principais destes:

Ramificação $(\perp)$ : surgiu no artigo original da trapdoor MIA [MI88] como uma alternativa para aumentar a velocidade de decriptografia em sistemas MPKC. Todavia, diversas criptoanálises comprovaram que esta melhoria causa uma perda significativa na segurança [Pat95, Pat96a, Fel04];

Sub-Corpo (/): aplicado pela primeira vez na assinatura digital SFlash ${ }^{v 1}$ (proposta por Patarin et al. em 1999 [PCG01a]) e posteriormente no UOV, foi considerado inseguro após algum tempo por Gilbert et al. em 2002 [GM02] e Braeken et al. em 2004 [BWP04];

Homogeneização $(h)$ : proposto por Wolf em sua tese de doutorado [Wol05], este modificador foi desenvolvido sob a luz dos modificadores "v" e "i" com o objetivo de contornar algumas criptoanálises que vinham atacando tais modificadores. Porém, neste mesmo trabalho o autor conclui que as modificações propostas não surtiam efeito na segurança.

\footnotetext{
${ }^{5}$ Adaptada a partir de [Wol05, pg. 57] e [BBD09, pg. 214].
} 
Desta forma, podemos pressupor que no momento da melhoria ou desenvolvimento de um criptossistema MPKC, há de se considerar a possibilidade de inserção do modificador genérico. Ponderando sobre qual é o ideal para aquele tipo de $\mathcal{M} \mathcal{Q}$-trapdoor, considerando suas peculiaridades e contribuições para segurança. Mesmo não sendo esta uma tarefa trivial, que pode, inclusive, gerar vulnerabilidades em vez de melhorias.

\subsection{Principais Criptoanálises dos $\mathrm{MPKC}$}

Como vimos anteriormente na Seção 2.4.1, em esquemas de Assinatura Digital, o objetivo principal de um adversário é conseguir gerar ao menos uma assinatura válida (porém falsificada) para determinada mensagem. Para tanto, o adversário pode, por exemplo, tentar recuperar a chave privada da vítima, e com isto, obter a assinatura desejada.

Neste caminho, no contexto dos MPKCs, podemos vislumbrar diversas técnicas de criptoanálise que tem como objetivo decifrar um determinado texto cifrado $y$ resolvendo o sistema de equações polinomiais tal que $\mathcal{P}(x)-y=0$, para com isto recuperar a chave privada. Normalmente estas técnicas utilizam características específicas do mapeamento central das $\mathcal{M} \mathcal{Q}$-trapdoors que atacam, para assim alcançar vantagens ou até mesmo quebrar um criptossistema com determinada escolha de parâmetros. Por isto, diz-se que entender estes ataques é imprescindível para nortear os estudos e também garantir a segurança dos esquemas de assinatura digital.

Todavia, não encontramos na literatura nenhum ataque que consiga recuperar a chave privada da vítima através da resolução das equações polinomiais do Quartz e também do esquema aprimorado que propomos nesta dissertação (para maiores detalhes sobre a segurança do HFEv-, veja a Seção 4.3). Pois além de estar baseado na intratabilidade da trapdoor HFE, ele ainda possui os modificadores genéricos "v" (vinagre) e "-"(menos) aplicados a ela.

Contudo, apenas como referência de estudos que foram levados em conta durante nosso trabalho, podemos citar os bem sucedidos ataques ao SFlash, formulados inicialmente por Dubois et al. em 2007 [DFSS07], onde o SFlash com seus parâmetros originais foi quebrado; e a proposta posterior, formulado por Bouillaguet et al. [BFMR11], que demonstrou ser possível quebrar este criptossistema com qualquer escolha de parâmetros. Também podemos referir um dos primeiros ataques a MPKC criados, nele, Patarin ataca a $\mathcal{M Q}$-trapdoor MIA (também chamada de $C^{*}$ ); lembrando que logo em seguida Patarin propõe o HFE (em [Pat96a]), uma generalização do MIA que substitui o mapeamento central originalmente proposto. Além disto, destacamos que também foram consideradas as diversas criptoanálises acerca do HFE sem modificadores genéricos [KS99, Cou01, Fau03, FJ03, GJS06, JDH08, DSW08, DH11, BFP12], bem como os ataques as trapdoors que inspiraram a criação do modificar "vinagre" OV e UOV [KS98, BWP04, BPB10].

Feldmann também desenvolveu um relevante estudo acerca de ataques a MPKC [Fel05], nele o autor divide as principais criptoanálises em dois grupos: ataques que procuram resolver um problema $\mathcal{M Q}$ sem utilizar nenhuma informação além da própria chave pública do sistema; e ataques mais especializados, que tentam obter vantagem a partir do conhecimento da estrutura do esquema a ser atacado. Destacamos que em nosso trabalho levamos em consideração os ataques contidos nos dois grupos definidos por Feldmann.

De maneira geral, podemos afirmar que todos os ataques genéricos conhecidos hoje em dia utilizam de alguma forma as bases de Gröbner, teoria formulada por Buchberger em 1965 [Buc65]. 
O algoritmo XL (eXtended Linearization), apresentado originalmente por Courtois et al. na EuroCrypt'2000 [CKPS00b], foi considerado durante algum tempo como sendo uma nova (e a principal) forma para solucionar o sistema de equações do problema $\mathcal{M Q}$. Entretanto, Ars et al. demonstraram em 2004 que o algoritmo XL é, na verdade, uma versão mais lenta do algoritmo F4 de Faugère $\left[\mathrm{AFI}^{+}\right.$04]. Sendo assim, como o algoritmo F4 é uma variante do algoritmo de Buchberger oriundo da teoria de bases de Gröbner [Fau99], dizemos então que o algoritmo XL não constitui uma alternativa para resolução do problema $\mathcal{M Q}$, mas sim apenas formaliza uma especialização da teoria de bases de Gröbner. Outro algoritmo que vale ser lembrado é o de Zhuang-Zi, proposto por Ding et al. em 2006 [DGS06b], este algoritmo difere-se do XL apenas no seu passo 3 quando efetua a escolha de um polinômio de menor grau ao invés da forma definida no XL. No entanto, vale ressaltar que os próprios autores do Zhuang-Zi, nas conclusões de sua proposta, já alertavam que não era esperado que seu algoritmo superasse os já vastamente utilizados algoritmos F4 e F5.

Acreditamos que uma explanação maior sobre as técnicas aqui citadas pouco acrescentaria a nossos objetivos, já que todos os detalhes podem ser consultados na integra em seus trabalhos originais, os quais constam nas referências desta dissertação. Destacamos, ainda, que nossa intenção ao formular esta seção foi apenas registrar os principais resultados alcançados até o momento na criptoanálise dos MPKC, para que com isso possamos escolher adequadamente os parâmetros de segurança, mantendo o foco em nosso objetivo principal e conservando o escopo estabelecido para este trabalho. 


\section{Capítulo 4}

\section{Revisando o Quartz}

Neste capítulo revisaremos o protocolo de assinatura digital Quartz, apresentado no NESSIE em 2001. Inicialmente, explanaremos sobre os aspectos gerais do HFE e exibiremos como é formada sua função de mapeamento central. Em seguida, explicaremos como funciona o algoritmo Quartz Original. Para então discutirmos sobre a segurança do Quartz e justificarmos a substituição da função hash (SHA-1) utilizada no algoritmo original pelo SHA-3.

\subsection{HFE (Hidden Field Equation)}

Após ter quebrado o MIA [Pat95], Patarin - fundamentado nas ideias desta trapdoor considerada insegura - desenvolveu uma nova função alçapão denominada Hidden Field Equations, ou simplesmente HFE [Pat96a]. Esta nova trapdoor é uma generalização que modifica a função de mapeamento central $F$ do MIA. Tal generalização tem como principal característica a troca dos monômios, empregados na trapdoor quebrada, por polinômios. Porém, é mantido o conceito de utilizar uma extensão do corpo $\mathbb{F}_{q}$, comumente denotado por $\mathbb{E}$, tal que $\mathbb{E}=\mathbb{F}_{q^{n}}$ (onde $q$ possua característica $p$, para algum $p$ primo, e $k \in \mathbb{N}$, tal que $q=p^{k}$ ), juntamente com o corpo $\mathbb{F}_{q}$. Assim sendo, podemos dizer que:

$$
\mathbb{F}^{n} \stackrel{S}{\mapsto} \mathbb{F}^{n} \stackrel{\varphi^{-1}}{\mapsto} \mathbb{E}^{n} \stackrel{F}{\mapsto} \mathbb{E}^{n} \stackrel{\varphi}{\mapsto} \mathbb{F}^{m} \stackrel{T}{\mapsto} \mathbb{F}^{m}
$$

caracteriza a função $\mathcal{M Q}$-trapdoor do HFE. Onde $\varphi$ é uma bijeção adicional de $\mathbb{E} \mapsto \mathbb{F}$, e $\varphi^{-1}$ é sua inversa.

Deste modo, sejam: $i$ e $j$ números naturais; $\xi_{i j}, \psi_{i}$ e $\mu$ elementos de $\mathbb{E}$; e $\theta, \sigma$ e $\gamma$ números inteiros; a função do mapeamento central fica definida como [Pat96b]:

$$
\begin{gathered}
f(x)=\sum_{i, j}^{d} \xi_{i j} x^{q^{\theta_{i j}}+q^{\sigma_{i j}}}+\sum_{i}^{d} \psi_{i} x^{q^{\gamma_{i}}}+\mu \\
\text { onde } \begin{cases}\xi_{i j} x^{q^{\theta_{i j}}+q^{\sigma_{i j}}} & \text { são os termos quadráticos, } \\
\psi_{i} x^{q^{\gamma_{i}}} & \text { são os termos lineares, } e \\
\mu & \text { são os termos constantes }\end{cases}
\end{gathered}
$$

tal que $f(x)$ seja um polinômio em $x$ sobre $\mathbb{E}_{q^{n}}$ com grau $d$, para $0 \leqslant \theta_{i j}, \sigma_{i j}, \gamma_{i} \leqslant d$.

Como $\mathbb{E}$ e $\mathbb{F}$ são isomórficos, podemos representar os elementos de $\mathbb{E}=\mathbb{F}_{q^{n}}$ numa $n$-tupla sobre $\mathbb{F}_{q}$, e a função (4.1) pode ser representada por polinômios com $n$ variáveis $x_{1}, x_{2}, \ldots, x_{n}$ também 
sobre $\mathbb{F}_{q}[$ Pat96a]. Ou seja,

$$
f(x)=f\left(x_{1}, \ldots, x_{n}\right)=\left(p_{1}\left(x_{1}, \ldots, x_{n}\right), \ldots, p_{n}\left(x_{1}, \ldots, x_{n}\right)\right) \in \mathbb{F}_{q}\left[x_{1}, \ldots, x_{n}\right]
$$

$\operatorname{com} p_{i}\left(x_{1}, \ldots, x_{n}\right) \in \mathbb{F}_{q}\left[x_{1}, \ldots, x_{n}\right]$, para $i=1,2, \ldots, n$.

Portanto, já que $p_{i}: x \mapsto x^{q^{n}}$ é uma função linear de $\mathbb{F}_{q^{n}} \mapsto \mathbb{F}_{q^{n}}$. Podemos dizer que existe uma matriz $A^{n \times n}=\left\{a_{i, j}\right\}$, onde $a_{i, j} \in \mathbb{F}_{q}$, de tal modo que:

$$
\begin{gathered}
f(x)=f\left(x_{1}, \ldots, x_{n}\right)=\left(p_{1}\left(x_{1}, \ldots, x_{n}\right), \ldots, p_{n}\left(x_{1}, \ldots, x_{n}\right)\right) \\
\Longrightarrow\left(x_{1} \cdot a_{1,1}+\ldots+x_{n} \cdot a_{n, 1} \quad \ldots \quad x_{n} \cdot a_{1, n}+\ldots+x_{n} \cdot a_{n, n}\right) .
\end{gathered}
$$

\subsection{Quartz Original}

Como vimos nos capítulos anteriores, o Quartz é um esquema de assinatura digital baseado no HFEv-, com escolha especial de parâmetros. Sua versão original proposta por Patarin, Courtois e Goubin em 2001 [PCG01b] foi atualizada pelos mesmos autores logo em seguida [CGP01], sendo que desde então adotamos esta última como versão original. Frisamos que uma versão não entra em confronto com a outra, portanto, devemos utilizá-las em conjunto para compreender este criptossistema com completude.

Neste esquema de assinatura, como os próprios modificadores genéricos já sugerem, algumas variáveis extra (chamadas de "variáveis vinagre") são adicionadas, e também, alguns "polinômios de perturbação" são inseridos no local dos polinômios removidos ${ }^{1}$. Além disto, Patarin et al. destacam que os parâmetros escolhidos para o Quartz são cuidadosamente selecionados para melhorar sua segurança e impedir o funcionamento dos principais ataques conhecidos [PCG01b].

O Quartz foi submetido e aceito no NESSIE ${ }^{2}$ (New European Schemes for Signatures, Integrity and Encryption), um projeto de pesquisa desenvolvido com a Information Societies Technology (IST) Programme of the European Commission para identificar sistemas criptográficos seguros que forneçam - em sentido amplo - confidencialidade e integridade dos dados, além de autenticidade das entidades [NES04]. De acordo com os relatórios públicos do $\mathrm{NESSIE}^{3}$, o principal trunfo deste esquema são suas assinaturas curtas (apenas 128 bits) e a fundamentação em um problema intratável até mesmo em computadores quânticos (o problema $\mathcal{M} \mathcal{Q}$ ) [MS01].

Contudo, o Quartz não foi selecionado para figurar no portfólio final desse projeto de pesquisa. Isto porque - em linhas gerais - o cálculo de suas chaves secretas foi considerado muito lento (comparando com os demais esquemas submetidos) [MS01, pg. 11]; por possuir algumas divergências nas especificações de sua implementação (quando confrontado com o requerido pelo NESSIE) [DS02, pg. 6]; e também por possuir uma arquitetura maleável que permite ao adversário obter uma segunda assinatura, caso ele possua um par (mensagem, assinatura) válido, com uma quantidade de cálculos muito menor do que o solicitado pelo projeto [JM03].

\footnotetext{
${ }^{1}$ Em algumas literaturas estes polinômios são chamados de polinômios secretos.

${ }^{2}$ Similar ao AES, RIPE e CRYPTREC. Maiores detalhes disponíveis em https://www.cosic.esat.kuleuven.be/ nessie/.

${ }^{3}$ Relatórios disponíveis em https://www.cosic.esat.kuleuven.be/nessie/reports/.
} 


\subsubsection{Parâmetros}

Na versão original do Quartz temos definido que: $q=2, d=129, h=103, v=4, r=3, n=107$ (pois $n \stackrel{\text { def }}{=} h+v$ ), $m=100$ (pois $m \stackrel{\text { def }}{=} h-r$ ) [PCG01b, CGP01, Cou04]; e a função pública $\mathcal{P}$ -função trapdoor - é um mapeamento de 107 bits para 100 bits, ou seja $\mathbb{F}^{107} \mapsto \mathbb{F}^{100}$ [PCG01b].

Com intuito de facilitar a leitura, destacamos na Tabela 4.1 o significado de cada um destes parâmetros, bem como algumas definições e terminologias pertinentes ao Quartz, para que o leitor não tenha que retornar a página xi para consultar a Lista de Símbolos completa deste trabalho.

\begin{tabular}{c|l}
\hline Símbolo & \multicolumn{1}{c}{ Significado } \\
\hline$q$ & Ordem do Corpo Finito $\mathbb{F}$, ou seja, $\mathrm{n}^{\circ}$ de elementos de $\mathbb{F}(q:=|\mathbb{F}|)$ \\
$d$ & Grau do sistema de equações $-d \in \mathbb{N}$ \\
$n$ & Número de variáveis $-n \in \mathbb{N}$ \\
$m$ & Número de equações $-m \in \mathbb{N}$ \\
$v$ & Número de variáveis vinagre $-v \in \mathbb{N}$ \\
$r$ & Número de polinômios removidos $-r \in \mathbb{N}$ \\
$h$ & $h \stackrel{\text { def }}{=} n-v$. Ou seja, $h \stackrel{\text { def }}{=}$ Número de variáveis - Número de variáveis \\
& vinagre. No Quartz, $h$ representa o grau da extensão do Corpo Finito \\
{$[\lambda]_{p \rightarrow q}$} & utilizado \\
$\|$ & Dada uma cadeia de bits $\lambda=\left(\lambda_{0}, \ldots, \lambda_{t}\right)$ e dois inteiros $p$ e $q$ tais que \\
$\lambda \| \mu$ & Concatenação \\
$p\left(x_{1}, \ldots, x_{n}\right)$ & Se $\lambda=\left(\lambda_{0}, \ldots, \lambda_{t}\right)$ e $\mu=\left(\mu_{0}, \ldots, \mu_{u}\right)$ são duas cadeias de bits, então \\
$\mathcal{P}=\left(p_{1}, \ldots, p_{m}\right)$ & Um polinômio de grau $d$ com $n$ variáveis sobre $\mathbb{F}$ \\
\hline
\end{tabular}

Tabela 4.1: Definições, Notação e Terminologia pertinentes ao Quartz.

Assim, dado que $h=103$, a extensão do corpo utilizada pelo Quartz fica definida como $\mathbb{F}_{2^{103}}=\mathbb{E}$. Mais precisamente, podemos dizer que $\mathbb{E}=\mathbb{F}_{2}[X] /\left(X^{103}+X^{9}+1\right)$, onde a bijeção $\varphi$ entre $\{0,1\}^{103}$ e $\mathbb{E}$ está definida como [CGP01]:

$$
\begin{gathered}
\forall \omega=\left(\omega_{0}, \ldots, \omega_{102}\right) \in\{0,1\}^{103} \\
\varphi(\omega)=\omega_{102} X^{102}+\ldots+\omega_{1} X+\omega_{0}\left(\bmod \left(X^{103}+X^{9}+1\right)\right) .
\end{gathered}
$$

\section{Parâmetros Privados}

Sabemos que em todos criptossistemas MPKC temos três parâmetros que compõe a chave privada: $S, F$ e $T$; todavia, no Quartz, além destes três parâmetros, temos um parâmetro adicional chamado de $\Delta$. Desta forma, segue que podemos descrever estes parâmetros como sendo [CGP01]:

1. $s$ : a transformação afim privada de $\{0,1\}^{107}$ para $\{0,1\}^{107}$, genericamente chamada de $S$. De maneira mais detalhada, este parâmetro pode ser descrito como uma matriz quadrada $107 \times 107$ e uma matriz coluna $107 \times 1$ sobre $\mathbb{F}_{2}$ da transformação $s$, com sua respectiva base canônica sobre $\{0,1\}^{107}$. Onde $S_{L}$ representa a matriz quadrada e $S_{C}$ a matriz coluna; 
2. $F_{V}$ : o mapeamento central privado genericamente chamado de $F$. Esta função de mapeamento $\left(F_{V}\right)_{V \in\{0,1\}^{4}}$ de $\mathbb{E}$ para $\mathbb{E}$, está definida por:

$$
F_{V}(Z)=\sum_{\substack{0 \leq i<j<103 \\ 2^{i}+2^{j} \leq 129}} \alpha_{i, j} \cdot Z^{2^{i}+2^{j}}+\sum_{\substack{0 \leq i<103 \\ 2^{i} \leq 129}} \beta_{i}(V) \cdot Z^{2^{i}}+\gamma(V)
$$

onde os $\alpha_{i, j}$ são elementos de $\mathbb{E}$ e cada $\beta_{i}(0 \leq i<103)$ é uma transformação afim de $\{0,1\}^{4}$ para $\mathbb{E}$, ou seja, a transformação $\beta_{i}$ satisfaz a seguinte condição:

$$
\forall V=\left(V_{0}, V_{1}, V_{2}, V_{3}\right) \in\{0,1\}^{4}, \quad \beta_{i}(V)=\sum_{0 \leq k<4} V_{k} \cdot \xi_{i, k}+v_{i}
$$

onde $\xi_{i, j}$ e $v_{i}$ são elementos de $\mathbb{E}$.

Temos ainda que $\gamma$ é uma transformação quadrática de $\{0,1\}^{4}$ para $\mathbb{E}$, ou seja, a transformação $\gamma$ satisfaz a seguinte condição:

$$
\forall V=\left(V_{0}, V_{1}, V_{2}, V_{3}\right) \in\{0,1\}^{4}, \quad \gamma(V)=\sum_{0 \leq k<\ell<4} V_{k} V_{\ell} \cdot \eta_{k, \ell}+\sum_{0 \leq k<4} V_{k} \cdot \sigma_{k}+\tau
$$

tal que todos $\eta_{k, \ell}, \sigma_{k}$ e $\tau$ sejam elementos de $\mathbb{E}$;

3. $t$ : a transformação afim privada de $\{0,1\}^{103}$ para $\{0,1\}^{103}$, genericamente chamada de $T$. De maneira mais detalhada, este parâmetro pode ser descrito como uma matriz quadrada $103 \times 103$ e uma matriz coluna $103 \times 1$ sobre $\mathbb{F}_{2}$ da transformação $t$, com sua respectiva base canônica sobre $\{0,1\}^{103}$. Onde $T_{L}$ representa a matriz quadrada e $T_{C}$ a matriz coluna;

4. $\Delta$ : uma cadeia de 80 bits privada, obtida de maneira pseudoaleatória.

\section{Parâmetros Públicos}

A chave pública do Quartz - assim como nos demais esquemas multivariáveis quadráticos - é a composição de suas funções privadas. Ou seja, a obtenção do parâmetro público deste criptossistema consiste em encontrarmos uma função $G$ de $\{0,1\}^{107}$ para $\{0,1\}^{100}$ tal que [CGP01]:

$$
G(X)=\left[t\left(\varphi^{-1}\left(F_{[s(X)]_{103 \rightarrow 106}}\left(\varphi\left([s(X)]_{0 \rightarrow 102}\right)\right)\right)\right)\right]_{0 \rightarrow 99},
$$

e divulgá-la para os demais usuários.

Deste modo, para construirmos o algoritmo, $G$ deve ser uma transformação quadrática sobre $\mathbb{F}_{2}$, ou seja:

$$
\left\{\begin{array}{c}
Y_{0}=P_{0}\left(X_{0}, \ldots, X_{106}\right) \\
\vdots \\
Y_{99}=P_{99}\left(X_{0}, \ldots, X_{106}\right)
\end{array}\right.
$$

onde cada $P_{i}$ (para $0 \leq i \leq 99$ ) é um polinômio quadrático da forma

$$
P_{i}\left(X_{0}, \ldots, X_{106}\right)=\sum_{0 \leq j<k<107} \zeta_{i, j, k} X_{j} X_{k}+\sum_{0 \leq j<107} \nu_{i, j} X_{j}+\rho_{i}
$$

e os elementos $\zeta_{i, j, k}, \nu_{i, j}$ e $\rho_{i}$ pertençam a $\mathbb{F}_{2}$. 


\subsubsection{Geração de Chaves}

Na Seção anterior, vimos quais são os parâmetros privados necessários na concepção do esquema de assinatura Quartz. Além disso, também levantamos como estes parâmetros privados dão origem à chave pública. Com isto, agora, discutiremos como gerar tais parâmetros e consequentemente originar as chaves deste criptossistema.

Destaca-se que todas as especificações aqui descritas seguirão a descrição original do Quartz [CGP01, Seção 4]. Porém, alguns detalhes sobre como gerar chaves em MPKCs levarão em conta o trabalho de Matsumoto e Imai (1988), de Wolf (2002a) e de Bernstein et al. (2009) [MI88, Wol02a, BBD09].

\section{Chave Privada}

Repassemos alguns elementos que devem ser gerados:

- Os seguintes elementos privados de $\mathbb{E}$ :

$$
\begin{cases}\alpha_{i, j} & \text { onde } 0 \leq i<j<103 \text { e } 2^{i}+2^{j} \leq 129 \\ \xi_{i, k} & \text { onde } 0 \leq i<8 \text { e } 0 \leq k<4 \\ v_{i} & \text { onde } 0 \leq i<8 \\ \eta_{k, \ell} & \text { onde } 0 \leq k<\ell<4 \\ \sigma_{k} & \text { onde } 0 \leq k<4 \\ \tau & \end{cases}
$$

- A matriz quadrada inversível $107 \times 107\left(S_{L}\right)$, e a matriz coluna $107 \times 1\left(S_{C}\right)$, ambas privadas, com seus coeficientes definidos como 0 ou 1 ;

- A matriz quadrada inversível $103 \times 103\left(T_{L}\right)$, e a matriz coluna $103 \times 1\left(T_{C}\right)$, ambas privadas, com seus coeficientes definidos como 0 ou 1 ;

- A cadeia de 80 bits privada $(\Delta)$.

Acerca destes elementos, Courtois et al. esclarecem que, por meio da transformação $\varphi$, gerar um elemento de $\mathbb{E}$ é equivalente a gerar uma cadeia de 103 bits [CGP01]. Além disto, os mesmos autores afirmam que podemos obter todos estes elementos utilizando um gerador de bit pseudoaleatório criptograficamente seguro (cryptographically secure pseudorandom bit generator - CSPRBG). Deste modo, a partir de uma semente cuja entropia seja no mínimo de 80 bits, tal CSPRBG produzirá um novo bit aleatório cada vez que for chamado.

Logo, podemos esquematizar a Geração de Chave Privada nos seguintes passos:

1. Determinar os coeficientes de

$$
F_{(0,0,0,0)}(Z)=\sum_{\substack{0 \leq i<j<103 \\ 2^{i}+2^{j} \leq 129}} \alpha_{i, j} \cdot Z^{2^{i}+2^{j}}+\sum_{\substack{0 \leq i<103 \\ 2^{i} \leq 129}} v_{i} \cdot Z^{2^{i}}+\tau
$$

da mais baixa para a mais alta potência de $Z$. Mais precisamente, os primeiros 103 bits produzidos pelo CSPRBG fornecem $\tau$ (quando aplicamos $\varphi$ ). Então, determinamos sucessivamente: $v_{0}, v_{1}, \alpha_{0,1}, v_{2}, \alpha_{0,2}, \alpha_{1,2}, v_{3}, \alpha_{0,3}, \alpha_{1,3}, \alpha_{2,3}, v_{4}, \alpha_{0,4}, \alpha_{1,4}, \alpha_{2,4}, \alpha_{3,4}, v_{5}, \alpha_{0,5}, \alpha_{1,5}, \alpha_{2,5}, \alpha_{3,5}$, 
$\alpha_{4,5}, v_{6}, \alpha_{0,6}, \alpha_{1,6}, \alpha_{2,6}, \alpha_{3,6}, \alpha_{4,6}, \alpha_{5,6}, v_{7}, \alpha_{0,7}$ (um de cada vez, utilizando o CSPRBG para gerar 103 novos bits aleatórios, e em seguida aplicamos $\varphi$ ).

2. Determinar os coeficientes de

$$
F_{(1,0,0,0)}(Z)-F_{(0,0,0,0)}(Z)=\sum_{\substack{0 \leq i<103 \\ 2^{i} \leq 129}} \xi_{i, 0} \cdot Z^{2^{i}}+\sigma_{0}
$$

da mais baixa para a mais alta potência de $Z$. Mais precisamente, os primeiros 103 bits produzidos pelo CSPRBG fornecem $\sigma_{0}$ (quando aplicamos $\varphi$ ). Então, determinamos sucessivamente: $\xi_{0,0}, \xi_{1,0}, \xi_{2,0}, \xi_{3,0}, \xi_{4,0}, \xi_{5,0}, \xi_{6,0}, \xi_{7,0}$ (um de cada vez, utilizando o CSPRBG para gerar 103 novos bits aleatórios, e em seguida aplicamos $\varphi$ ).

3. Determinar os coeficientes de

$$
F_{(0,1,0,0)}(Z)-F_{(0,0,0,0)}(Z)=\sum_{\substack{0 \leq i<103 \\ 2^{i} \leq 129}} \xi_{i, 1} \cdot Z^{2^{i}}+\sigma_{1}
$$

da mais baixa para a mais alta potência de $Z$. Mais precisamente, os primeiros 103 bits produzidos pelo CSPRBG fornecem $\sigma_{1}$ (quando aplicamos $\varphi$ ). Então, determinamos sucessivamente: $\xi_{0,1}, \xi_{1,1}, \xi_{2,1}, \xi_{3,1}, \xi_{4,1}, \xi_{5,1}, \xi_{6,1}, \xi_{7,1}$ (um de cada vez, utilizando o CSPRBG para gerar 103 novos bits aleatórios, e em seguida aplicamos $\varphi$ ).

4. Determinar os coeficientes de

$$
F_{(0,0,1,0)}(Z)-F_{(0,0,0,0)}(Z)=\sum_{\substack{0 \leq i<103 \\ 2^{i} \leq 129}} \xi_{i, 2} \cdot Z^{2^{i}}+\sigma_{2}
$$

da mais baixa para a mais alta potência de $Z$. Mais precisamente, os primeiros 103 bits produzidos pelo CSPRBG fornecem $\sigma_{2}$ (quando aplicamos $\varphi$ ). Então, determinamos sucessivamente: $\xi_{0,2}, \xi_{1,2}, \xi_{2,2}, \xi_{3,2}, \xi_{4,2}, \xi_{5,2}, \xi_{6,2}, \xi_{7,2}$ (um de cada vez, utilizando o CSPRBG para gerar 103 novos bits aleatórios, e em seguida aplicamos $\varphi$ ).

5. Determinar os coeficientes de

$$
F_{(0,0,0,1)}(Z)-F_{(0,0,0,0)}(Z)=\sum_{\substack{0 \leq i<103 \\ 2^{i} \leq 129}} \xi_{i, 3} \cdot Z^{2^{i}}+\sigma_{3}
$$

da mais baixa para a mais alta potência de $Z$. Mais precisamente, os primeiros 103 bits produzidos pelo CSPRBG fornecem $\sigma_{3}$ (quando aplicamos $\varphi$ ). Então, determinamos sucessivamente: $\xi_{0,3}, \xi_{1,3}, \xi_{2,3}, \xi_{3,3}, \xi_{4,3}, \xi_{5,3}, \xi_{6,3}, \xi_{7,3}$ (um de cada vez, utilizando o CSPRBG para gerar 103 novos bits aleatórios, e em seguida aplicamos $\varphi$ ).

6. Determinar os coeficientes remanescentes - que correspondem a parte quadrática de $\gamma(V)$ de maneira consecutiva e em ordem lexicográfica: $\eta_{0,1}, \eta_{0,2}, \eta_{0,3}, \eta_{1,2}, \eta_{1,3}, \eta_{2,3}$ (um de cada vez, utilizando o CSPRBG para gerar 103 novos bits aleatórios, e em seguida aplicamos $\varphi$ ). 
7. Gerar uma matriz triangular inferior $107 \times 107\left(I_{S}\right)$ e uma matriz triangular superior $107 \times 107$ $\left(S_{S}\right)$, onde todos coeficientes sejam 0 ou 1 , executando as seguintes rotinas:

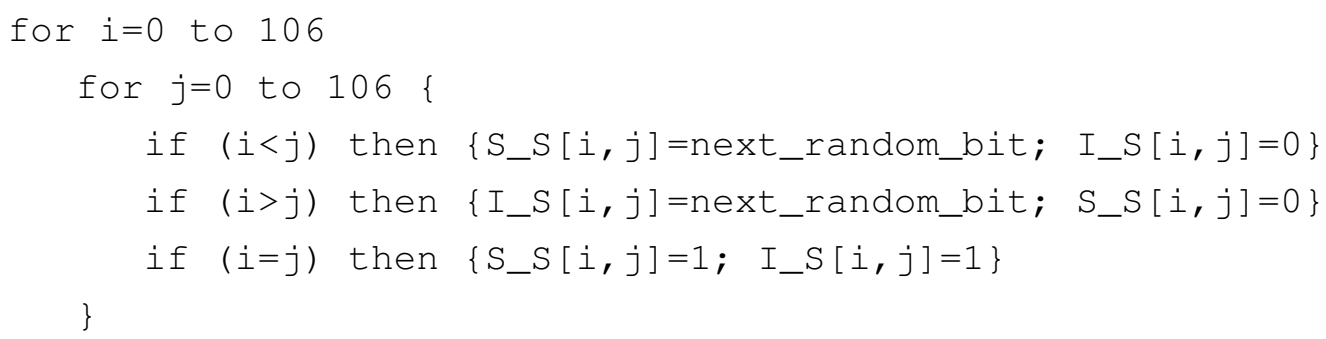

Em seguida, defina $S_{L}=I_{S} \times S_{S}$.

8. Gerar $S_{C}$ utilizando o CSPRBG para obter 107 novos bits aleatórios, indo do topo da matriz coluna até sua base.

9. Gerar uma matriz triangular inferior $103 \times 103\left(I_{T}\right)$ e uma matriz triangular superior $103 \times 103$ $\left(S_{T}\right)$, onde todos coeficientes sejam 0 ou 1 , executando as seguintes rotinas:

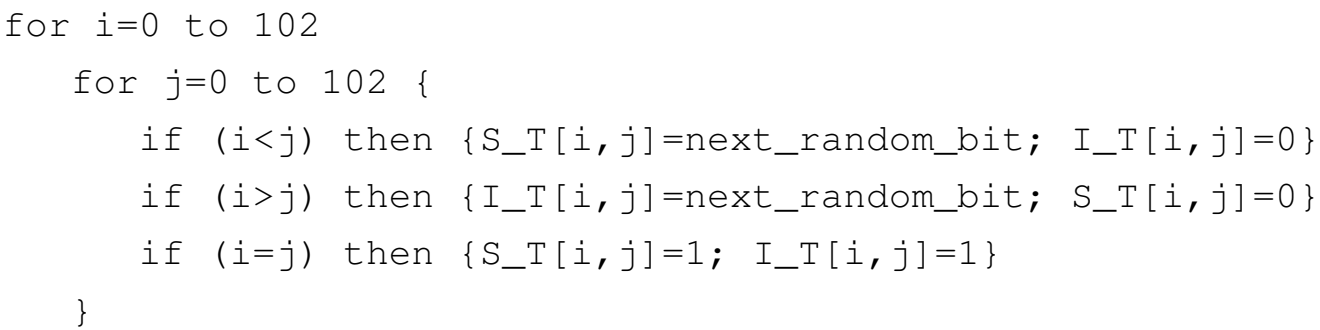

Em seguida, defina $T_{L}=I_{T} \times S_{T}$.

10. Gerar $T_{C}$ utilizando o CSPRBG para obter 103 novos bits aleatórios, indo do topo da matriz coluna até sua base.

11. Por último, gerar $\Delta$ utilizando o CSPRBG para obter uma cadeia de 80 bits pseudoaleatórios.

Note que para a completa geração da chave privada é necessário um espaço de 29.867 bits, que são gerados "aleatoriamente" pelo CSPRBG. Ou seja, são necessários $3.193+927+927+927+$ $927+618+(107 \times 107)+107+(103 \times 103)+103+80=29.867$ bits $\cong 3$ Kbytes.

\section{Chave Pública}

Apesar dos artigos que especificam o Quartz [PCG01b, CGP01] não fornecerem muitos detalhes sobre como obter a chave pública $G$ a partir da chave privada, podemos presumir uma forma de gerar esta chave pública analisando o trabalho de Matsumoto e Imai, onde eles apresentam a trapdoor MIA [MI88]. Isto pode ser feito porque o MIA possui o mesmo formato de chave pública do HFE [Wol02a], ou seja, sua chave pública é a composição de duas transformações afins com um mapeamento central que utiliza bijeções para mapear os elementos de $\mathbb{E}$ para $\mathbb{F}$ e vice-versa.

Em linhas gerais, Matsumoto e Imai explicam que para obter a chave pública a partir da chave privada devemos efetuar uma interpolação de polinômios para polinômios multivariáveis [MI88]. Para isto, basta cifrar um $x$ qualquer utilizando $s, F_{V}$ e $t$, respectivamente, e definir o resultado $y$ 
desta encriptação como sendo os coeficientes de cada um dos $P_{i}$ polinômios da função pública $G$. Assim, obteremos uma chave pública tal que $G(X)=\left[t\left(\varphi^{-1}\left(F_{[s(X)]_{103 \rightarrow 106}}\left(\varphi\left([s(X)]_{0 \rightarrow 102}\right)\right)\right)\right)\right]_{0 \rightarrow 99}$.

Vale ressaltar também que Bernstein et al. definem como sendo igual a $m n((n+3) / 2)$ o tamanho da chave pública de criptossistemas do tipo "Big Field" [BBD09]. Desta forma, temos que a chave pública do Quartz necessita de $100 \times 107 \times((107+3) / 2)=588.500$ bits $\cong 71$ Kbytes para ser armazenada.

\subsubsection{Assinando Mensagens}

Exploramos anteriormente como, de uma forma genérica, sistemas criptográficos MPKC assinam mensagens (veja Seção 3.3.1). No entanto, vale lembrar que cada esquema de uma família de criptossistemas possui características próprias, e estas características únicas são o que distinguem esquemas de uma mesma família. Desta forma, descreveremos nesta seção sobre o processo de assinar uma mensagem $M$ com a assinatura digital Quartz, detalhando, quando necessário, suas singularidades.

Frisamos que as informações aqui contidas estão fundamentadas na versão atualizada do Quartz Original (proposta por Courtois et al. [CGP01]) e que as especificações anteriores [PCG01b], pertinentes ao processo de assinar uma mensagem, não são aceitas como "oficiais" na atualidade.

Assim, seja $M$ uma mensagem representada por uma cadeia de bits, e $S$ a assinatura obtida desta mensagem. Então, os procedimentos necessários à obtenção de $S$ devem ser realizados conforme segue (veja Figura 4.1):

1. Sejam $M_{0}, M_{1}, M_{2}$ e $M_{3}$ quatro cadeias de 160 bits definidas por:

$$
\begin{gathered}
M_{0}=\operatorname{SHA}-1(M), \\
M_{1}=\operatorname{SHA}-1\left(M_{0} \| 0\right), \\
M_{2}=\operatorname{SHA}-1\left(M_{0} \| 1\right), \\
M_{3}=\operatorname{SHA}-1\left(M_{0} \| 2\right) .
\end{gathered}
$$

2. Sejam $H_{1}, H_{2}, H_{3}$ e $H_{4}$ quatro cadeias de 100 bits definidas por:

$$
\begin{gathered}
H_{1}=\left[M_{1}\right]_{0 \rightarrow 99}, \\
H_{2}=\left[M_{1}\right]_{100 \rightarrow 159} \|\left[M_{2}\right]_{0 \rightarrow 39}, \\
H_{3}=\left[M_{2}\right]_{40 \rightarrow 139}, \\
H_{4}=\left[M_{2}\right]_{140 \rightarrow 159} \|\left[M_{3}\right]_{0 \rightarrow 79} .
\end{gathered}
$$

3. Seja $\tilde{S}$ uma cadeia de 100 bits, tal que $\tilde{S}$ seja inicializada com $00 \ldots 0$.

4. Para $i=1$ até 4 , faça:

(a) Calcule a cadeia de 100 bits $Y$ definida por:

$$
Y=H_{i} \oplus \tilde{S}
$$

(b) Calcule a cadeia de 160 bits $W$ definida por:

$$
W=\operatorname{SHA}-1(Y \| \Delta) .
$$




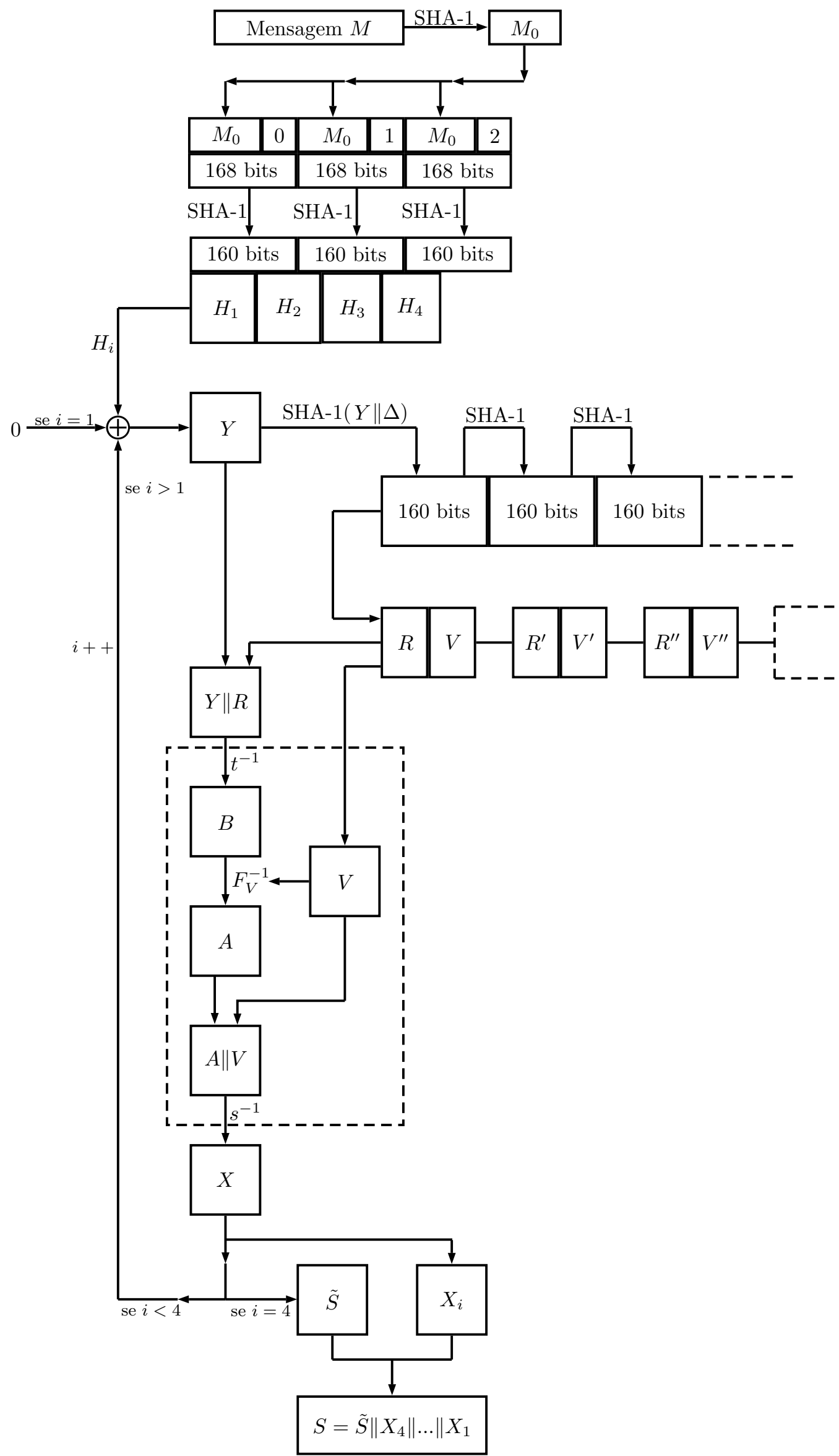

Figura 4.1: Assinando com Quartz Original (começando com $i=1$ ). 
(c) Obtenha a cadeia de 3 bits $R$ definida por:

$$
R=[W]_{0 \rightarrow 2}
$$

(d) Obtenha a cadeia de 4 bits $V$ definida por:

$$
V=[W]_{3 \rightarrow 6}
$$

(e) Calcule $B$ tal que ele seja um elemento de $\mathbb{E}$ definido por:

$$
B=\varphi\left(t^{-1}(Y \| R)\right)
$$

(f) Considerando a seguinte equação polinomial em $Z$ sobre $\mathbb{E}$ :

$$
F_{V}(Z)=B
$$

i. Se a equação $F_{V}(Z)=B$ não tiver solução, troque $W$ por SHA-1( $\left.W\right)$ e retornar ao passo 4c.

ii. Neste passo a equação $F_{V}(Z)=B$ tem uma ou mais soluções em $\mathbb{E}$. Logo, temos que $A(1), A(2), \ldots, A(\delta)$ são as soluções de $F_{V}(Z)=B$.

iii. Se $F_{V}(Z)=B$ tiver apenas uma solução, defina $A=A(1)$. Caso contrário, aplique a função hash em cada uma das soluções, ou seja $I(j)=\operatorname{SHA}-1(A(j))$. Em seguida escolha o $A(j)$ que resulta no menor $I(j)$, considerando a ordenação big-endian.

(g) Calcule a cadeia de 107 bits $X$ definida por:

$$
X=s^{-1}\left(\varphi^{-1}(A) \| V\right) \text {. }
$$

(h) Defina um novo valor para a cadeia de 100 bits $\tilde{S}$ como sendo:

$$
\tilde{S}=[X]_{0 \rightarrow 99}
$$

(i) Obtenha a cadeia de 7 bits $X_{i}$ definida por:

$$
X_{i}=[X]_{100 \rightarrow 106}
$$

5. A assinatura $S$ é a cadeia de 128 bits definida por:

$$
S=\tilde{S}\left\|X_{4}\right\| X_{3}\left\|X_{2}\right\| X_{1}
$$

\subsubsection{Verificando Assinatura}

Embasado nas mesmas justificativas elencadas na Seção anterior, apresentaremos agora, o processo de verificação de assinatura do Quartz. Ressaltando, novamente, que todos os elementos aqui descritos são extraídos da versão atualizada do esquema de assinatura digital Quartz [CGP01]. 
Desta forma, dadas uma mensagem $M$ - representada por uma cadeia de bits - e uma assinatura $S$, que neste caso é uma cadeia de 128 bits. Então, os procedimentos que seguem devem ser realizados para verificar se $S$ é ou não uma assinatura válida para $M$ (veja o algoritmo esquematizado na Figura $4.2)$.

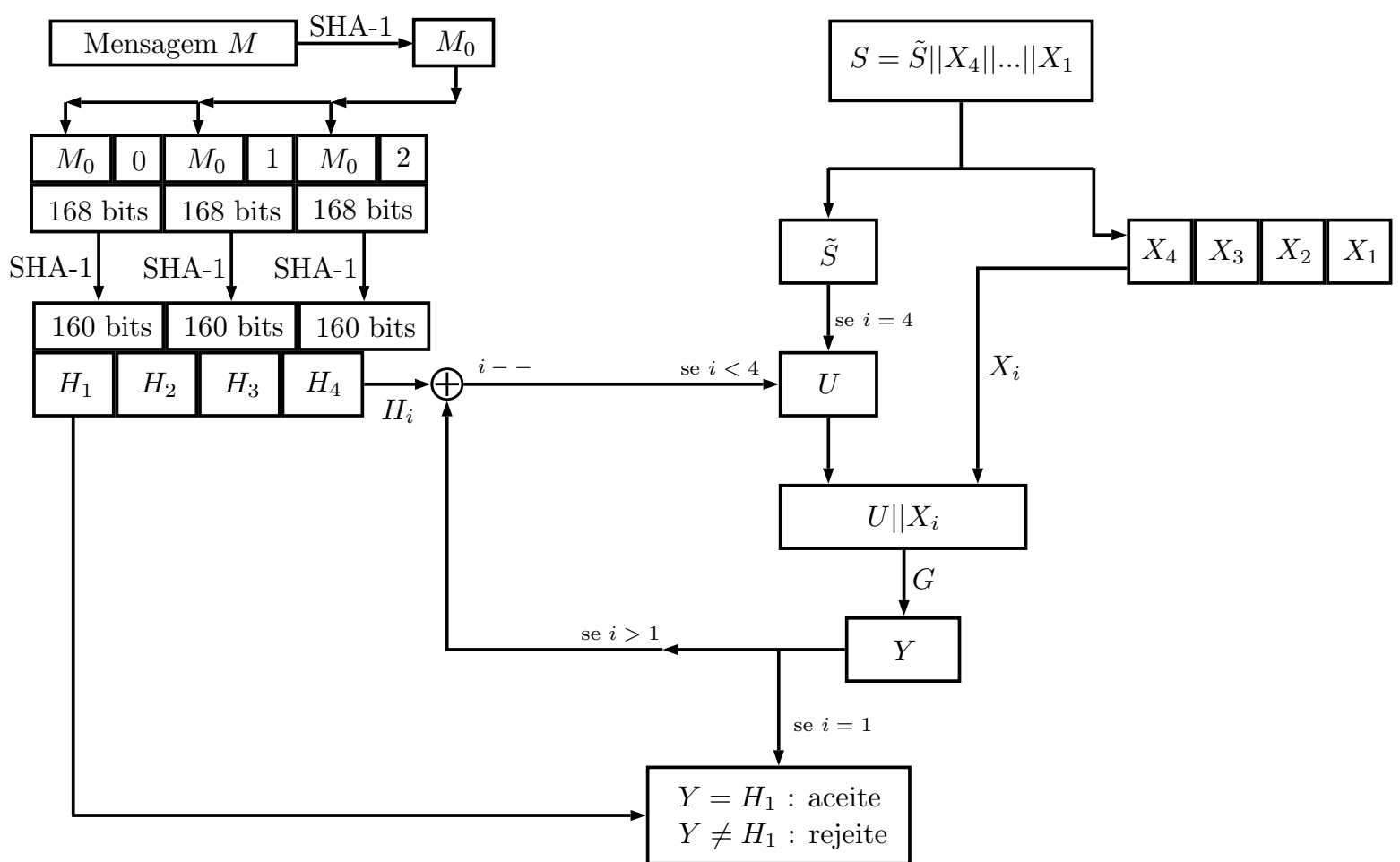

Figura 4.2: Verificando Assinatura com Quartz Original (comę̧ando com $i=4$ ).

1. Sejam $M_{0}, M_{1}, M_{2}$ e $M_{3}$ quatro cadeias de 160 bits definidas por:

$$
\begin{gathered}
M_{0}=\operatorname{SHA}-1(M), \\
M_{1}=\operatorname{SHA}-1\left(M_{0} \| 0\right), \\
M_{2}=\operatorname{SHA}-1\left(M_{0} \| 1\right), \\
M_{3}=\operatorname{SHA}-1\left(M_{0} \| 2\right) .
\end{gathered}
$$

2. Sejam $H_{1}, H_{2}, H_{3}$ e $H_{4}$ quatro cadeias de 100 bits definidas por:

$$
\begin{aligned}
& H_{1}=\left[M_{1}\right]_{0 \rightarrow 99}, \\
H_{2}= & {\left[M_{1}\right]_{100 \rightarrow 159} \|\left[M_{2}\right]_{0 \rightarrow 39}, } \\
& H_{3}=\left[M_{2}\right]_{40 \rightarrow 139}, \\
H_{4}= & {\left[M_{2}\right]_{140 \rightarrow 159} \|\left[M_{3}\right]_{0 \rightarrow 79} . }
\end{aligned}
$$

3. Seja $\tilde{S}$ uma cadeia de 100 bits definida por:

$$
\tilde{S}=[S]_{0 \rightarrow 99} .
$$


4. Sejam $X_{4}, X_{3}, X_{2}$ e $X_{1}$ quatro cadeias de 7 bits definidas por:

$$
\begin{aligned}
& X_{4}=[S]_{100 \rightarrow 106}, \\
& X_{3}=[S]_{107 \rightarrow 113}, \\
& X_{2}=[S]_{114 \rightarrow 120}, \\
& X_{1}=[S]_{121 \rightarrow 127} .
\end{aligned}
$$

5. Seja $U$ uma cadeia de 100 bits, tal que $U$ seja inicializada com $\tilde{S}$.

6. Para $i=4$ até 1 , faça:

(a) Calcule a cadeia de 100 bits $Y$ definida por:

$$
Y=G\left(U \| X_{i}\right)
$$

(b) Defina um novo valor para a cadeia de 100 bits $U$ como sendo:

$$
U=Y \oplus H_{i}
$$

7. Se $U$ é igual a cadeia $00 \ldots 0$, aceite a assinatura. Caso contrário, rejeite-a.

\subsection{Sobre a segurança do Quartz (HFEv-)}

Conforme levantado na Seção 3.7, existem diversos ataques capazes de recuperar a chave privada em criptossistemas desenvolvidos a partir da versão básica do HFE (ou seja, a trapdoor HFE sem modificadores aplicados a ela). Porém, até o momento, poucas criptoanálises foram capazes de sobrepujar a segurança adicionada pelos modificadores genéricos.

Ironicamente, uma das primeiras criptoanálises do HFE com modificadores que fora publicada afirmava decrementar a segurança desta trapdoor com, justamente, os modificadores "v" (vinagre), "_" (menos), ou os dois aplicados simultaneamente; além de também atacar sua versão básica [FJ03]. Este trabalho foi desenvolvido por Faugère e Joux em 2003, e nele os autores afirmavam ser possível recuperar a chave privada do Quartz com um esforço muito menor do que $2^{80}$ triplo-DES ${ }^{4}$ através de um ataque algébrico viabilizado pelo algoritmo F5 [FJ03], desenvolvido anteriormente por Faugère (frisando que o algoritmo F5 é baseado na teoria de bases de Gröbner [cF02]). Todavia, algum tempo após o desenvolvimento deste ataque, Courtois publicou uma versão estendida de [Cou02] onde ele mostra que o ataque desenvolvido por Faugère e Joux possui informações imprecisas ou enganosas, que acabam tornando sua criptoanálise inválida para o HFEv- e Quartz [Cou04, Seção 8.2]. Sobre este ataque, ainda vale ressaltar, que Wolf (em sua tese de doutorado) alertara sobre os argumentos utilizados por Faugère e Joux, afirmando que era necessário ter cautela antes de adotar tal ataque, uma vez ele ainda não havia sido analisado por outros pesquisadores [Wol05, Seção 6.1.2].

Acreditamos que os estudos realizados por Courtois e Wolf ocorreram de maneira independente e em paralelo. Sendo assim, a suspeita de Wolf juntamente com as explicações de Courtois são

\footnotetext{
${ }^{4}$ Estimativa de segurança anunciada em [PCG01b, CGP01, Cou01].
} 
suficientes para conjecturarmos que o Quartz (HFEv-) é resistente ao ataque algébrico que visa a recuperação da chave privada, desenvolvido por Faugère e Joux.

Posteriormente, visando o HFE com modificadores, alguns outros ataques capazes de recuperar a chave privada foram criados. Porém nenhum que atingisse o Quartz [DGS06a, BBD09, LFPW11].

Apenas para informação, podemos mencionar a criptoanálise desenvolvida por Ding e Schmidt em 2005, onde os autores demonstram ser possível quebrar o HFEv quando $v=1$, utilizando uma extensão do ataque de Kipnis-Shamir [DS05]. O ataque ao HFEi (HFE com perturbação interna) também vale ser lembrado, nele Dubois et al. demonstram que, com parâmetros moderados, esta variação é insegura a criptoanálise diferencial [DGS07]. Além disto, recentemente uma nova criptoanálise a um criptossistema baseado em HFE foi publicada, neste trabalho Bettale et al. se baseiam no ataque de Kipnis-Shamir para quebrar o multi-HFE ${ }^{5}$ em apenas 9 dias [BFP12].

Contudo, lembramos que tentar recuperar a chave privada não é o único objetivo de um adversário que ataca esquemas de assinatura digital (para maiores detalhes retorne à Seção 2.4.1). Uma abordagem possível é tentar gerar uma assinatura válida (porém falsificada) sem poder determinar ou modificar a mensagem cuja assinatura foi forjada. Este é o nível de sucesso mais baixo para um adversário, porém (conforme estabelecemos na Definição 2.4.1.1), se alcançado, é suficiente para considerarmos um esquema de assinatura inseguro.

Seguindo esta abordagem (ou seja, conseguir uma falsificação existencial através de um ataque adaptativo de mensagem escolhida), Joux e Martinet - baseados em axiomas do Ataque pelo Paradoxo de Aniversário - provaram que o Quartz é maleável, demonstrando que caso o adversário possua um par (mensagem, assinatura) válido, ele conseguirá obter uma segunda assinatura com $2^{m / 2}$ computações e $2^{m / 2}$ chamadas ao oráculo de assinatura, com um método que consiste em encontrar a segunda pré-imagem sem se preocupar com a inversão da função pública $G$ [JM03]. Assim, sob este cenário, estima-se que um adversário do Quartz consegue forjar uma segunda assinatura com somente $2^{50}$ computações e $2^{50}$ chamadas ao oráculo aleatório, logo muito inferior aos padrões segurança atuais que são de, no mínimo, $2^{112}$ [BR11].

Apesar disto, recentemente Sakumoto et al. apresentaram um trabalho sugerindo que os modelos usuais de prova de segurança não devem ser diretamente aplicados a trapdoors como o HFE e UOV [SSH11a]. Além disto, os autores desenvolveram um novo modelo de prova de segurança para esquemas de assinatura digital baseado em HFE e UOV, frisando que nenhum modelo deste tipo existia até o momento da publicação desse artigo. Neste novo modelo, juntamente com pequenas modificações também propostas neste trabalho, as assinaturas passam a ser uniformemente distribuídas [SSH11a], e com esta nova distribuição, Sakumoto et al. afirmam que os esquemas de assinatura baseados em HFE e UOV podem atingir um nível de segurança resistente a falsificação existencial através de um ataque adaptativo de mensagem escolhida, e fornecem um teorema para calcular a segurança provável destes esquemas modificados [SSH11a].

Assim, fundamentados nas diversas criptoanálises aqui citadas e principalmente na nova prova de segurança e modificações desenvolvidas pro Sakumoto et al. em 2011, seguiremos propondo nosso aprimoramento para o Quartz nas seções subsequentes contidas neste capítulo.

\footnotetext{
${ }^{5}$ Multi-HFE não é HFE com modificadores, mas trata-se de uma generalização do HFE.
} 


\subsection{A questão do SHA-1}

SHA é um acrônimo para Secure Hash Algorithm, uma família de funções hash que tem suas versões desenvolvidas pelo NIST (National Institute of Standards and Technology). O primeiro membro da família SHA, lançado em 1993, foi chamado de SHA-0. Este primeiro algoritmo caracterizava-se, principalmente, por aceitar entradas de no máximo $2^{64}$ bits e gerar saídas de 160 bits [NIS95]. Embora o NIST tenha mantido os mesmos tamanhos da entrada e saída, em 1995 foi lançado o SHA-1 visando substituir o SHA-0 [NIS95]. Por manter praticamente a mesma estrutura do SHA-0 (uma vez que sua mudança mais significativa é um deslocamento circular de 1 bit a esquerda), o SHA-1 foi rapidamente aderido pelos desenvolvedores de sistemas criptográficos.

Sabemos que algoritmos de assinatura e verificação são mais rápidos quando aplicados sobre o resultado de uma função hash $(y)$ do que quando aplicado diretamente sobre sua entrada $(x)$, isto porque $y$ é relativamente muito mais curto que $x$ [Ter08, Cap. 7]. Motivado por este atributo das funções hash, o Quartz emprega o SHA-1 em diversos pontos do seu algoritmo de assinatura e, consequentemente, no de verificação também. Mais precisamente, o uso do SHA-1 pode ser vislumbrado nos passos 1, 4b, 4(f)i e 4(f)iii do algoritmo de assinatura, e no passo 1 do algoritmo de verificação.

No entanto, a cada ano que passa a resistência a colisões do SHA-1 tem sido consideravelmente reduzida. Em 2005, Wang et al. publicaram um algoritmo para colisões do SHA-1 reduzido a 58 iterações com a complexidade $2^{33}$, sendo este o principal marco no declínio do SHA-1 [WYY05].

Devido também a este fato, o NIST publicou há poucos meses um relatório técnico proibindo a utilização do SHA-1 em qualquer esquema de assinatura digital que requeira uma segurança maior do que 80 bits [Dan12, Seção 5.2]. Entretanto, antes de tornar público este relatório, o NIST já vinha sinalizando o abandono do SHA-1.

Em 2002, o NIST lonçou três novas variantes do SHA: SHA-256, SHA-384 e SHA-512; coletivamente chamados de SHA-2 [NIS02]. Mais recentemente, em 02 de novembro de 2007, o NIST iniciou uma competição - similar a realizada para selecionar o AES - com a finalidade de escolher o SHA-3. Esta competição foi oficialmente chamada de AHS (Advanced Hashing Standard), e concluiu-se no dia 02 de outubro de 2012 com a escolha do algoritmo Keccak para o posto de SHA- $3^{6}$.

Além disto, porém não obstante desta temática, Joux publicou em 2004 um trabalho averiguando a segurança em funções hash iteradas (situação presente no passo 1 dos algoritmos de assinatura e verificação). Neste trabalho o autor demonstra que concatenando-se os resultados de funções hash a resistência a colisões é de apenas $\mathcal{O}\left(n 2^{n / 2}\right)$ e não $\mathcal{O}\left(2^{n}\right)$ como esperava-se.

Desta forma, acreditamos ser latente a necessidade de atualização do Quartz (e qualquer outro esquema de assinatura digital que utilize o SHA-1) quanto ao emprego desta função hash em suas rotinas. Pois além de estar indo de encontro com relatórios do NIST (ver [Dan12, Seção 5.2]), este esquema também pode estar adicionando fragilidades em seu algoritmo ao utilizar funções hash iteradas, conforme demonstrado por Joux em 2004 [Jou04].

\footnotetext{
${ }^{6}$ Mais detalhes disponíveis em http://csrc.nist.gov/groups/ST/hash/sha-3/winner_sha-3.html
} 


\section{Capítulo 5}

\section{Aprimorando o Quartz}

Neste capítulo vamos apresentar um novo protocolo de assinatura digital baseado no Quartz de Patarin, Courtois e Goubin; porém com um nível de segurança contra ataques existenciais adaptativos de mensagem escolhida estimado em $2^{112}$, em vez de $2^{50}$ do protocolo original. Explicaremos porque substituímos a função hash (SHA-1) utilizada no algoritmo original pelo SHA-3, esclarecendo como esta alteração contribuiu para a segurança de nossa proposta e ainda proporcionou um ganho médio de eficiência de $75 \%$ (aproximadamente) no processo de iniciação dos vetores que serão utilizados pelos algoritmos de assinatura e verificação. Demonstraremos, também, que nosso protocolo aprimorado realiza 4.096 vezes menos computações para negar uma assinatura falsa. Além de descrever porque as adaptações proposta por Sakumoto et al. [SSH11a] em seu modelo de prova para esquemas de assinatura digital baseados nas trapdoors UOV e HFE foram acatadas em nossa proposta.

\subsection{Quartz Aprimorado}

Agora que já estudamos os detalhes pertinentes ao Quartz, podemos iniciar a explicação acerca do nosso modelo aprimorado. Iniciaremos esta Seção abordando quais foram os parâmetros escolhidos para o Quartz Aprimorado, pois a escolha de parâmetros além de definir o trade-off entre segurança e performance também garante a resistência contra as criptoanálises conhecidas, quando feita corretamente.

Em seguida, descreveremos os algoritmos de Geração de Chaves, Assinatura e Verificação. Nestes algoritmos será possível notar três grandes mudanças. A primeira delas está no fato de utilizarmos somente uma transformação afim no processo de assinatura das mensagens. Desta forma, temos que a chave pública será a composição de apenas: o mapeamento central, uma bijeção que mapeia os elementos de $\mathbb{F}$ para $\mathbb{E}$ e uma transformação afim, ou seja, $G=F_{V} \circ \varphi \circ s$. Lembramos que, devido realizar apenas operações lineares, uma segunda transformação afim não adiciona segurança alguma ao criptossistema [BBD09, LFPW11], e não executá-la proporciona uma melhora na performance do processo de assinatura e geração de chaves.

Outra mudança está na substituição do SHA-1 pelo SHA-3 no momento de inicializar os vetores de bits que serão utilizados no processo de assinatura e verificação de assinaturas, bem como no momento de gerar as variáveis $R$ e $V$ do algoritmo de assinatura. Esta modificação nos ajuda a não obtermos uma mesma assinatura para mensagens distintas, já que aumenta a segurança contra colisões de $2^{33}$ no SHA-1 [WYY05] para uma segurança maior que $2^{112}$ no SHA-3 [jCPB ${ }^{+} 12$ ], e 
ainda proporciona um ganho de eficiência uma vez que não é executada iteradamente para obter uma saída com o tamanho adequado.

A terceira grande mudança esta no fato de concatenarmos um salt $\Gamma$ à mensagem $M$ antes de empregarmos a função de hash nesta mensagem (para ser mais específico, isso ocorre na inicialização de vetores de bits, Passo 2 do algoritmo de assinatura e Passo 4 do algoritmo de verificação de assinatura). Frisamos que esta modificação não é proveniente de nosso estudo, ela foi originalmente proposta por Sakumoto et al. em 2011 para que as assinaturas se tornassem uniformemente distribuídas, e com isto o modelo de prova que estava sendo proposto neste mesmo trabalho pudesse ser utilizado [SSH11a]. Apenas aderimos esta adaptação para que pudéssemos comprovar a segurança de nosso aprimoramento perante ataques adaptativos de mensagem escolhida que executam chamadas ao oráculo aleatório, prova que não existe no protocolo de assinatura Quartz Original [SSH11a].

Frisamos que tais alterações definem, em linhas gerais, como o nosso modelo aprimorado funciona. Porém, detalhes e peculiaridades sobre cada uma delas serão abordados nas próximas seções. Além disso, vale ressaltar que na Seção 5.2 explanaremos sobre o impacto de cada uma dessas modificações e escolha de parâmetros, elencando seus ganhos e perdas, como é natural que ocorra em qualquer modificação de criptossistema.

\subsubsection{Parâmetros}

Em nossa versão aprimorada do Quartz temos definido que: $q=2, d=129, h=229, v=2$, $r=5, n=231$ (pois $n \stackrel{\text { def }}{=} h+v$ ), $m=224$ (pois $m \stackrel{\text { def }}{=} h-r$ ); e a função pública $\mathcal{P}$ - função trapdoor - é um mapeamento de 231 bits para 224 bits, ou seja $\mathbb{F}^{231} \mapsto \mathbb{F}^{224}$.

Temos definido, ainda, um parâmetro adicional $g$, onde $g$ expressa o tamanho do salt aleatório $\Gamma$ que será concatenado a mensagem antes dela servir como entrada para a função hash, ou seja, $g=|\Gamma|$. Conforme já mencionado, Sakumoto et al., em seu novo modelo de prova, propuseram a utilização deste salt aleatório para uniformizar as assinaturas em esquemas de assinatura digital baseados no HFE [SSH11a], sendo estimado um tamanho aproximado de $\log \left(q_{\text {assina }}\left(q_{\text {hash }}+q_{\text {assina }}\right)\right)$ bits para que o esquema de assinatura seja considerado seguro [SSH11a, Seção 4]. Sabemos que $q_{\text {hash }}$ e $q_{\text {assina }}$ correspondem, respectivamente, à quantidade de consultas aos oráculos de hash e assinatura; e que em provas de esquemas de assinatura digital normalmente são considerados $q_{\text {assina }}=2^{30}$ e $q_{\text {hash }}=2^{60}$ [BR96]. Assim, segue que $g=96$ bits.

Como estabelecemos que $h=229$, a extensão do corpo utilizada pelo Quartz Aprimorado fica definida como $\mathbb{F}_{2^{229}}=\mathbb{E}$. Mais precisamente, podemos dizer que $\mathbb{E}=\mathbb{F}_{2}[X] /\left(X^{229}+X^{9}+X^{6}+\right.$ $\left.X^{5}+X^{2}+X+1\right)$, onde a bijeção $\varphi$ entre $\{0,1\}^{229}$ e $\mathbb{E}$ está definida como:

$$
\begin{gathered}
\forall \omega=\left(\omega_{0}, \ldots, \omega_{228}\right) \in\{0,1\}^{229} \\
\varphi(\omega)=\omega_{228} X^{228}+\ldots+\omega_{1} X+\omega_{0}\left(\bmod \left(X^{229}+X^{9}+X^{6}+X^{5}+X^{2}+X+1\right)\right) .
\end{gathered}
$$

\section{Parâmetros Privados}

Estudamos que, genericamente, em todos criptossistemas MPKC temos três parâmetros que compõem a chave privada: $S, F$ e $T$. Vimos ainda que, no Quartz Original, além destes três parâmetros, temos um parâmetro adicional chamado de $\Delta$. Porém, como em nossa versão aprimorada 
do Quartz utilizaremos apenas uma transformação afim, podemos descrever os parâmetros privados de nosso aprimoramento como sendo:

1. $s$ : a transformação afim privada de $\{0,1\}^{231}$ para $\{0,1\}^{231}$, genericamente chamada de $S$. De maneira mais detalhada, este parâmetro pode ser descrito como uma matriz quadrada $231 \times 231$ e uma matriz coluna $231 \times 1$ sobre $\mathbb{F}_{2}$ da transformação $s$, com sua respectiva base canônica sobre $\{0,1\}^{231}$. Onde $S_{L}$ representa a matriz quadrada e $S_{C}$ a matriz coluna;

2. $F_{V}$ : o mapeamento central privado genericamente chamado de $F$. Esta função de mapeamento $\left(F_{V}\right)_{V \in\{0,1\}^{2}}$ de $\mathbb{E}$ para $\mathbb{E}$, está definida por:

$$
F_{V}(Z)=\sum_{\substack{0 \leq i<j<229 \\ 2^{i}+2^{j} \leq 129}} \alpha_{i, j} \cdot Z^{2^{i}+2^{j}}+\sum_{\substack{0 \leq i<229 \\ 2^{i} \leq 129}} \beta_{i}(V) \cdot Z^{2^{i}}+\gamma(V)
$$

onde os $\alpha_{i, j}$ são elementos de $\mathbb{E}$ e cada $\beta_{i}(0 \leq i<229)$ é uma transformação afim de $\{0,1\}^{2}$ para $\mathbb{E}$, ou seja, a transformação $\beta_{i}$ satisfaz a seguinte condição:

$$
\forall V=\left(V_{0}, V_{1}\right) \in\{0,1\}^{2}, \quad \beta_{i}(V)=\sum_{0 \leq k<2} V_{k} \cdot \xi_{i, k}+v_{i}
$$

onde $\xi_{i, j}$ e $v_{i}$ são elementos de $\mathbb{E}$.

Temos ainda que $\gamma$ é uma transformação quadrática de $\{0,1\}^{2}$ para $\mathbb{E}$, ou seja, a transformação $\gamma$ satisfaz a seguinte condição:

$$
\forall V=\left(V_{0}, V_{1}\right) \in\{0,1\}^{2}, \quad \gamma(V)=\sum_{0 \leq k<\ell<2} V_{k} V_{\ell} \cdot \eta_{k, \ell}+\sum_{0 \leq k<2} V_{k} \cdot \sigma_{k}+\tau
$$

tal que todos $\eta_{k, \ell}, \sigma_{k}$ e $\tau$ sejam elementos de $\mathbb{E}$;

3. $\Delta$ : uma cadeia de 80 bits privada, obtida de maneira pseudoaleatória.

\section{Parâmetros Públicos}

A chave pública do Quartz Aprimorado - assim como nos demais esquemas multivariáveis quadráticos - é a composição de suas funções privadas. Ou seja, a obtenção do parâmetro público deste criptossistema consiste em encontrarmos uma função $G$ de $\{0,1\}^{231}$ para $\{0,1\}^{224}$ tal que:

$$
G(X)=\left[F_{[s(X)]_{229 \rightarrow 230}}\left(\varphi\left([s(X)]_{0 \rightarrow 228}\right)\right)\right]_{0 \rightarrow 223},
$$

e divulgá-la para os demais usuários.

Deste modo, para construirmos o algoritmo, $G$ deve ser uma transformação quadrática sobre $\mathbb{F}_{2}$, ou seja:

$$
\left\{\begin{array}{c}
Y_{0}=P_{0}\left(X_{0}, \ldots, X_{230}\right) \\
\vdots \\
Y_{223}=P_{223}\left(X_{0}, \ldots, X_{230}\right)
\end{array}\right.
$$


onde cada $P_{i}$ (para $0 \leq i \leq 223$ ) é um polinômio quadrático da forma

$$
P_{i}\left(X_{0}, \ldots, X_{230}\right)=\sum_{0 \leq j<k<231} \zeta_{i, j, k} X_{j} X_{k}+\sum_{0 \leq j<231} \nu_{i, j} X_{j}+\rho_{i}
$$

e os elementos $\zeta_{i, j, k}, \nu_{i, j}$ e $\rho_{i}$ pertençam a $\mathbb{F}_{2}$.

\subsubsection{Geração de Chaves}

Na Seção 4.2.2 vimos como ocorre a geração de chaves do Quartz Original, que -em linhas geraispode ser resumida em chamadas sucessivas a um gerador de bit pseudoaleatório criptograficamente seguro (cryptographically secure pseudorandom bit generator - CSPRBG) que dará origem aos parâmetros privados, onde, posteriormente será realizada uma interpolação entre tais parâmetros para gerar a chave pública do criptossistema.

O fato é que a geração de chaves de nosso aprimoramento pouco se difere da proposta original. Para ser mais específico, a diferença está apenas no "tamanho" dos parâmetros escolhidos e na utilização de somente uma transformação afim no momento da composição da chave pública.

Desta forma, prosseguiremos - nesta Seção - apenas descrevendo quais são os elementos a serem criados, detalhando os passos de sua concepção, para posteriormente apresentarmos o cálculo do tamanho das chaves.

\section{Chave Privada}

Repassemos alguns elementos que devem ser gerados:

- Os seguintes elementos privados de $\mathbb{E}$ :

$$
\begin{cases}\alpha_{i, j} & \text { onde } 0 \leq i<j<229 \text { e } 2^{i}+2^{j} \leq 129 \\ \xi_{i, k} & \text { onde } 0 \leq i<8 \text { e } 0 \leq k<2 \\ v_{i} & \text { onde } 0 \leq i<8 \\ \eta_{k, \ell} & \text { onde } 0 \leq k<\ell<2 \\ \sigma_{k} & \text { onde } 0 \leq k<2 \\ \tau & \end{cases}
$$

- A matriz quadrada inversível $231 \times 231\left(S_{L}\right)$, e a matriz coluna $231 \times 1\left(S_{C}\right)$, ambas privadas, com seus coeficientes definidos como 0 ou 1 ;

- A cadeia de 80 bits privada $(\Delta)$.

Com o intuito de criar tais elementos, podemos esquematizar a Geração de Chave Privada de nosso aprimoramento nos seguintes passos:

1. Determinar os coeficientes de

$$
F_{(0,0)}(Z)=\sum_{\substack{0 \leq i<j<229 \\ 2^{i}+2^{j} \leq 129}} \alpha_{i, j} \cdot Z^{2^{i}+2^{j}}+\sum_{\substack{0 \leq i<229 \\ 2^{i} \leq 129}} v_{i} \cdot Z^{2^{i}}+\tau
$$

da mais baixa para a mais alta potência de $Z$. Mais precisamente, os primeiros 229 bits produzidos pelo CSPRBG fornecem $\tau$ (quando aplicamos $\varphi$ ). Então, determinamos sucessivamente: $v_{0}, v_{1}, \alpha_{0,1}, v_{2}, \alpha_{0,2}, \alpha_{1,2}, v_{3}, \alpha_{0,3}, \alpha_{1,3}, \alpha_{2,3}, v_{4}, \alpha_{0,4}, \alpha_{1,4}, \alpha_{2,4}, \alpha_{3,4}, v_{5}, \alpha_{0,5}, \alpha_{1,5}, \alpha_{2,5}, \alpha_{3,5}$, 
$\alpha_{4,5}, v_{6}, \alpha_{0,6}, \alpha_{1,6}, \alpha_{2,6}, \alpha_{3,6}, \alpha_{4,6}, \alpha_{5,6}, v_{7}, \alpha_{0,7}$ (um de cada vez, utilizando o CSPRBG para gerar 229 novos bits aleatórios, e em seguida aplicamos $\varphi$ ).

2. Determinar os coeficientes de

$$
F_{(1,0)}(Z)-F_{(0,0)}(Z)=\sum_{\substack{0 \leq i<229 \\ 2^{i} \leq 129}} \xi_{i, 0} \cdot Z^{2^{i}}+\sigma_{0}
$$

da mais baixa para a mais alta potência de $Z$. Mais precisamente, os primeiros 229 bits produzidos pelo CSPRBG fornecem $\sigma_{0}$ (quando aplicamos $\varphi$ ). Então, determinamos sucessivamente: $\xi_{0,0}, \xi_{1,0}, \xi_{2,0}, \xi_{3,0}, \xi_{4,0}, \xi_{5,0}, \xi_{6,0}, \xi_{7,0}$ (um de cada vez, utilizando o CSPRBG para gerar 229 novos bits aleatórios, e em seguida aplicamos $\varphi$ ).

3. Determinar os coeficientes de

$$
F_{(0,1)}(Z)-F_{(0,0)}(Z)=\sum_{\substack{0 \leq i<229 \\ 2^{i} \leq 129}} \xi_{i, 1} \cdot Z^{2^{i}}+\sigma_{1}
$$

da mais baixa para a mais alta potência de $Z$. Mais precisamente, os primeiros 229 bits produzidos pelo CSPRBG fornecem $\sigma_{1}$ (quando aplicamos $\varphi$ ). Então, determinamos sucessivamente: $\xi_{0,1}, \xi_{1,1}, \xi_{2,1}, \xi_{3,1}, \xi_{4,1}, \xi_{5,1}, \xi_{6,1}, \xi_{7,1}$ (um de cada vez, utilizando o CSPRBG para gerar 229 novos bits aleatórios, e em seguida aplicamos $\varphi$ ).

4. Determinar o coeficiente remanescente $\eta_{0,1}$, que correspondem a parte quadrática de $\gamma(V)$, utilizando o CSPRBG para gerar 229 novos bits aleatórios, e em seguida aplicamos $\varphi$.

5. Gerar uma matriz triangular inferior $231 \times 231\left(I_{S}\right)$ e uma matriz triangular superior $231 \times 231$ $\left(S_{S}\right)$, onde todos coeficientes sejam 0 ou 1 , executando as seguintes rotinas:

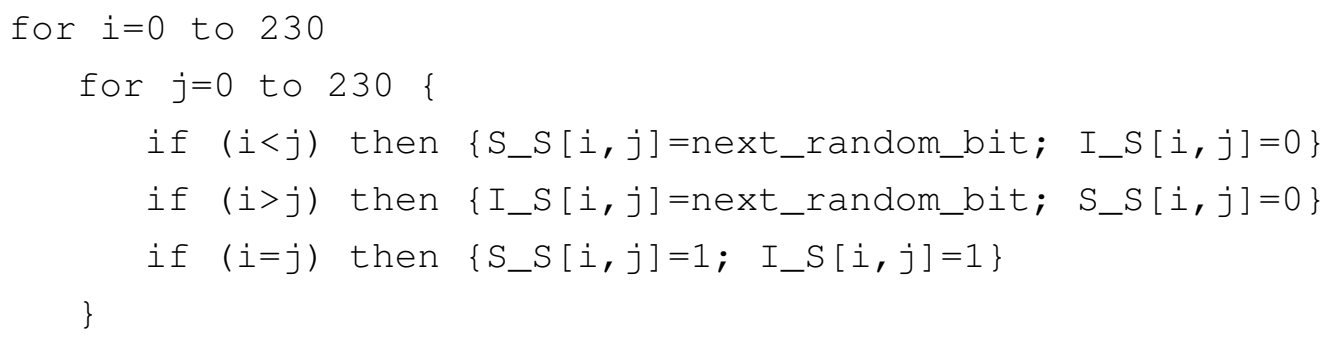

Em seguida, defina $S_{L}=I_{S} \times S_{S}$.

6. Gerar $S_{C}$ utilizando o CSPRBG para obter 231 novos bits aleatórios, indo do topo da matriz coluna até sua base.

7. Por último, gerar $\Delta$ utilizando o CSPRBG para obter uma cadeia de 80 bits pseudoaleatórios.

Note que para a completa geração da chave privada é necessário um espaço de 65.122 bits, que são gerados "aleatoriamente" pelo CSPRBG. Ou seja, são necessários $7.099+2.061+2.061+$ $229+(231 \times 231)+231+80=65.122$ bits $\cong 8$ Kbytes para armazenar a chave privada do Quartz Aprimorado. 


\section{Chave Pública}

Como o tamanho da chave pública de sistemas criptográficos do tipo "Big Field" é igual a $m n((n+3) / 2)$ [BBD09]. Então, temos que a chave pública do nosso aprimoramento necessita de $224 \times 231 \times((231+3) / 2)=6.054 .048$ bits $\cong 739$ Kbytes para ser armazenada.

Lembrando que para obtermos a chave pública $G$ a partir da chave privada é necessário que efetuemos uma interpolação de polinômios para polinômios multivariáveis tal que:

$$
G(X)=\left[F_{[s(X)]_{229 \rightarrow 230}}\left(\varphi\left([s(X)]_{0 \rightarrow 228}\right)\right)\right]_{0 \rightarrow 223} .
$$

\subsubsection{Assinando Mensagens}

Seja $M$ uma mensagem representada por uma cadeia de bits, e $S$ a assinatura obtida desta mensagem. Então, em nosso esquema aprimorado, os procedimentos necessários a obtenção de $S$ devem ser realizados conforme segue (veja Figura 5.1):

1. Seja $\Gamma$ uma cadeia de 96 bits, tal que $\Gamma \in_{R}\{0,1\}^{96}$;

2. Seja $M_{0}$ uma cadeia de 512 bits definida por:

$$
M_{0}=\operatorname{SHA}-3(M \| \Gamma)
$$

3. Sejam $H_{1}$ e $H_{2}$ duas cadeias de 224 bits definidas por:

$$
\begin{gathered}
H_{1}=\left[M_{0}\right]_{0 \rightarrow 223}, \\
H_{2}=\left[M_{0}\right]_{224 \rightarrow 447} .
\end{gathered}
$$

4. Seja $\tilde{S}$ uma cadeia de 224 bits, tal que $\tilde{S}$ seja inicializada com $00 \ldots 0$.

5. Para $i=1$ até 2 , faça:

(a) Calcule a cadeia de 224 bits $Y$ definida por:

$$
Y=H_{i} \oplus \tilde{S}
$$

(b) Calcule a cadeia de 512 bits $W$ definida por:

$$
W=\operatorname{SHA}-3(Y \| \Delta) \text {. }
$$

(c) Obtenha a cadeia de 5 bits $R$ definida por:

$$
R=[W]_{0 \rightarrow 4}
$$

(d) Obtenha a cadeia de 2 bits $V$ definida por:

$$
V=[W]_{5 \rightarrow 6}
$$

(e) Considerando a seguinte equação polinomial em $Z$ sobre $\mathbb{E}$ :

$$
F_{V}(Z)=(Y \| R) .
$$




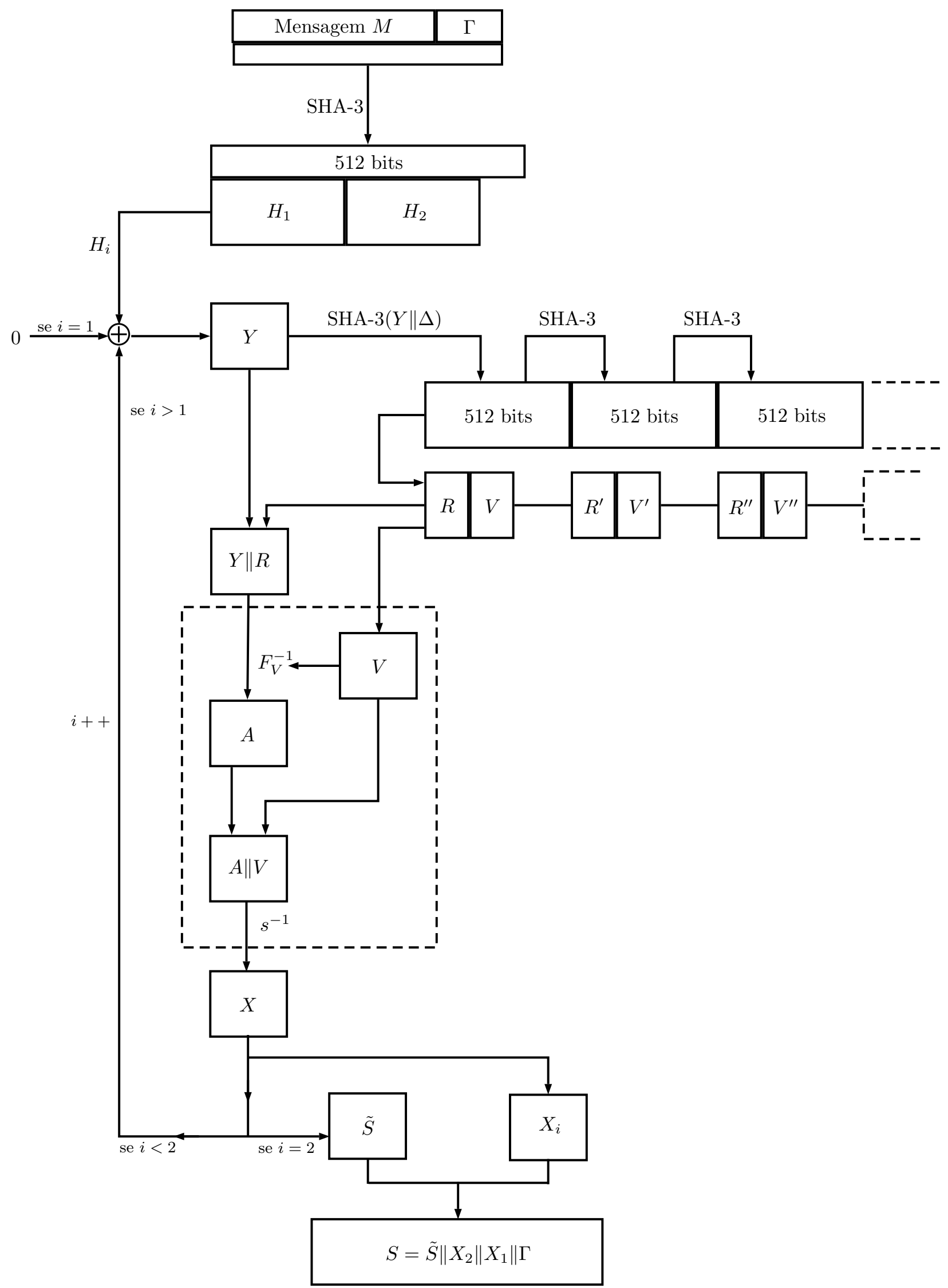

Figura 5.1: Assinando com Quartz Aprimorado (começando com $i=1$ ). 
i. Se a equação $F_{V}(Z)=(Y \| R)$ não tiver solução, troque $W$ por SHA-3( $\left.W\right)$ e retornar ao passo $5 \mathrm{c}$.

ii. Neste passo a equação $F_{V}(Z)=(Y \| R)$ tem uma ou mais soluções em $\mathbb{E}$. Logo, temos que $A(1), A(2), \ldots, A(\delta)$ são as soluções de $F_{V}(Z)=(Y \| R)$.

iii. Se $F_{V}(Z)=(Y \| R)$ tiver apenas uma solução, defina $A=A(1)$. Caso contrário, aplique a função hash em cada uma das soluções, ou seja $I(j)=\operatorname{SHA}-3(A(j))$. Em seguida escolha o $A(j)$ que resulta no menor $I(j)$, considerando a ordenação big-endian.

(f) Calcule a cadeia de 231 bits $X$ definida por:

$$
X=s^{-1}\left(\varphi^{-1}(A) \| V\right) \text {. }
$$

(g) Defina um novo valor para a cadeia de 224 bits $\tilde{S}$ como sendo:

$$
\tilde{S}=[X]_{0 \rightarrow 223}
$$

(h) Obtenha a cadeia de 7 bits $X_{i}$ definida por:

$$
X_{i}=[X]_{224 \rightarrow 230} .
$$

6. A assinatura $S$ é a cadeia de 334 bits definida por:

$$
S=\tilde{S}\left\|X_{2}\right\| X_{1} \| \Gamma
$$

\subsubsection{Verificando Assinatura}

Dadas uma mensagem $M$ - representada por uma cadeia de bits - e uma assinatura $S$, que neste caso é uma cadeia de 334 bits. Então, no Quartz Aprimorado, os procedimentos que seguem devem ser realizados para verificar se $S$ é ou não uma assinatura válida para $M$ (veja o algoritmo esquematizado na Figura 5.2).

1. Seja $\tilde{S}$ uma cadeia de 224 bits definida por:

$$
\tilde{S}=[S]_{0 \rightarrow 223}
$$

2. Sejam $X_{2}$ e $X_{1}$ duas cadeias de 7 bits definidas por:

$$
\begin{aligned}
X_{2} & =[S]_{224 \rightarrow 230}, \\
X_{1} & =[S]_{231 \rightarrow 237} .
\end{aligned}
$$

3. Seja $\Gamma$ uma cadeia de 96 bits definida por:

$$
\Gamma=[S]_{238 \rightarrow 334} .
$$

4. Seja $M_{0}$ uma cadeia de 512 bits definida por:

$$
M_{0}=\operatorname{SHA}-3(M \| \Gamma) \text {. }
$$




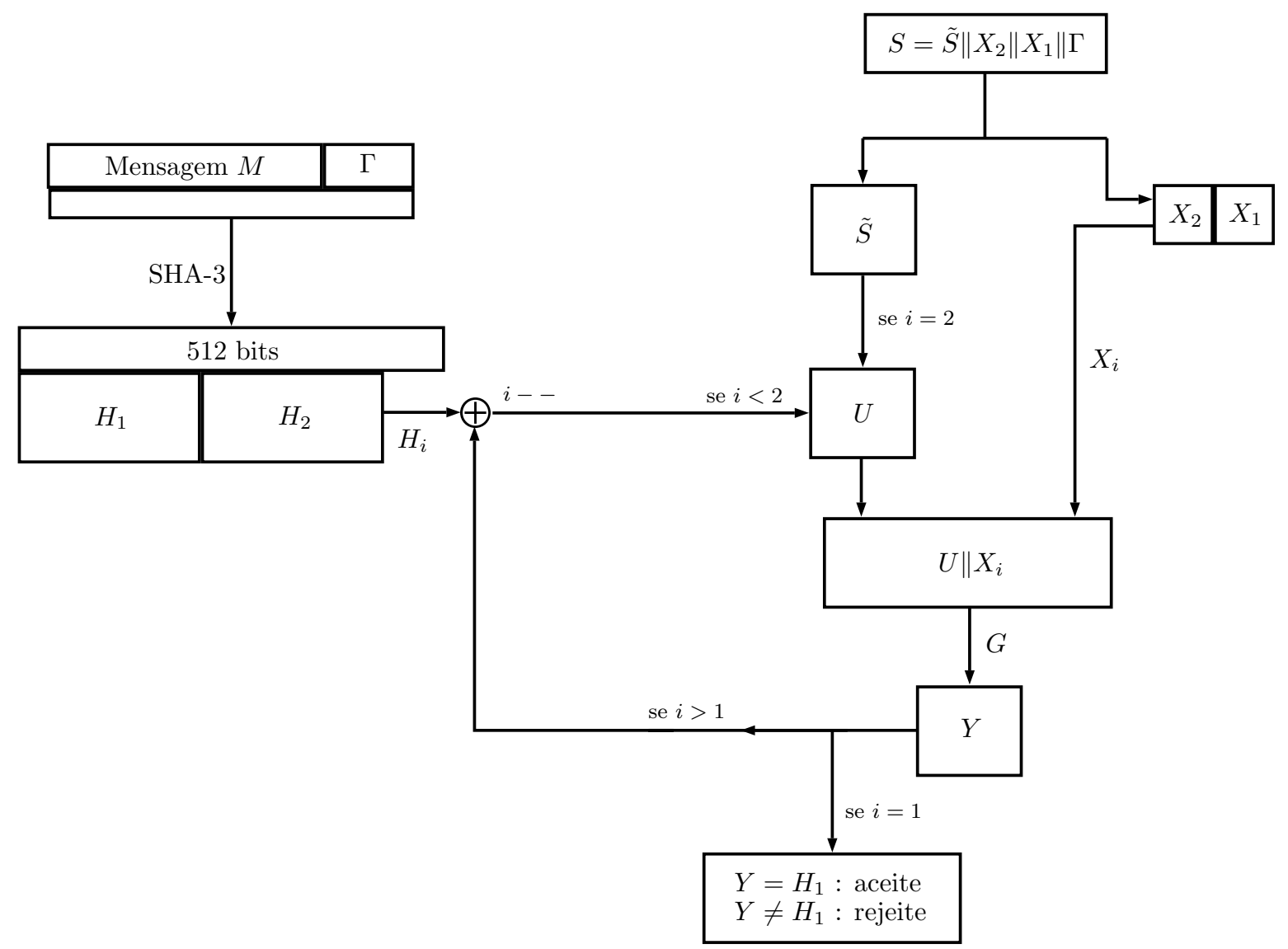

Figura 5.2: Verificando Assinatura com Quartz Aprimorado (começando com $i=2$ ).

5. Sejam $H_{1}$ e $H_{2}$ duas cadeias de 224 bits definidas por:

$$
\begin{gathered}
H_{1}=\left[M_{0}\right]_{0 \rightarrow 223}, \\
H_{2}=\left[M_{0}\right]_{224 \rightarrow 447} .
\end{gathered}
$$

6. Seja $U$ uma cadeia de 224 bits, tal que $U$ seja inicializada com $\tilde{S}$.

7. Para $i=2$ até 1 , faça:

(a) Calcule a cadeia de 224 bits $Y$ definida por:

$$
Y=G\left(U \| X_{i}\right)
$$

(b) Defina um novo valor para a cadeia de 224 bits $U$ como sendo:

$$
U=Y \oplus H_{i}
$$

8. Se $U$ é igual a cadeia $00 \ldots . .0$, aceite a assinatura. Caso contrário, rejeite-a. 


\subsection{Análise da proposta}

Para a análise de nosso protocolo Quartz Aprimorado vamos inicialmente explicar porque foram escolhidos os parâmetros elencados na Seção 5.1.1, para isto, descreveremos os benefícios de adotar tais parâmetros, justificando o impacto que tal escolha gera na segurança, abordando também a possível perda ou ganho de eficiência que tal modificação pode gerar, quando comparada ao esquema original. Explanaremos novamente, porém com um foco distinto, sobre a substituição da função de hash SHA-1 (utilizada no modelo original) pela função de hash SHA-3 (escolhida para nosso aprimoramento). E ainda, justificaremos porque é interessante adotarmos as modificações propostas por Sakumoto et al. em seu novo modelo de prova para esquemas de assinaturas baseados em HFE [SSH11a], mesmo sabendo que tais modificações acarretam um aumento de 96 bits no tamanho final da assinatura.

Contudo, como acreditamos ser dedutível que uma segunda rodada de operações lineares não adicione segurança alguma a um esquema baseado na intratabilidade de equações multivariáveis quadráticas, não nos preocuparemos em dar maiores detalhes sobre a não utilização de duas transformações afim em nosso aprimoramento. Sendo que o leitor pode consultar maiores detalhes sobre o tema em [KPG99], [DGS06a], [BBD09] e [BFFP11].

\section{Escolha de Parâmetros}

Sabemos que no Quartz, caso o adversário possua um par (mensagem, assinatura) válido, é possível que este adversário obtenha uma segunda assinatura válida com $2^{m / 2}$ computações e $2^{m / 2}$ chamadas ao oráculo aleatório através de um ataque que não necessita inverter a função pública $G$ já que baseia-se em axiomas do Ataque pelo Paradoxo do Aniversário [JM03]. Como nosso aprimoramento não modifica a estrutura geral do Quartz, apenas a adapta; podemos deduzir que tal ataque também é válido para ele. Desta forma, temos que $m \geq 224$ para obtermos um nível de segurança de no mínimo $2^{112}$ (padrão exigido para sistemas criptográficos atuais [BR11]). Ou seja, a quantidade de equações de nosso sistema de equações multivariáveis quadráticas é que determinará a segurança (ou insegurança) de nosso criptossistema.

Todavia, ao definirmos nossos parâmetros não nos preocupamos somente com o tamanho de $m$. Isto porque ao estabelecermos parâmetros para instanciar uma função $\mathcal{M} \mathcal{Q}$, devemos ter $n>m$ e $n \approx m$ para que o problema permaneça intratável. Pois caso $n<m$, teríamos um sistema de equações superdefinido, o que tornaria a sua resolução consideravelmente "fácil" [CKPS00a]. Por outro lado, caso $n>>m$, teríamos um sistema de equações com muito mais variáveis do que equações, o que possibilitaria ao adversário utilizar algoritmos muito mais velozes do que a busca exaustiva [CGMT02]. Também existe o fato de Ding e Schmidt em 2005 terem demonstrado ser possível quebrar o HFEv quando $v=1$ [DS05], assim, tomamos o cuidado de escolher um $v>1$, porém não excessivamente maior. Além disto, escolhemos cuidadosamente o valor de $h$ para que o mesmo fosse primo (fato que também ocorre no modelo original [PCG01b, CGP01]); isto porque até hoje não foi apresentada nenhuma criptoanálise que atinja MPKCs que utilizem extensões de corpos com característica igual a um número primo [Cou04, Wol05, Fel05, LFPW11].

Desta forma, lembramos que os parâmetros de nosso modelo aprimorado são: $m=224, n=231$, $h=229, v=2, r=5, q=2, d=129$ e $g=96$. 
Com estes parâmetros, constatamos dois inconvenientes em nosso aprimoramento. O primeiro deles está no aumento excessivo das chaves pública e privada de nosso criptossistema, pois, conforme ilustrado nas Seções 4.2.2 e 5.1.2, a chave privada aumenta de 3 Kbytes no Quartz Original para 8 Kbytes em nosso protocolo, sendo que a chave pública salta de 71 Kbytes para 739 Kbytes. Este tamanho exagerado das chaves é apontado como a principal, se não a única, desvantagem dos MPKCs quando comparados com sistemas criptográficos tradicionais como o RSA ou ECC [BBD09]. Por exemplo, o tamanho da chave pública do RSA para uma segurança similar ao aprimoramento que estamos propondo é de apenas 2048 bits, enquanto a chave pública do Quartz Aprimorado é de um pouco mais que 739 Kbytes.

No entanto, lembramos que operações com bases e expoentes de centenas de bits de comprimento (para criptossistemas baseados em Curvas Elípticas e, especialmente, RSA) são significativamente caras para dispositivos embarcados sem um co-processador [BBD09]. Desta forma, neste cenário MPKCs apresentam algumas vantagens compensatórias e ainda oferecem grande potencial para este tipo de dispositivos. Pois - por possuir assinaturas pequenas - após um determinado número de assinaturas o tráfego gerado pelos MPKCs será significativamente menor que o gerado por criptossistemas clássicos; sendo que, conforme abordado no início do Capítulo 3, também existem diversos trabalhos demonstrando que implementações de protocolos derivados desta primitiva são rápidas e eficientes, tanto em software, quanto em hardware [BERW08, $\mathrm{CCC}^{+}$09], além de serem indicados como uma boa opção para sistemas embarcados com restrição de processamento [DGS06a, BBD09, Hei09]. Para ilustrar um cenário com dispositivos de processamento restrito onde o uso de nosso esquema aprimorado seja mais vantajoso que o uso do RSA-2048, podemos utilizar os radares eletrônicos para controle de velocidade instalados pela Companhia de Engenharia e Tráfego (CET) da cidade de São Paulo. Conforme dados divulgados pela companhia, em 2012 foram registradas 3,2 milhões de infrações [Rib13] pelos 576 radares instalados em São Paulo [CET13]. O que nos dá uma média aproximada de 463 multas por mês em cada um destes radares. Assim, após menos de 8 meses (em média) o tráfego de rede gerado pelas assinaturas e chave pública de radares que implementassem o Quartz Aprimorado já seria menor que o tráfego gerado por radares com o RSA2048. Além de também gerar uma economia no momento da aquisição destes equipamentos, pois necessitariam de dispositivos com arquitetura mais barata já que não careceriam de co-processador para efetuar os seus cálculos.

O outro inconveniente de nossa escolha de parâmetros está na perda de eficiência dos algoritmos de Geração e Chaves e Assinatura (perda que pode ser constatada nas Tabelas 6.1 e 6.2 do próximo Capítulo). Em linhas gerais, acreditamos que tal ineficiência se deu devido ao aumento significativo na quantidade de objetos e instâncias a serem manipuladas por nossa implementação, sendo que melhorias como paralelismo ou instruções de máquina possam facilmente ser incorporadas a futuras implementações que visem à melhoria deste quesito. Como a eficiência de nossa implementação de referência não era o principal objetivo de nosso trabalho, buscamos fazê-la da maneira mais didática possível, definindo os passos conforme discorrido nesta dissertação, tornando-a totalmente sequencial.

Contudo, aliado ao expressivo ganho no nível de segurança (para maiores detalhes consulte a próxima Seção), a escolha de parâmetros do nosso esquema aprimorado proporcionou, também, uma melhoria no algoritmo de Verificação de Assinatura. Isto porque testaremos até 4.096 vezes menos hipóteses de utilização da chave pública no momento da resolução da função $G$, enquanto 
estamos verificando a validade de uma assinatura (Passo 7a do algoritmo de verificação do Quartz Aprimorado). Para sermos mais específicos, consideremos as seguintes características: (a) o mapeamento central $F_{V}$ de $\mathbb{E}$ para $\mathbb{E}$ utilizado tanto na assinatura de mensagens quanto na composição da chave pública terá seu número de possibilidades para $V$ variando conforme a quantidade de variáveis vinagre utilizadas pelo criptossistema, pois $\left(F_{V}\right)_{V \in\{0,1\}^{v}}$; (b) estas possibilidades representam um total de $2^{v}$ chaves públicas a serem geradas pelo algoritmo de Geração de Chaves; (c) como o Quartz (tanto o original quanto nosso modelo aprimorado) realiza operações iteradas para assinar as mensagens, e antecipadamente não podemos definir quais das $2^{v}$ possibilidades de variáveis vinagres foram utilizadas no processo de assinatura, temos que, seja $K$ o número de iterações do algoritmo, então todas as $\left(2^{v}\right)^{K}$ combinações devem ser testadas para que o algoritmo de verificação negue uma assinatura falsa. Deste modo $\left(2^{4}\right)^{4}=2^{16}$ possibilidades devem ser testadas durante a resolução de $G$ no Quartz Original e $\left(2^{2}\right)^{2}=2^{4}$ no Quartz Aprimorado, o que representa um intervalo de possibilidades $2^{12}=4.096$ vezes menor em nosso aprimoramento.

\section{Substituição do SHA-1 pelo SHA-3}

Anteriormente, na Seção 4.4 elencamos as principais criptoanálises e relatórios técnicos que desqualificam a utilização do SHA-1 para qualquer finalidade criptográfica. No entanto, não nos prolongamos na explicação acerca dos impactos negativos que a adoção de uma função de hash "quebrada" pode causar a um esquema de assinatura digital. Mas agora, utilizando conceitos abordados na Seção 2.4 (onde expomos as noções gerais de esquemas de assinatura digital) seguiremos descrevendo os impactos lesivos a tupla de algoritmos (GERA, Assina, Verifica), deste possível emprego de uma função de hash insegura.

Através da simples definição do algoritmo GERA podemos vislumbrar que o mesmo não seria afetado caso uma função de hash mal selecionada fosse empregada no esquema em que ele compõe, pois tal algoritmo apenas recebe como entrada um parâmetro do sistema $1^{\lambda}$ e retorna um par de chaves $(p k, s k)$.

Por outro lado, sabemos que algoritmos de assinatura (Assina) e verificação (VERIFICA) são mais rápidos quando aplicados sobre o resultado de uma função hash $(y)$ do que quando aplicado diretamente sobre sua entrada $(x)$, isto porque $y$ é relativamente muito mais curto que $x$ [Ter08, Cap. 7]. Logo, caso a função hash $H()$ não seja resistente a colisões, um adversário poderia obter uma mesma assinatura para duas mensagens distintas. Ou seja, dado um par de legíveis $x_{1}$ e $x_{2}$, onde $x_{1} \neq x_{2}$ acarrete $H\left(x_{1}\right)=H\left(x_{2}\right)$, então $\sigma=\operatorname{AssinA}_{s k}\left(H\left(x_{1}\right)\right)=\operatorname{AssinA}_{s k}\left(H\left(x_{2}\right)\right)$. Isto claramente é indesejável pois, mesmo que a mensagem forjada não faça o menor sentido, em nenhum esquema de assinatura digital deseja-se que mensagens distintas possuam uma mesma assinatura (para maiores detalhes acerca de segurança e ataques em esquemas de assinaturas, retorne a Seção 2.4.1). Caso isto ocorra, teríamos ainda que $\operatorname{VerIFICA}_{s k}\left(M, \operatorname{AssinA}_{s k}\left(H\left(x_{1}\right)\right)\right)=$ $\operatorname{VeRIFICA}_{s k}\left(M, \operatorname{AssinA}_{s k}\left(H\left(x_{2}\right)\right)\right)=1$, ou seja, o algoritmo de verificação aceitaria as assinaturas, ferindo, também, os princípios de autenticidade e irretratabilidade, essenciais a esquemas de assinaturas digital.

Para ilustrar o quão prejudicial pode ser utilizar uma função hash inadequada, pensemos em nosso aprimoramento. Suponha que em vez de utilizarmos o SHA-3 de 512 bits (que tem sua segurança estimada em $\left.2^{256}\left[\mathrm{jCPB}^{+} 12\right]\right)$ utilizássemos o SHA-1. Desta forma, um adversário de nosso 
criptossistema poderia forjar uma segunda assinatura com menos de $2^{33}$ operações $^{1}$ sem atacar diretamente o nosso protocolo. Portanto, acreditamos que substituir a função SHA-1 pelo SHA-3 seja imprescindível para mantermos nosso esquema aprimorado dentro da segurança estimada. Sendo que, conforme pode ser vislumbrado nas Tabelas 6.1 e 6.2, a adesão ao SHA-3 além de ajudar na segurança do Quartz Aprimorado também proporciona um ganho de eficiência no momento de inicializarmos os vetores. Tal melhoria ocorre em virtude da não realização de operações iteradas e também por não concatenar suas saídas para obter vetores do tamanho estabelecido pelo algoritmo de assinatura.

\section{Modificação proposta por Sakumoto et al. em 2011}

Sabemos que a necessidade de pessoas comunicarem-se de forma sigilosa através de um canal inseguro fez com que a criptografia nascesse. Sabemos, também, que no início ela era encarada mais como uma arte: a arte de comunicar-se secretamente através de canais públicos; do que como uma ciência. Sendo seu desenvolvimento essencialmente empírico, ou seja, um criptossistema era bom porque ninguém sabia como quebrá-lo, e no dia em que alguém conseguisse quebrá-lo, ele deixaria de ser adequado. Desta forma, tínhamos que a segurança de um sistema criptográfico estava primeiramente ligada ao "segredo" em torno de sua construção do que na intratabilidade de seu problema. No entanto, nas últimas décadas, a criptografia vem mudando cada vez mais, alterando o seu status de uma arte para o de uma ciência, de maneira que um pesquisador possa avaliar a segurança provida por um criptossistema e que um usuário possa confiar seus segredos a um esquema baseado não na intuição dos que o criaram mas sim em evidências matemáticas [CDD07]. Neste sentido, temos que as provas de segurança (fundamentadas basicamente por lemas, axiomas e teoremas, oriundos da matemática e teoria da computação) também seguem em constante evolução, e a cada novo protocolo desenvolvido, pesquisadores se esforçam para fundamentar a segurança deste criptossistema em argumentos que comprovem sua intratabilidade.

No Quartz, este "ciclo evolucionário" não foi diferente, pois inicialmente (no artigo que submetia este novo esquema de assinatura ao NESSIE [PCG01b, CGP01]) seus autores apenas justificavam a dificuldade de quebrar seu protocolo, não fornecendo nenhuma prova matemática devido a falta de modelo apropriado para demonstrar a segurança de criptossistemas baseados em equações multivariáveis quadráticas. Alguns anos depois, o primeiro modelo de prova para MPKCs foi formalizado [Cou04], neste trabalho, Courtois apresentava um modelo de prova que estimava a segurança de criptossistemas baseados nesta primitiva quando colocados sob ataques em que o adversário possua apenas a chave pública da vítima [Cou04, pg. 31]. Apesar de ser uma prova matemática, este modelo é considerado "fraco", visto que em cenários reais o adversário facilmente pode obter (através de interceptações, por exemplo) muito mais informações do que somente a chave pública da vítima.

Felizmente, há pouco tempo Sakumoto et al. desenvolveram um novo modelo de prova, demonstrando que criptossistemas baseados nas trapdoors HFE e UOV podem ser existencialmente seguros contra ataques adaptativos de mensagem escolhida [SSH11a]. Este novo modelo de prova é considerado "forte", pois dá amplos poderes ao adversário e exige o seu nível de sucesso mais baixo; além de também estar alinhado com o que fora estipulado na Definição 2.4.1.1 desta dissertação. No entanto, para utilizarmos este modelo na demonstração de segurança de um criptossistema baseado no HFE,

\footnotetext{
${ }^{1}$ Segurança contra colisões estimada para o SHA-1 [WYY05].
} 
como é o caso do Quartz Aprimorado, necessitamos concatenar um salt a mensagem antes de empregarmos a função de hash nesta mesma mensagem afim de obtermos assinaturas uniformemente distribuídas [SSH11a]. Esta modificação acarreta um aumento no tamanho final da assinatura, em nosso modelo aprimorado este aumento é de 96 bits, porém, mesmo com este aumento no tamanho final da assinatura, consideramos viável a adesão desta modificação já que nosso esquema aprimorado poderá ser provado como sendo "fortemente infalsificável" em vez de somente "infalsificável", como ocorre no Quartz Original.

\subsection{Estimativa de Segurança}

Nesta seção, iremos inicialmente olhar para a probabilidade de recuperar a chave privada do Quartz (HFEv-) através do melhor ataque conhecido na atualidade. Em seguida, como a modificação proposta por Sakumoto et al. foi aderida por nosso aprimoramento, buscaremos determinar a segurança exata de nosso criptossistema de acordo com o novo modelo de prova proposto pelos mesmos autores. Por fim, visando demonstrar que o ataque de Joux e Martinet é computacionalmente inviável em nosso aprimoramento, calcularemos quantas computações e quantas chamadas ao oráculo aleatório serão necessárias para que um adversário derive uma segunda assinatura caso ele possua um par (mensagem, assinatura) válido.

\section{Melhor ataque ao Quartz (HFEv-)}

Discutimos anteriormente na Seção 4.3 que até o momento não foi desenvolvido nenhum ataque ao Quartz capaz de recuperar a chave privada (inverter a função $G$ ) com um esforço menor do que o Ataque por Força Bruta, ou seja, a trapdoor HFEv- permanece segura [DGS06a, BBD09, LFPW11].

Além disto, em 2010, Bouillaguet et al. apresentaram um algoritmo para resolução de equações polinomiais em $\mathbb{F}_{2}$ que pode ser empregado para solucionar qualquer instância de problema $\mathcal{M Q}$ onde, evidentemente, $q=2$. Neste algoritmo, em vez de utilizarem bases de Gröbner (principalmente devido a necessidade exponencial de memória para sua implementação) Bouillaguet et al. resolveram utilizar uma abordagem diferente, baseando-se no algoritmo padrão de Busca Exaustiva $\left[\mathrm{BCC}^{+} 10\right]$. Com este novo método os autores deste trabalho demonstraram ser possível encontrar todos os zeros de um polinômio de grau $d$ com $n$ variáveis efetuando apenas $d .2^{n}$ operações binárias $\left[\mathrm{BCC}^{+} 10\right.$, Teorema 1]. Como este é o algoritmo para resolução de equações polinomiais através da Busca Exaustiva mais rápido da atualidade, então, podemos conjecturar que um adversário conseguirá inverter a função pública $G$ com uma probabilidade estimada em:

$$
\epsilon^{\prime} \leq \frac{1}{d .2^{n}}
$$

Desta forma, com os parâmetros adotados em nossa proposta de aprimoramento, temos que:

$$
\epsilon^{\prime} \leq \frac{1}{129.2^{231}} \approx 2^{-238}
$$




\section{Estimativa de segurança segundo Sakumoto et al.}

No apêndice A de [SSH11a], onde consta a demonstração dos Teoremas formulados por Sakumoto et al., os autores mostram que a probabilidade do algoritmo de inversão, simulado pelo oráculo aleatório, encontrar a inversa da assinatura $S$ utilizando chamadas a este oráculo aleatório e a chave pública $G$ é de aproximadamente $\epsilon\left(1-\left(q_{\text {hash }}+q_{\text {assina }}\right) q_{\text {assina }} 2^{-g}\right) /\left(q_{\text {hash }}+q_{\text {assina }}+1\right)$. Onde $q_{\text {hash }}$ e $q_{\text {assina }}$ correspondem, respectivamente, a quantidade de consultas aos oráculos de hash e assinatura. E $g$ corresponde ao tamanho do salt aleatório inserido na inicialização de vetores do algoritmo proposto, lembrando que $g=\log \left(q_{\text {assina }}\left(q_{\text {hash }}+q_{\text {assina }}\right)\right)$-bits.

Como, em provas de esquemas de assinatura digital normalmente são considerados $q_{\text {assina }}=2^{30}$ e $q_{\text {hash }}=2^{60}$ [BR96]. Então, obtemos [SSH11a, Teorema 2]:

$$
\epsilon=\frac{\epsilon^{\prime}\left(q_{\text {hash }}+q_{\text {assina }}+1\right)}{\left(1-\left(q_{\text {hash }}+q_{\text {assina }}\right) q_{\text {assina }} 2^{-t}\right)} \approx \epsilon^{\prime} \cdot 2^{60}
$$

Assim, utilizando este Teorema que compõe o novo modelo de prova de segurança proposto por Sakumoto et al. e o $\epsilon^{\prime}$ calculado anteriormente, temos que a probabilidade de um adversário recuperar a chave privada do Quartz Aprimorado utilizando um oráculo aleatório é de:

$$
\epsilon \approx 2^{-238} \cdot 2^{60} \Longrightarrow \epsilon \approx 2^{-178}
$$

\section{Estimativa de esforço para o ataque de Joux e Martinet}

Discutimos no decorrer deste trabalho que a recuperação da chave privada através da inversão da função pública $G$ não é a única abordagem que um adversário pode adotar no momento de atacar um esquema de assinatura digital (veja Seção 2.4.1). Utilizando outra destas possíveis abordagens, vimos que Joux e Martinet em 2003 desenvolveram um poderoso ataque ao Quartz; neste trabalho, os autores - baseados em axiomas do Ataque pelo Paradoxo de Aniversário - provaram que este criptossistema é maleável, demonstrando que caso o adversário possua um par (mensagem, assinatura) válido, ele conseguirá obter uma segunda assinatura com $2^{m / 2}$ computações e $2^{m / 2}$ chamadas ao oráculo de assinatura, com um método que consiste em encontrar a segunda pré-imagem sem se preocupar com a inversão da função pública $G$ [JM03, Seção 3.2].

Desta forma, com os parâmetros adotados em nossa proposta de aprimoramento, temos que através deste ataque o adversário terá que realizar $2^{224 / 2}=2^{112}$ computações e $2^{224 / 2}=2^{112}$ chamadas ao oráculo de assinatura.

Portanto, como para recuperar a chave privada do Quartz Aprimorado será necessário um esforço maior do que $2^{178}$ e para derivar uma segunda assinatura através do ataque de Joux e Martinet o adversário terá que efetuar mais de $2^{112}$ operações e chamadas ao oráculo de assinatura, podemos concluir que nossa proposta de aprimoramento está dentro das recomendações do NIST [BR11], ou seja, a complexidade dos ataques os tornam computacionalmente inviável. 


\subsection{Comparando o Quartz Aprimorado com outros protocolos}

Visando fornecer mais subsídios ao leitor, para o mesmo possa ponderar sobre a relevância de nossa proposta, na Tabela 5.1, listamos o tamanho das assinaturas de alguns outros esquemas baseados no problema $\mathcal{M Q}$. Além disto, para também haver uma comparação com esquemas de assinatura mais convencionais e já padronizados, incluímos o comprimento das assinaturas do ECDSA e do RSA. Frisamos que as informações listados na referida Tabela tem como referência um nível de segurança de aproximadamente $2^{100}$, sendo tal segurança calculada de acordo com suas fontes, que também encontram-se listadas na Tabela a seguir.

\begin{tabular}{|c|c|c|c|c|c|c|c|}
\hline \multicolumn{2}{|r|}{ Criptossistema } & $q$ & $d$ & $m$ & $n$ & $\begin{array}{c}\text { Tamanho da Assinatura } \\
\text { (em bits) }\end{array}$ & Referência \\
\hline \multirow{5}{*}{ 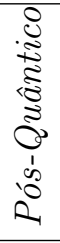 } & CyclicUOV & 256 & 256 & 77 & 77 & 624 & [PBB10a] \\
\hline & Rainbow & 16 & 30 & 58 & 58 & 352 & [PBB10b] \\
\hline & NC-Rainbow & 256 & 17 & 26 & 26 & 672 & [YST12] \\
\hline & CyclicRainbow & 256 & 17 & 26 & 26 & 344 & [PBB10a] \\
\hline & Quartz Aprimorado & 2 & 129 & 224 & 231 & 334 & Nosso \\
\hline$\underset{ت}{.}$ & \multirow{2}{*}{\multicolumn{5}{|c|}{$\begin{array}{l}\text { ECDSA } \\
\text { RSA }\end{array}$}} & 400 & [NIS09] \\
\hline 胥 & & & & & & 2.048 & [BR11] \\
\hline
\end{tabular}

Tabela 5.1: Tamanho das assinaturas de alguns criptossistemas.

Compreendemos que o tamanho da assinatura não é a única métrica a ser avaliada no momento da adesão de um esquema de assinatura digital. Porém, entendemos que este é um quesito importante para a economia de tráfego de rede, além de ser um ponto extremamente forte de nosso aprimoramento. 


\section{Capítulo 6}

\section{Implementação de Referência}

Nossa implementação tem como objetivo comparar o tempo gasto pelo Quartz Original e pelo Quartz Aprimorado durante a inicialização de vetores, geração de chaves, assinatura de mensagens, verificação de assinatura verdadeira e a verificação de uma assinatura falsa; uma vez que estas são operações básicas pertinentes a qualquer esquema de assinatura digital.

Como visamos desenvolver uma implementação de fácil compreensão e também portável, optamos por utilizar a linguagem de programação Java.

Devido ser desenvolvido em Java, destacamos que nos baseamos no Projeto QuartzLight, que tem como autor Christopher Wolf [Wol02b]. Este projeto implementa uma versão mais "frágil" do Quartz [Wol02a], porém, mesmo com esta vulnerabilidade, é interessante para nós devido seus diversos métodos e classes que podem ser re-utilizados para fatorarmos polinômios sobre Corpos Finitos e executarmos operações sobre $G F\left(2^{n}\right)$ e matrizes binárias.

Assim sendo, seguiremos este Capítulo descrevendo nossa implementação de referência e também explicando como foram realizados os testes executados a partir desta implementação; expondo, em seguida, os tempos obtidos nestes testes.

Lembramos ainda, que o código fonte desta implementação está disponível em nossa página pessoal (http://www.ime.usp.br/ ewe/QuartzAprimorado/) para que o mesmo possa ser baixado, alterado e/ou executado conforme a necessidade e interesse de cada usuário.

\subsection{Descrição da implementação}

Observando os algoritmos de geração de chaves, assinatura e verificação (tanto do Quartz original quanto do nosso esquema aprimorado), podemos perceber que estes algoritmos utilizam geradores pseudoaleatórios, funções de hash e operadores algébricos que necessariamente não precisam ser implementados juntamente com eles, mas, podem ser acoplados de acordo com as necessidades e arquitetura de cada cenário que venham a ser empregados.

Neste sentido, visando não ultrapassar o escopo de nosso trabalho, destacamos que utilizamos algumas bibliotecas e aplicações de terceiros. Mais especificamente, ressaltamos que para gerarmos os bits pseudoaleatórios criptograficamente seguros utilizamos a biblioteca Security do Java SE 7 [Ora13b]; lembrando que tais bits são necessários para definirmos os coeficientes de $F_{V}$, determinarmos os elementos das matrizes que compõem as transformações afim, e também selecionarmos $\Delta$ e $\Gamma$. 
Já para obtermos os resultados das funções de hash SHA-1 e SHA-3, utilizamos bibliotecas criptográficas da linguagem de programação Python [Pyt13a, Pyt13b]. Salientamos que optamos por utilizar estas bibliotecas devido à inexistência de implementações do SHA-3 em Java. Assim, buscando manter as mesmas características no momento da aferição de tempo gasto na inicialização de vetores do Quartz Original e do Quartz Aprimorado, selecionamos as referidas bibliotecas oriundas da mesma linguagem de programação. Frisando que, assim como o Java, a linguagem de programação Python também é altamente portável, além de poder ser integrada a aplicações de outras linguagens de programação.

Além disto, conforme abordado anteriormente, sabemos que o projeto QuartzLight pode ser reutilizado para fatorarmos polinômios sobre Corpos Finitos e executarmos operações sobre $G F\left(2^{n}\right)$ e matrizes binárias [Wol02b], desta forma, segue que apenas adaptamos este projeto - através da reescrita de métodos e alteração de parâmetros - para não desprendermos tempo implementando novamente estas funcionalidades.

Ainda sobre esta temática, advertimos que nenhuma "nova" ferramenta de cronômetro foi desenvolvida para aferirmos os tempos de execução de nossa implementação. Ao invés disto nós utilizamos chamadas a métodos estabelecidos na Classe System, nativa do Java [Ora13a], para compararmos o tempo gasto pelos algoritmos do Quartz Original e do Quartz Aprimorado.

Por fim, a esta descrição de nossa implementação, somente acrescentamos que procuramos fazer tal implementação da forma mais didática possível (comentando seu código fonte e inserindo referências a textos e artigos), seguindo fielmente a descrição contida nos Capítulos 4 e 5 desta dissertação. Isto porque, com esta implementação, não visamos somente a eficiência, mas também buscamos comprovar sua viabilidade em cenários "reais" e auxiliar o leitor na compreensão deste criptossistema.

\subsection{Testes realizados}

Utilizando nossa implementação do Quartz em sua versão original e também em sua versão aprimorada - proposta por este trabalho -, simulamos e realizamos os testes de coleta dos tempos de execução dos algoritmos de geração de chaves, inicialização de vetores, assinatura e verificação (tanto de assinaturas legítimas quanto de assinaturas falsas).

Para esta simulação, utilizamos dois computadores distintos. Sendo eles:

Brucutu: processador Intel Xeon E5645 de 2,4 GHz $\times 24$, com 128 GB de memória RAM, utilizando o Sistema Operacional Linux Debian 7.0 (wheezy), OpenJDK 1.6.0_27 IcedTea e Python 2.7.3;

Ewerton-PC: processador Intel Core i7-2670QM de 2,2 GHz, com 8 GB de memória RAM, utilizando o Sistema Operacional Linux Ubuntu 12.10 (quantal), Java 1.7.0_25 da Oracle e Python 2.7.3.

Nesses computadores, rodamos os testes em apenas uma linha de execução (thread) e efetuamos um total de 1.000 repetições para cada um dos quesitos analisados, coletando o tempo de barreira (horário em que a função encerrou seu processamento menos o horário inicial da chamada da função) em cada uma destas repetições. Com isto, nós obtivemos o intervalo e a média de tempo gasto em cada um destes computadores. 


\subsection{Tempos obtidos nos testes}

Apresentamos nas Tabelas 6.1 e 6.2 o intervalo e a média de tempo gasto pelo Quartz Original e pelo Quartz Aprimorado para inicializar os vetores, gerar as chaves, assinar as mensagens e verificar as assinaturas verdadeiras e falsas em cada um dos computadores utilizados durante os nossos testes. Optamos por apresentar o intervalo em vez da variância ou desvio padrão pois acreditamos que esta medida nos dá uma melhor visão de quanto os tempos no modelo original do Quartz variam.

\begin{tabular}{|c|c|c|c|c|}
\hline & & & Quartz Original & Quartz Aprimorado \\
\hline \multirow{4}{*}{ Inicialização dos Vetores } & & Média (ms) & 158 & - \\
\hline & SHA-1 & Intervalo (ms) & $121-236$ & - \\
\hline & SHA 3 & Média (ms) & - & 40 \\
\hline & SHA-3 & Intervalo (ms) & - & $34-57$ \\
\hline \multirow{2}{*}{ Geração de Chaves } & & 16,9 & 75,1 \\
\hline & \multicolumn{2}{|c|}{ Intervalo (s) } & $16,5-17,7$ & $74,2-77,8$ \\
\hline \multirow{2}{*}{ Assinatura } & \multirow{2}{*}{\multicolumn{2}{|c|}{$\begin{array}{c}\text { Média (s) } \\
\text { Intervalo (s) }\end{array}$}} & 5,2 & 19,1 \\
\hline & & & $4,4-27,2$ & $18,9-20,0$ \\
\hline \multirow{2}{*}{ Verificação de Assinatura } & \multirow{2}{*}{\multicolumn{2}{|c|}{$\begin{array}{c}\text { Média (ms) } \\
\text { Intervalo }(\mathrm{ms})\end{array}$}} & 3.814 & 18 \\
\hline & & & $4-3.927$ & $17-40$ \\
\hline \multirow{2}{*}{ Verificação de Assinatura Falsa } & \multirow{2}{*}{\multicolumn{2}{|c|}{$\begin{array}{c}\text { Média }(\mathrm{ms}) \\
\text { Intervalo }(\mathrm{ms})\end{array}$}} & 60.074 & 180 \\
\hline & & & $52.067-62.258$ & $159-194$ \\
\hline
\end{tabular}

Tabela 6.1: Tempos obtidos durante a realização dos testes no Brucutu.

Acreditamos que a discussão levantada na Seção 5.2 - durante a análise da proposta de nosso aprimoramento - seja suficiente para justificar os tempos obtidos em nossos testes. Ou seja, a substituição do SHA-1 pelo SHA-3 além de ajudar na segurança do Quartz Aprimorado também proporcionou um ganho de eficiência de aproximadamente $75 \%$ no momento da Inicialização dos Vetores; sendo que tal melhoria ocorreu principalmente devido a não realização de operações iteradas e também por não concatenar suas saídas para obter vetores do tamanho estabelecido pelo algoritmo de assinatura.

\begin{tabular}{|c|c|c|c|c|}
\hline & & & Quartz Original & Quartz Aprimorado \\
\hline \multirow{4}{*}{ Inicialização dos Vetores } & & Média (ms) & 62 & - \\
\hline & SHA-1 & Intervalo (ms) & $47-130$ & - \\
\hline & SHA 2 & Média (ms) & - & 15 \\
\hline & SHA-3 & Intervalo (ms) & - & $12-44$ \\
\hline \multirow{2}{*}{ Geração de Chaves } & & Média (s) & 18,5 & 87,0 \\
\hline & & tervalo (s) & $15,6-26,8$ & $72,2-108,3$ \\
\hline \multirow{2}{*}{ Assinatura } & & Média (s) & 5,4 & 16,6 \\
\hline & & tervalo $(\mathrm{s})$ & $4,3-169,2$ & $16,5-25,6$ \\
\hline \multirow{2}{*}{ Verificação de Assinatura } & & édia (ms) & 164 & 35 \\
\hline & Int & ervalo (ms) & $136-2.447$ & $33-53$ \\
\hline \multirow{2}{*}{ Verificação de Assinatura Falsa } & \multirow{2}{*}{\multicolumn{2}{|c|}{$\begin{array}{c}\text { Média (ms) } \\
\text { Intervalo }(\mathrm{ms})\end{array}$}} & 43.248 & 99 \\
\hline & & & $36.197-54.591$ & $96-145$ \\
\hline
\end{tabular}

Tabela 6.2: Tempos obtidos durante a realização dos testes no Ewerton-PC.

Além disso, observamos que os algoritmos de Geração de Chaves e Assinatura têm sua eficiência prejudicada devido a nossa escolha de parâmetros (cerca de 360 \% acrescido no tempo de Geração de Chaves e $240 \%$ na Assinatura), isto porque tal escolha ocasionou um aumento significativo na quantidade de objetos e instâncias a serem manipuladas por nossa implementação.

Contudo, a Verificação de Assinatura de nosso aprimoramento mostrou-se significativamente melhor do que a do modelo original, sendo possível observar um ganho de 99,5\% (no Brucutu) e cerca de 78 \% (no Ewerton-PC) durante a verificação de assinaturas legítimas e aproximadamente 
99,7\% quando trata-se de assinaturas falsas; lembrando que no Quartz Aprimorado, durante a resolução da função $G$, são testadas até 4.096 vezes menos hipóteses de utilização da chave pública do que no Quartz Original. 


\section{Capítulo 7}

\section{Conclusão}

Nossa principal contribuição nesta pesquisa foi a apresentação de um novo protocolo de assinatura digital, baseado em sistemas polinomiais multivariáveis quadráticos. Nossa proposta foi construída a partir do esquema de assinatura digital Quartz, submetido ao NESSIE por Patarin, Courtois e Goubin [PCG01b, CGP01], utilizando - da mesma forma que o protocolo original - a trapdoor HFE como base para a construção de nossa função $\mathcal{M} \mathcal{Q}$, porém adotando apenas uma transformação afim no momento da assinatura e da geração de chaves, além de substituir a função de hash SHA-1, utilizada no esquema original, por uma função alinhada aos padrões de segurança atuais.

Neste trabalho, iniciamos explanando as definições e conceitos imprescindíveis à compreensão do Quartz, para posteriormente provermos uma breve e sintética visão dos MPKCs. Em seguida, examinamos o Quartz Original e apresentamos nossa proposta de aprimoramento. Nesse ponto, discutimos o impacto das adaptações sugeridas e estimamos a segurança de nosso modelo aprimorado. Destacamos que para realizar esta estimativa, utilizamos o novo modelo de prova proposto por Sakumoto et al. em 2011 [SSH11a], assim, comprovamos a segurança do Quartz Aprimorado contra ataques adaptativos de mensagem escolhida que realizem chamadas ao oráculo aleatório. Lembrando que este tipo de demonstração não seria possível sem as modificações incluídas em nosso aprimoramento.

Como resultado, obtivemos um criptossistema com um nível de segurança estimado em $2^{112}$, contra os $2^{50}$ do protocolo original. Nossa proposta apresenta, ainda, um ganho de eficiência na inicialização dos vetores que serão utilizados pelo algoritmo de assinatura; para ser mais específico, através de nossos testes - realizados a partir de nossa implementação de referência - constatamos um ganho de aproximadamente $75 \%$. Além disto, mostramos que no Quartz Aprimorado, durante a resolução da função $G$, são testadas até 4.096 vezes menos hipóteses de utilização da chave pública, quando comparado com o Quartz Original. Todavia, observamos que devido aos parâmetros escolhidos para nosso criptossistema, houve um aumento significativo no tamanho das chaves, fato que também acarretou uma perda de eficiência nos algoritmos de geração de chaves e assinatura.

Contudo, consideramos que este trabalho atendeu a finalidade e expectativas às quais se propôs, apresentando uma implementação do Quartz (tanto em seu modelo original quanto aprimorado) que comprova sua viabilidade em cenários "reais" e contribuindo com as pesquisas realizadas na área de criptografia pós-quântica. No entanto, ressaltamos que o mesmo é apenas uma pequena parcela do que pode ser pesquisado em relação a este assunto, já que as discussões em relação a criptossistemas resistentes até mesmo a computadores quânticos é uma recente fonte de pesquisa que começa a ser explorada. 


\subsection{Trabalhos Futuros}

Em virtude do tamanho das chaves de nosso aprimoramento, acreditamos que uma possível extensão para nosso trabalho seria pesquisar uma maneira de reduzi-las. Neste sentido, acreditamos que dois recentes artigos possam contribuir, inicialmente, nestas investigações. O primeiro deles é o estudo desenvolvido por Petzoldt, Bulygin e Buchmann em 2010; nele, os autores apresentam uma nova forma de gerar as chaves do UOV e do Rainbow, reduzindo em até $62 \%$ o tamanho da chave pública destes criptossistemas, através de uma construção que utiliza Anéis Cíclicos [PBB10a]. À outra pesquisa que julgamos interessante para extensão de nosso trabalho foi desenvolvida por Yasuda, Sakurai e Takagi em 2012; neste artigo, os autores utilizam Anéis Não Comutativos para obter uma redução de aproximadamente $75 \%$ no tamanho das chaves privadas do Rainbow, além de diminuírem o tempo de assinatura em cerca de $34 \%$ [YST12]. Frisamos que, até o momento, não encontramos nenhuma pesquisa que analisasse o impacto dessas novas formas de gerar chaves sendo aplicadas ao HFE. Porém, conjecturamos que elas possam ser aproveitadas, visto que as trapdoors em que foram aplicadas são da mesma classe de criptossistemas do HFE (MPKCs), sendo necessário, então, verificar seu impacto na segurança e calcular o tamanho das assinaturas geradas neste possível novo criptossistema derivado da junção destas ideias, ou seja, seria necessário estimar o trade-off neste novo cenário.

Outra sugestão para trabalhos futuros seria buscar uma prova de segurança mais eficiente (tight) no modelo do oráculo aleatório para protocolos baseados na trapdoor HFE. Isto porque, conforme vimos durante a estimativa de segurança do Quartz Aprimorado, com o modelo de prova proposto por Sakumoto et al. [SSH11a] perdemos em média 60 bits de segurança (para maiores detalhes, retorne a Seção 5.3). Apesar de ser imprescindível, este modelo de prova não pode ser considerado eficiente já que a probabilidade de inversão da função pública sofre um decréscimo acentuado. Entretanto, entendemos que este aperfeiçoamento de modelos de prova é natural (e necessário) visto que em alguns outros esquemas de assinatura isto já aconteceu. Por exemplo, no protocolo Rabin-Williams, inicialmente, os modelos de prova de segurança adicionavam um salt aleatório enorme às mensagens e algumas dezenas de bits de segurança eram perdidos; com o passar dos anos, novas pesquisas foram realizadas e novos modelos de prova foram apresentados, desta forma, à medida que uma nova prova era apresentada, o tamanho do salt aleatório era reduzido e menos bits de segurança eram perdidos; seguindo esta evolução, em 2012, Magri comprovou, sem adicionar nenhum salt, que quebrar o protocolo Rabin-Williams é equivalente a solucionar o problema em que ele se baseia, ou seja, nenhum bit de segurança é perdido [Mag12]. 


\section{Apêndice A}

\section{Fundamentos Matemáticos}

O objetivo deste Apêndice é introduzir o leitor à teoria de corpos finitos. Não intencionamos, nem poderíamos, esgotar toda a teoria matemática interligada a este assunto, desta forma, caso seja necessário, sugerimos que o leitor consulte [DI82], [MP07], [HPS08] e [Sho08] para obter informações mais completas e detalhadas.

\section{A.1 Grupo}

Um Grupo $\mathbb{G}$ é composto pelo par $(\mathbf{G}, \bullet)$, onde $\mathbf{G}$ é um conjunto não vazio e $\bullet$ é uma operação binária definida sobre os elementos de $\mathbf{G}$, sendo que para $\mathbb{G}$ ser considerado um Grupo ele deve possuir as seguintes propriedades [DI82]:

Associatividade: $\forall a, b, c \in \mathbf{G}:(a \bullet b) \bullet c=a \bullet(b \bullet c)$. Ou seja, a operação $\bullet$ é associativa quando é irrelevante a ordem pela qual agrupamos as operações $\bullet$, isto quando ela aparecer mais de uma vez em uma mesma expressão;

Elemento Neutro: Existe um elemento $i \in \mathbf{G}$, também chamado de identidade, tal que $\forall a \in \mathbf{G}: a \bullet i=i \bullet a=a$. Ou seja, quando $i$ for um dos elementos envolvidos na operação, o resultado será igual ao outro elemento;

Elemento Simétrico ou Inverso: Para cada elemento $a \in \mathbf{G}$ existe um elemento $\bar{a} \in \mathbf{G}$, chamado de inverso de $a$, tal que $a \bullet \bar{a}=\bar{a} \bullet a=i$, sendo $i$ o elemento neutro anteriormente citado.

Como consequência destas propriedades temos que:

1. $\mathbf{G}$ possui apenas um elemento neutro, senão, caso houvessem dois elementos $i, i^{\prime} \in \mathbf{G}$, ambos sendo elementos neutro, então teríamos $i=i \bullet i^{\prime}=i^{\prime}$, o que não é possível;

2. Cada elemento de $\mathbf{G}$ possui um e apenas um elemento simétrico. Pois, sejam $\bar{a}$ e $\bar{a}^{\prime}$ dois elementos simétricos de $a$, logo, por definição, teríamos que $\bar{a}=\bar{a} \bullet i=\bar{a} \bullet\left(a \bullet \bar{a}^{\prime}\right)=$ $(\bar{a} \bullet a) \bullet \bar{a}^{\prime}=i \bullet \bar{a}^{\prime}=\bar{a}^{\prime}$, ou seja $\bar{a}=\bar{a}^{\prime}$, tendo $a$ apenas um elemento simétrico.

Caso a operação $\bullet$ seja comutativa, ou seja, $\forall a, b \in \mathbf{G}: a \bullet b=b \bullet a$, chamamos este grupo de Grupo Comutativo ou Abeliano. 
Quando a lei de composição considerada for uma "adição" diremos que o grupo em questão é um Grupo Aditivo ao passo que se a lei for uma "multiplicação" nos referiremos a ele como Grupo Multiplicativo [DI82]. Na Tabela A.1 vemos os símbolos comumente utilizados, de acordo com seus tipos de grupos.

\begin{tabular}{l|c|c|c}
\hline \multicolumn{1}{c|}{ Grupo } & Operação • & Elemento Neutro $i$ & Inverso de $a$ \\
\hline Multiplicativo & $*$ & 1 & $a^{-1}$ \\
Aditivo & + & 0 & $-a$ \\
\hline
\end{tabular}

Tabela A.1: Símbolos utilizados em cada tipo de Grupo.

Chamamos de ordem de um grupo a quantidade de elementos que compõem o conjunto $\mathbf{G}$, ou seja, ordem $=|\mathbf{G}|$. Caso $\mathbf{G}$ seja infinito, diremos então que o grupo possui ordem infinita. Na literatura, normalmente os autores se referem simplesmente a $\mathbf{G}$ para citar tanto o grupo propriamente dito, quanto o conjunto que o compõe.

\section{A.2 Anel}

Um Anel $\mathbb{R}$ é composto pela tripla $(\mathbf{R},+, *)$, onde $\mathbf{R}$ é um conjunto não vazio e + e $*$ são duas operações binárias, adição e multiplicação, sendo que para $\mathbb{R}$ ser considerado um Anel ele deve possuir as seguintes propriedades [Sho08]:

Grupo Abeliano Aditivo: O par $(\mathbf{R},+)$ forma um Grupo Abeliano;

Associatividade de *: A operação * é associativa. A ordem pela qual agrupamos as operações de multiplicação, quando ela aparece mais de uma vez em uma expressão, é irrelevante, ou seja, $\forall a, b, c \in \mathbf{R}:(a * b) * c=a *(b * c)$;

Distributividade: $\forall a, b, c \in \mathbf{R}: a *(b+c)=(a * b)+(a * c)$. Ou seja, a operação $*$ é distributiva sobre + .

Temos, ainda, Anéis com propriedades adicionais e nomes especiais, podendo $\mathbb{R}$ ser um [MP07]:

Anel com Identidade: Existe um elemento $i \in \mathbf{R}$, tal que $a * i=i * a=a$ para todo $a \in \mathbf{R}$. Neste caso, $i$ é chamado de elemento neutro da multiplicação, podendo também ser denotado simplesmente por 1 ;

Anel Comutativo: $\forall a, b \in \mathbf{R}: a * b=b * a$. Ou seja, a operação $*$ é comutativa;

Domínio de Integridade: Se $\mathbb{R}$ é um anel comutativo com identidade e se $\forall a, b \in \mathbf{R}: a * b=$ 0 , tem-se que $a=0$ ou $b=0$;

Anel com Divisão: Se os elementos não nulos de $\mathbf{R}$ formam um grupo sob a multiplicação.

\section{A.3 Corpo}

Dizemos que um Corpo $\mathbb{F}$ é um anel comutativo com divisão [MP07]. Logo, todo elemento não nulo possui um elemento inverso com relação a multiplicação, ou seja, $\forall a \in \mathbf{F}$, existe $a^{-1} \in \mathbf{F}$ : $a * a^{-1}=1$. 
Quando o conjunto dos elementos é finito, chamamos $\mathbb{F}$ de Corpo Finito. Corpos Finitos também são chamados de Corpos de Galois em homenagem ao matemático francês Évariste Galois, que contribuiu significativamente para a teoria de corpos finitos.

Em criptografia, normalmente utilizamos Corpos Finitos que podem possuir ordem somente no formato $p^{n}$, onde $p$ é um primo, chamado de característica do Corpo, e $n$ é um inteiro positivo [Sho08, Teoremas 7.5 e 7.7].

\section{A.4 Espaço Vetorial}

Um Espaço Vetorial $\mathbb{V}$ é composto pela tupla $(\mathbf{V},+, *, \mathbb{F})$, onde $\mathbf{V}$ é um conjunto não vazio, + e $*$ são duas operações binárias, adição e multiplicação, sendo + definida sobre os elementos de $\mathbf{V}$ e $*$ definida por $\mathbb{F} \times \mathbf{V} \mapsto \mathbf{V}$ e $\mathbb{F}$ é um corpo. Normalmente, os elementos de $\mathbf{V}$ são chamados de vetores e os elementos do conjunto de $\mathbb{F}$ de escalares. Sendo que para $\mathbb{V}$ ser considerado um Espaço Vetorial ele deve possuir as seguintes propriedades [Sho08]:

Grupo Abeliano Aditivo: O par $(\mathbf{V},+)$ forma um Grupo Abeliano;

Associatividade de $*$ : A operação $*$ é associativa. A ordem pela qual agrupamos as operações de multiplicação, quando ela aparece mais de uma vez em uma expressão, é irrelevante, ou seja, $\forall a, b \in \mathbb{F}$ e $\forall v \in \mathbf{V}: a *(b * v)=(a * b) * v$;

Distributividade: $\forall a \in \mathbb{F}$ e $\forall u, v \in \mathbf{V}: a *(u+v)=(a * u)+(a * v)$. Ou seja, a operação $*$ é distributiva sobre +;

Distributividade sobre adição no Corpo $\mathbb{F}: \forall a, b \in \mathbb{F}$ e $\forall v \in \mathbf{V}:(a+b) * v=(a * v)+(b * v)$. Ou seja, a operação ast é distributiva sobre + no Corpo $\mathbb{F}$;

Elemento Neutro de $*: \forall v \in \mathbf{V}: 1 * v=v$. Isto é, seja 1 o elemento neutro de $\mathbb{F}$, então, quando ele for um dos elementos envolvidos na operação $*$, o resultado será igual ao elemento vetor.

Comumente denotamos espaço vetorial pelo símbolo do corpo elevado ao número de elementos de cada vetor, ou seja, $\mathbb{F}^{n}$ onde $n$ representa o número de elementos do vetor. 
APÊNDICE A 


\section{Referências}

$\left[\mathrm{AFI}^{+} 04\right]$ Gwénolé Ars, Jean-Charles Faugère, Hideki Imai, Mitsuru Kawazoe e Makoto Sugita. Comparison between XL and Gröbner Basis Algorithms. Em PilJoong Lee, editor, Advances in Cryptology - ASIACRYPT 2004, volume 3329 of Lecture Notes in Computer Science, páginas 338-353. Springer Berlin Heidelberg, 2004. Citado na pág. 22

[BBD09] Daniel J. Bernstein, Johannes Buchmann e Erik Dahmen, editors. Post-Quantum Cryptography. Springer, 2009. Citado na pág. 2, 13, 14, 15, 16, 18, 19, 20, 27, 30, 35, 37, 42, $46,47,50$

$\left[\mathrm{BCC}^{+} 10\right]$ Charles Bouillaguet, Hsieh-Chung Chen, Chen-Mou Cheng, Tung Chou, Ruben Niederhagen, Adi Shamir e Bo-Yin Yang. Fast Exhaustive Search for Polynomial Systems in $\mathbb{F}_{2}$. Em Stefan Mangard e François-Xavier Standaert, editors, Cryptographic Hardware and Embedded Systems, CHES 2010, volume 6225 of Lecture Notes in Computer Science, páginas 203-218. Springer Berlin Heidelberg, 2010. Citado na pág. 50

$\left[\mathrm{BCD}^{+} 04\right]$ Johannes Buchmann, Carlos Coronado, Martin Döring, Daniela Engelbert, Christoph Ludwig, Raphael Overbeck, Arthur Schmidt, Ulrich Vollmer e Ralf-Philipp Weinmann. Post-Quantum Signatures. Cryptology ePrint Archive, Report 2004/297. http:/ / eprint. iacr.org/2004/297, 2004. Último acesso em 25/07/2013. Citado na pág. 2

[BERW08] Andrey Bogdanov, Thomas Eisenbarth, Andy Rupp e Christopher Wolf. Time-area Optimized Public-key Engines: $\mathcal{M Q}$-Cryptosystems as Replacement for Elliptic Curves? Em Elisabeth Oswald e Pankaj Rohatgi, editors, Cryptographic Hardware and Embedded Systems - CHES 2008, volume 5154 of Lecture Notes in Computer Science, páginas 45-61. Springer Berlin Heidelberg, 2008. Citado na pág. 2, 13, 47

[BFFP11] Charles Bouillaguet, Jean-Charles Faugère, Pierre-Alain Fouque e Ludovic Perret. Practical Cryptanalysis of the Identification Scheme Based on the Isomorphism of Polynomial with One Secret Problem. Em Dario Catalano, Nelly Fazio, Rosario Gennaro e Antonio Nicolosi, editors, Public Key Cryptography - PKC 2011, volume 6571 of Lecture Notes in Computer Science, páginas 473-493. Springer Berlin Heidelberg, 2011. Citado na pág. $16,19,46$

[BFMR11] Charles Bouillaguet, Pierre-Alain Fouque e Gilles Macario-Rat. Practical key-recovery for all possible parameters of SFLASH. Cryptology ePrint Archive, Report 2011/271. http://eprint.iacr.org/2011/271, 2011. Último acesso em 10/06/2013. Citado na pág. 16, 19,21

[BFP12] Luk Bettale, Jean-Charles Faugère e Ludovic Perret. Cryptanalysis of HFE, multi-HFE and variants for odd and even characteristic. Designs, Codes and Cryptography, páginas 1-52, 2012. Citado na pág. 21, 35

[BPB10] Stanislav Bulygin, Albrecht Petzoldt e Johannes Buchmann. Towards provable security of the Unbalanced Oil and Vinegar signature scheme under direct attacks. Cryptology ePrint Archive, Report 2010/420. http://eprint.iacr.org/2010/420, 2010. Último acesso em 11/06/2013. Citado na pág. 21 
[BR96] Mihir Bellare e Phillip Rogaway. The exact security of digital signatures: How to sign with RSA and Rabin. Em U. Maurer, editor, Advances in Cryptology - EUROCRYPT 96 Proceedings, volume 1070 of Lecture Notes in Computer Science, páginas 399-416. Springer-Verlag, 1996. Citado na pág. 38, 51

[BR11] Elaine Barker e Allen Roginsky. NIST Special Publication 800-131a - Transitions: Recommendation for Transitioning the Use of Cryptographic Algorithms and Key Lengths. Relatório técnico, National Institute of Standards and Technology, NIST, U.S. Department of Commerce, Washington DC. http://csrc.nist.gov/publications/ nistpubs/800-131A/sp800-131A.pdf, 2011. Último acesso em 09/07/2013. Citado na pág. iii, v, 35, 46, 51, 52

[BRA08] BRASIL. Decreto $\mathrm{n}^{\circ}$ 6.583, de 29 de setembro de 2008, 2008. Promulga o Acordo Ortográfico da Língua Portuguesa, assinado em Lisboa, em 16 de dezembro de 1990. Citado na pág. 10

[Buc65] Bruno Buchberger. An Algorithm for Finding the Basis Elements in the Residue Class Ring Modulo a Zero Dimensional Polynomial Ideal (German). Tese de Doutorado, Institute of Mathematics, University of Innsbruck (English Translation: J. of Symbolic Computation, Special Issue on Logic, Mathematics, and Computer Science: Interactions. Volume 41, Number 3-4, Pages 475-511, 2006), 1965. Citado na pág. 21

[BWP04] An Braeken, Christopher Wolf e Bart Preneel. A study of the security of Unbalanced Oil and Vinegar signature schemes. Cryptology ePrint Archive, Report 2004/222. http: //eprint.iacr.org/2004/222, 2004. Último acesso em 11/06/2013. Citado na pág. 20, 21

$\left[\mathrm{CCC}^{+}\right.$09] AnnaInn-Tung Chen, Ming-Shing Chen, Tien-Ren Chen, Chen-Mou Cheng, Jintai Ding, EricLi-Hsiang Kuo, FrostYu-Shuang Lee e Bo-Yin Yang. SSE Implementation of Multivariate PKCs on Modern x86 CPUs. Em Christophe Clavier e Kris Gaj, editors, Cryptographic Hardware and Embedded Systems - CHES 2009, volume 5747 of Lecture Notes in Computer Science, páginas 33-48. Springer Berlin Heidelberg, 2009. Citado na pág. 2, 13, 47

[CDD07] Rafael Dantas Castro, Ricardo Dahab e Augusto Jun Devegili. Introdução à segurança demonstrável. Em Anais do VII Simpósio Brasileiro em Segurança da Informacão e de Sistemas Computacionais, páginas 103-152, 2007. Citado na pág. 7, 9, 49

[CET13] CET. Radares. Companhia de Engenharia de Tráfego de São Paulo - CET. http: //cetsp1.cetsp.com.br/radar/, 2013. Último acesso em 13/07/2013. Citado na pág. 47

[cF02] Jean charles Faugère. A new efficient algorithm for computing Gröbner Bases without reduction to zero (F5). Em ISSAC 02: Proceedings of the 2002 International Symposium on Symbolic and Algebraic Computation, páginas 75-83, 2002. Citado na pág. 34

[CGMT02] Nicolas Courtois, Louis Goubin, Willi Meier e Jean-Daniel Tacier. Solving underdefined systems of multivariate quadratic equations. Em David Naccache e Pascal Paillier, editors, Public Key Cryptography, volume 2274 of Lecture Notes in Computer Science, páginas 211-227. Springer Berlin Heidelberg, 2002. Citado na pág. 15, 46

[CGP01] Nicolas T. Courtois, Louis Goubin e Jacques Patarin. Quartz, an asymmetric signature scheme for short signatures on PC. Primitive specification and supporting documentation (second revised version). 2001. Citado na pág. 3, 17, 24, 25, 26, 27, 29, 30, 32, 34, 46, 49,57

[CKPS00a] Nicolas Courtois, Alexander Klimov, Jacques Patarin e Adi Shamir. Efficient algorithms for solving overdefined systems of multivariate polynomial equations. Em Bart Preneel, 
editor, Advances in Cryptology - EUROCRYPT 2000, volume 1807 of Lecture Notes in Computer Science, páginas 392-407. Springer Berlin Heidelberg, 2000. Citado na pág. 15, 46

[CKPS00b] Nicolas Courtois, Alexander Klimov, Jacques Patarin e Adi Shamir. Efficient algorithms for solving overdefined systems of multivariate polynomial equations. Em Bart Preneel, editor, Advances in Cryptology - EUROCRYPT 2000, volume 1807 of Lecture Notes in Computer Science, páginas 392-407. Springer Berlin Heidelberg, 2000. Citado na pág. 22

[Cou01] Nicolas T. Courtois. The security of Hidden Field Equations (HFE). Em David Naccache, editor, Topics in Cryptology - CT-RSA 2001, volume 2020 of Lecture Notes in Computer Science, páginas 266-281. Springer Berlin Heidelberg, 2001. Citado na pág. 21, 34

[Cou02] Nicolas T. Courtois. Generic Attacks and the Security of Quartz. Em YvoG. Desmedt, editor, Public Key Cryptography - PKC 2003, volume 2567 of Lecture Notes in Computer Science, páginas 351-364. Springer Berlin Heidelberg, 2002. Citado na pág. 34

[Cou04] Nicolas T. Courtois. Short signatures, provable security, generic attacks and computational security of multivariate polynomial schemes such as HFE, QUARTZ and SFLASH. Cryptology ePrint Archive, Report 2004/143. http://eprint.iacr.org/2004/143, 2004. Versão extendida e revista do artigo Generic Attacks and the Security of Quartz publicado no PKC 2003. Último acesso em 12/06/2013. Citado na pág. 2, 13, 19, 25, 34, 46, 49

[Dan12] Quynh Dang. NIST Special Publication 800-107: Recommendation for Applications Using Approved Hash Algorithms. Relatório técnico, National Institute of Standards and Technology, NIST, U.S. Department of Commerce, Washington DC. http://csrc. nist.gov/publications/nistpubs/800-107-rev1/sp800-107-rev1.pdf, 2012. Último acesso em 09/07/2013. Citado na pág. 36

[Deu85] David Deutsch. Quantum theory, the Church-Turing principle and the universal quantum computer. Proceedings of the Royal Society of London Ser. A, A400:97-117, 1985. Citado na pág. 2

[DFSS07] Vivien Dubois, Pierre-Alain Fouque, Adi Shamir e Jacques Stern. Practical cryptanalysis of SFLASH. Em Alfred Menezes, editor, Advances in Cryptology - CRYPTO 200\%, volume 4622 of Lecture Notes in Computer Science, páginas 1-12. Springer Berlin Heidelberg, 2007. Citado na pág. 16, 19, 21

[DGS06a] Jintai Ding, Jason E. Gower e Dieter Schmidt. Multivariate public key cryptosystems, volume 25 of Advances in information security. Springer, 2006. Citado na pág. 2, 13, 14, $35,46,47,50$

[DGS06b] Jintai Ding, Jason E. Gower e Dieter S. Schmidt. Zhuang-zi: A new algorithm for solving multivariate polynomial equations over a finite field. Cryptology ePrint Archive, Report 2006/038. http://eprint.iacr.org/2006/038, 2006. Último acesso em 10/06/2013. Citado na pág. 22

[DGS07] Vivien Dubois, Louis Granboulan e Jacques Stern. Cryptanalysis of hfe with internal perturbation. Em Tatsuaki Okamoto e Xiaoyun Wang, editors, Public Key Cryptography - PKC 2007, volume 4450 of Lecture Notes in Computer Science, páginas 249-265. Springer Berlin Heidelberg, 2007. Citado na pág. 35

[DH76] Whitfield Diffie e Martin E. Hellman. New directions in cryptography. Information Theory, IEEE Transactions on, 22(6):644-654, 1976. Citado na pág. 6 
[DH11] Jintai Ding e TimothyJ. Hodges. Inverting HFE systems is quasi-polynomial for all fields. Em Phillip Rogaway, editor, Advances in Cryptology - CRYPTO 2011, volume 6841 of Lecture Notes in Computer Science, páginas 724-742. Springer Berlin Heidelberg, 2011. Citado na pág. 21

[DI82] Hygino H. Domingues e Gelson Iezzi. Álgebra Moderna. Atual, 2a edição, 1982. Citado na pág. 59, 60

[DS02] Emmanuelle Dottax e École Normale Supérieure. Tweak reviews: ESIGN, RSA-PSS, QUARTZ and SFLASH. NES/DOC/ENS/WP1/018/1. Relatório técnico, 112002. Último acesso em 04/07/2013. Citado na pág. 24

[DS05] Jintai Ding e Dieter Schmidt. Cryptanalysis of HFEv and Internal Perturbation of HFE. Em Serge Vaudenay, editor, Public Key Cryptography - PKC 2005, volume 3386 of Lecture Notes in Computer Science, páginas 288-301. Springer Berlin Heidelberg, 2005. Citado na pág. 35, 46

[dSM12] Fabio de Salles Monteiro. Protocolo de Identificação baseado em Polinômios Multivariáveis Quadráticos. Dissertação de Mestrado, Instituto de Matemática e Estatística, Universidade de São Paulo, Brasil. http://www.teses.usp.br/teses/disponiveis/45/45134/ tde-19032013-104154/pt-br.php, 2012. Último acesso em 25/07/2013. Citado na pág. 2

[DSW08] Jintai Ding, Dieter Schmidt e Fabian Werner. Algebraic attack on HFE revisited. Em Tzong-Chen $\mathrm{Wu}$, Chin-Laung Lei, Vincent Rijmen e Der-Tsai Lee, editors, Information Security, volume 5222 of Lecture Notes in Computer Science, páginas 215-227. Springer Berlin Heidelberg, 2008. Citado na pág. 21

[DWY07] Jintai Ding, Christopher Wolf e Bo-Yin Yang. $\ell$-invertible cycles for Multivariate $\mathcal{Q}$ uadratic $(\mathcal{M Q})$ public key cryptography. Em Tatsuaki Okamoto e Xiaoyun Wang, editors, Public Key Cryptography - PKC 2007, volume 4450 of Lecture Notes in Computer Science, páginas 266-281. Springer Berlin Heidelberg, 2007. Citado na pág. 19

[Fau99] Jean-Charles Faugère. A new efficient algorithm for computing Gröbner bases (F4). Journal of Pure and Applied Algebra, 139(1-3):61 - 88, 1999. Citado na pág. 22

[Fau03] Jean-Charles Faugère. Algebraic cryptanalysis of HFE using gröbner bases. HAL CCSd - CNRS, Fevereiro 2003. Citado na pág. 21

[FD85] Harriet Fell e Whitfield Diffie. Analysis of a public key approach based on polynomial substitution. Em HughC. Williams, editor, Advances in Cryptology - CRYPTO 85 Proceedings, volume 218 of Lecture Notes in Computer Science, páginas 340-349. Springer Berlin Heidelberg, 1985. Citado na pág. 13

[Fel04] Patrick Felke. On the Affine Transformations of HFE-Cryptosystems and Systems with Branches. Cryptology ePrint Archive, Report 2004/367. http://eprint.iacr.org/2004/ 367, 2004. Último acesso em 03/07/2013. Citado na pág. 20

[Fel05] Adam Thomas Feldmann. A survey of attacks on Multivariate Cryptosystems. Dissertação de Mestrado, University of Waterloo, Ontario, Canada, 2005. Citado na pág. 21, 46

[FJ03] Jean-Charles Faugère e Antoine Joux. Algebraic cryptanalysis of Hidden Field Equation (HFE) cryptosystems using gröbner bases. Em Dan Boneh, editor, Advances in Cryptology - CRYPTO 2003, volume 2729 of Lecture Notes in Computer Science, páginas 44-60. Springer Berlin Heidelberg, 2003. Citado na pág. 21, 34 
[GJ79] Michael R. A. Garey e David S. Johnson. Computers and Intractability: A Guide to the Theory of NP-Completeness. A Series of Books in the Mathematical Sciences. W. H. Freeman, 1979. Citado na pág. 14

[GJS06] Louis Granboulan, Antoine Joux e Jacques Stern. Inverting HFE is Quasipolynomial. Em Cynthia Dwork, editor, Advances in Cryptology - CRYPTO 2006, volume 4117 of Lecture Notes in Computer Science, páginas 345-356. Springer Berlin Heidelberg, 2006. Citado na pág. 21

[GM02] Henri Gilbert e Marine Minier. Cryptanalysis of SFLASH. Em LarsR. Knudsen, editor, Advances in Cryptology - EUROCRYPT 2002, volume 2332 of Lecture Notes in Computer Science, páginas 288-298. Springer Berlin Heidelberg, 2002. Citado na pág. 20

[GMR88] Shafi Goldwasser, Silvio Micali e Ronald Rivest. A Digital Signature Scheme Secure Against Adaptive Chosen-Message Attacks. SIAM Journal on Computing, 17(2):281308, 1988. Citado na pág. 10

[Hei09] Raymond A. Heindl. New Directions in Multivariate Public Key Cryptography. Tese de Doutorado, Graduate School of Clemson University - Clemson, SC, 2009. Citado na pág. 2, 13, 47

[HPS08] Jeffrey Hoffstein, Jill Pipher e J.H. Silverman. An Introduction to Mathematical Cryptography. Springer Publishing Company, Incorporated, 1 edição, 2008. Citado na pág. 59

[jCPB ${ }^{+}$12] Shu jen Chang, Ray Perlner, William E. Burr, Meltem Sönmez Turan, John M. Kelsey, Souradyuti Paul e Lawrence E. Bassham. NIST Interagency or Internal Reports 7896: Third-Round Report of the SHA-3 Cryptographic Hash Algorithm Competition. Relatório técnico, National Institute of Standards and Technology, NIST, U.S. Department of Commerce, Washington DC. http://nvlpubs.nist.gov/nistpubs/ir/2012/NIST. IR.7896.pdf, 2012. Último acesso em 09/07/2013. Citado na pág. 37, 48

[JDH08] Xin Jiang, Jintai Ding e Lei Hu. Kipnis-shamir attack on HFE revisited. Em Dingyi Pei, Moti Yung, Dongdai Lin e Chuankun Wu, editors, Information Security and Cryptology, volume 4990 of Lecture Notes in Computer Science, páginas 399-411. Springer Berlin Heidelberg, 2008. Citado na pág. 21

[JM03] Antoine Joux e Gwenaëlle Martinet. Some weaknesses in Quartz Signature Scheme. NES/DOC/ENS/WP5/026/1. Relatório técnico, Janeiro 01 2003. Último acesso em 12/06/2013. Citado na pág. iii, v, 24, 35, 46, 51

[Jou04] Antoine Joux. Multicollisions in iterated hash functions. application to cascaded constructions. Em Matt Franklin, editor, Advances in Cryptology - CRYPTO 2004, volume 3152 of Lecture Notes in Computer Science, páginas 306-316. Springer Berlin Heidelberg, 2004. Citado na pág. 36

[KPG99] Aviad Kipnis, Jacques Patarin e Louis Goubin. Unbalanced Oil and Vinegar signature schemes. Em Jacques Stern, editor, Advances in Cryptology - EUROCRYPT 99, volume 1592 of Lecture Notes in Computer Science, páginas 206-222. Springer Berlin Heidelberg, 1999. Citado na pág. 16, 19, 46

[KS98] Aviad Kipnis e Adi Shamir. Cryptanalysis of the Oil and Vinegar signature scheme. Em Hugo Krawczyk, editor, Advances in Cryptology - CRYPTO '98, volume 1462 of Lecture Notes in Computer Science, páginas 257-266. Springer Berlin Heidelberg, 1998. Citado na pág. 21 
[KS99] Aviad Kipnis e Adi Shamir. Cryptanalysis of the HFE Public Key Cryptosystem by Relinearization. Em CRYPTO 99: Proceedings of the 19th Annual International Cryptology Conference on Advances in Cryptology, páginas 19-30, London, UK, 1999. Springer-Verlag. Citado na pág. 21

[LFPW11] Dongdai Lin, Jean-Charles Faugère, Ludovic Perret e Tianze Wang. On enumeration of polynomial equivalence classes and their application to MPKC. Cryptology ePrint Archive, Report 2011/055. http://eprint.iacr.org/2011/055, 2011. Último acesso em 29/06/2013. Citado na pág. 16, 19, 35, 37, 46, 50

[Mag12] Bernardo Caraponale Magri. Assinatura digital Rabin-Williams sem randomização e com prova eficiente de segurança. Dissertação de Mestrado, Instituto de Matemática e Estatística, Universidade de São Paulo, Brasil. http://www.teses.usp.br/ teses/disponiveis/45/45134/tde-10092012-165253/pt-br.php, 2012. Último acesso em 21/07/2013. Citado na pág. 58

[MI88] Tsutomu Matsumoto e Hideki Imai. Public quadratic polynomial-tuples for efficient signature-verification and message-encryption. Em Lecture Notes in Computer Science on Advances in Cryptology - EUROCRYPT 88, páginas 419-453, New York, NY, USA, 1988. Springer-Verlag New York, Inc. Citado na pág. 13, 19, 20, 27, 29

[MIHM85] T. Matsumoto, H. Imai, H. Harashima e H. Miyagawa. High speed signature scheme using compact public key. Em National Conference of system and information of the Electronic Communication Association of year Sowa 60, páginas 9-5. 1985. Citado na pág. 13

[MOVR96] Alfred J. Menezes, Paul C. Van Oorschot, Scott A. Vanstone e R. L. Rivest. Handbook of Applied Cryptography. CRC Press, Boca Raton, FL, USA, $1^{a}$ edição, 1996. Citado na pág. 6

[MP07] Ariane M. Masuda e Daniel Panario. Tópicos de Corpos Finitos com Aplicações em Criptografia e Teoria de Códigos. Associação Intituto Nacional de Matemática Pura e Aplicada - IMPA, 2007. Citado na pág. 59, 60

[MS01] Gwenaëlle Martinet e École Normale Supérieure. QUARTZ, FLASH and SFLASH. NES/DOC/ENS/WP3/006/2. Relatório técnico, Março 7 2001. Último acesso em 14/06/2013. Citado na pág. 3, 24

[NC10] Michael A. Nielsen e Isaac L. Chuang. Quantum Computation and Quantum Information: 10th Anniversary Edition. Cambridge University Press, 2010. Citado na pág. 2, 14

[NES04] NESSIE. Final report of European project IST-1999-12324: New European Schemes for Signatures, Integrity, and Encryption (NESSIE), (abril de 2004). https:/ /www.cosic. esat.kuleuven.be/nessie/Bookv015.pdf. Relatório técnico, Abril 2004. Último acesso em 10/06/2013. Citado na pág. 3, 16, 24

[NIS95] NIST. FIPS 180-1: Secure hash standard. Relatório técnico, National Institute of Standards and Technology, NIST, U.S. Department of Commerce, Washington DC. http://www.itl.nist.gov/fipspubs/fip180-1.htm, 1995. Último acesso em 09/07/2013. Citado na pág. 36

[NIS02] NIST. FIPS 180-2: Secure hash standard. Relatório técnico, National Institute of Standards and Technology, NIST, U.S. Department of Commerce, Washington DC. http://csrc.nist.gov/publications/fips/fips180-2/fips180-2.pdf, 2002. Último acesso em 09/07/2013. Citado na pág. 36 
[NIS09] NIST. FIPS 186-3: Digital Signature Standard (DSS). Relatório técnico, National Institute of Standards and Technology, NIST, U.S. Department of Commerce, Washington DC. http://csrc.nist.gov/publications/fips/fips186-3/fips_186-3.pdf, 2009. Último acesso em 16/07/2013. Citado na pág. 52

[NTCP03] Louis Goubin Nicolas T. Courtois e Jacques Patarin. SFLASHv3, a fast asymmetric signature scheme. Cryptology ePrint Archive, Report 2003/211. http://eprint.iacr.org/ 2003/211, 2003. Último acesso em 28/06/2013. Citado na pág. 16, 19

[Ora13a] Oracle. Class System. Oracle and/or its affiliates. http://docs.oracle.com/javase/7/ docs/api/java/lang/System.html, 2013. Último acesso em 18/07/2013. Citado na pág. 54

[Ora13b] Oracle. Java SE Security. Oracle and/or its affiliates. http://www.oracle. com/technetwork/java/javase/tech/index-jsp-136007.html, 2013. Último acesso em 18/07/2013. Citado na pág. 53

[OS84] H. Ong e Claus-Peter Schnorr. Signatures through approximate representations by quadratic forms. Em David Chaum, editor, Advances in Cryptology, páginas 117-131. Springer US, 1984. Citado na pág. 13

[Pat95] Jacques Patarin. Cryptanalysis of the Matsumoto and Imai Public Key Scheme of Eurocrypt'88. Em Don Coppersmith, editor, Advances in Cryptology - CRYPT0 95, volume 963 of Lecture Notes in Computer Science, chapter 20, páginas 248-261. Springer Berlin / Heidelberg, Berlin, Heidelberg, Julho 1995. Citado na pág. 3, 13, 20, 23

[Pat96a] Jacques Patarin. Hidden Field Equations (HFE) and Isomorphisms of Polynomials (IP): Two new families of asymmetric algorithms. Em Ueli Maurer, editor, Advances in Cryptology - EUROCRYPT 96, volume 1070 of Lecture Notes in Computer Science, páginas 33-48. Springer-Verlag, 12-16 Maio 1996. Citado na pág. iii, v, 3, 19, 20, 21, 23, 24

[Pat96b] Jacques Patarin. Hidden Field Equations (HFE) and Isomorphisms of Polynomials (IP): Two new families of asymmetric algorithms - Extended Version. Springer-Verlag, 1996. Citado na pág. 23

[PBB10a] Albrecht Petzoldt, Stanislav Bulygin e Johannes Buchmann. CyclicRainbow - A Multivariate Signature Scheme with a Partially Cyclic Public Key. Em Guang Gong e KishanChand Gupta, editors, Progress in Cryptology - INDOCRYPT 2010, volume 6498 of Lecture Notes in Computer Science, páginas 33-48. Springer Berlin Heidelberg, 2010. Citado na pág. 52,58

[PBB10b] Albrecht Petzoldt, Stanislav Bulygin e Johannes Buchmann. Selecting parameters for the Rainbow Signature Scheme. Em Nicolas Sendrier, editor, Post-Quantum Cryptography, volume 6061 of Lecture Notes in Computer Science, páginas 218-240. Springer Berlin Heidelberg, 2010. Citado na pág. 52

[PCG01a] Jacques Patarin, Nicolas Courtois e Louis Goubin. FLASH, a Fast Multivariate Signature Algorithm. Em David Naccache, editor, Topics in Cryptology - CT-RSA 2001, volume 2020 of Lecture Notes in Computer Science, páginas 298-307. Springer Berlin Heidelberg, 2001. Citado na pág. 20

[PCG01b] Jacques Patarin, Nicolas T. Courtois e Louis Goubin. QUARTZ, 128-bit Long Digital Signatures. Em David Naccache, editor, Topics in Cryptology - CT-RSA 2001, volume 2020 of Lecture Notes in Computer Science, páginas 282-297. Springer Berlin Heidelberg, 2001. Citado na pág. 3, 24, 25, 29, 30, 34, 46, 49, 57 
[PG97] Jacques Patarin e Louis Goubin. Trapdoor one-way permutations and Multivariate Polynomials - Extended Version. Em Proc. of ICICS 97, LNCS 1334, páginas 356-368. Springer, 1997. Citado na pág. iii, v, 2, 6, 14, 15

[Pyt13a] Python. SHA-1 message digest algorithm. Python Software Foundation. http://docs. python.org/2/library/sha.html, 2013. Último acesso em 18/07/2013. Citado na pág. 54

[Pyt13b] Python. SHA-3 (Keccak) for Python 2.6 - 3.4. Python Software Foundation. https: //pypi.python.org/pypi/pysha3/0.2.1, 2013. Último acesso em 18/07/2013. Citado na pág. 54

[Rib13] Bruno Ribeiro. SP arrecadou R $\$ 799$ mi com multas de trânsito em 2012. Estadão.com.br . http://www.estadao.com.br/noticias/geral, sp-arrecadou-r-799-mi-com-multas-de-transito-em-2012,985087,0.htm, $2013 . \quad$ Último acesso em 13/07/2013. Citado na pág. 47

[Sho97] Peter W. Shor. Polynomial-Time Algorithms for Prime Factorization and Discrete Logarithms on a Quantum Computer. SIAM Journal on Computing, 26(5):1484-1509, 1997. Citado na pág. iii, v, 2

[Sho08] Victor Shoup. A Computational Introduction to Number Theory and Algebra. Cambridge University Press, $2^{\text {a }}$ edição, 2008. Citado na pág. 59, 60, 61

[Sin08] Simon Singh. Livro Dos Códigos, O. Record, 2008. Citado na pág. 1

[Sip12] Michael Sipser. Introdução à Teoria da Computação: tradução da $2^{a}$ Edição Norte Americana. Cengage Learning, 2012. Citado na pág. 5

[SSH11a] Koichi Sakumoto, Taizo Shirai e Harunaga Hiwatari. On provable security of UOV and HFE Signature Schemes against Chosen-Message Attack. Em Bo-Yin Yang, editor, Post-Quantum Cryptography, volume 7071 of Lecture Notes in Computer Science, páginas 68-82. Springer Berlin Heidelberg, 2011. Citado na pág. 10, 35, 37, 38, 46, 49, 50, $51,57,58$

[SSH11b] Koichi Sakumoto, Taizo Shirai e Harunaga Hiwatari. Public-Key Identification Schemes Based on Multivariate Quadratic Polynomials. Em Phillip Rogaway, editor, Advances in Cryptology - CRYPTO 2011, volume 6841 of Lecture Notes in Computer Science, páginas 706-723. Springer Berlin Heidelberg, 2011. Citado na pág. 15

[Ste11] Jacques Stern. "post quantum" cryptography: An imaginary interview, 2011. Slides da apresentação realizada na Advanced School of Cryptography, Campinas, SP, Outubro 2011. Citado na pág. 13

[Ter08] Routo Terada. Segurança de dados: Criptografia em redes de computador. Blucher, $2^{\mathrm{a}}$ revisada e ampliada edição, 2008. Citado na pág. 6, 7, 8, 36, 48

[WBP04] Christopher Wolf, An Braeken e Bart Preneel. Efficient cryptanalysis of RSE(2)PKC and RSSE(2)PKC. Cryptology ePrint Archive, Report 2004/237. http://eprint.iacr. org $/ 2004 / 237,2004$. Último acesso em 02/07/2013. Citado na pág. 19

[Wol02a] Christopher Wolf. Implementing QUARTZ in java. Draft for the $3^{\text {rd }}$ NESSIE Workshop. http://www.christopher-wolf.de/ql/quartzJava.pdf, 2002. Último acesso em 05/07/2013. Citado na pág. 27, 29, 53

[Wol02b] Christopher Wolf. QuartzLight in Java. http://www.christopher-wolf.de/ql/, 2002. Último acesso em 17/07/2013. Citado na pág. 53, 54 
[Wol05] Christopher Wolf. Multivariate Quadratic Polynomials in Public Key Cryptography. Tese de Doutorado, Katholieke Universiteit Leuven - Faculteit Ingenieurswetenschappen - Departement Elektrotechniek(ESAT), 2005. Citado na pág. 20, 34, 46

[WP05] Christopher Wolf e Bart Preneel. Taxonomy of Public Key Schemes based on the problem of $\mathcal{M}$ ultivariate $\mathcal{Q}$ uadratic equations. Cryptology ePrint Archive, Report 2005/077. http://eprint.iacr.org/2005/077, 2005. Último acesso em 28/06/2013. Citado na pág. $14,15,16,17,18,19,20$

[WY05] Xiaoyun Wang e Hongbo Yu. How to Break MD5 and Other Hash Functions, volume 3494 of Lecture Notes in Computer Science, chapter 2, páginas 19-35. Springer Berlin Heidelberg, Berlin, Heidelberg, Maio 2005. Citado na pág. 18

[WYY05] Xiaoyun Wang, Yiqun Lisa Yin e Hongbo Yu. Finding collisions in the full SHA-1. Em Advances in Cryptology - CRYPTO 2005: 25th Annual International Cryptology Conference, Santa Barbara, California, USA, August 14-18, 2005, Proceedings, volume 3621 of Lecture Notes in Computer Science, páginas 17-36. Springer, 2005. Citado na pág. $18,36,37,49$

[YST12] Takanori Yasuda, Kouichi Sakurai e Tsuyoshi Takagi. Reducing the Key Size of Rainbow using non-commutative rings. Em Orr Dunkelman, editor, Topics in Cryptology - CTRSA 2012, volume 7178 of Lecture Notes in Computer Science, páginas 68-83. Springer Berlin Heidelberg, 2012. Citado na pág. 52, 58

[Yuv79] Gideon Yuval. How to Swindle Rabin. Cryptologia, 3(3):187-191, 1979. Citado na pág. 8, 18 